Florida International University

FIU Digital Commons

FIU Electronic Theses and Dissertations

University Graduate School

3-19-2014

\title{
Development of Test-Based Wind-Driven Rain Intrusion Model for Hurricane-Induced Building Interior and Contents Damage
}

Thomas Baheru

tbahe001@fiu.edu

DOI: $10.25148 /$ etd.FI14040817

Follow this and additional works at: https://digitalcommons.fiu.edu/etd

Part of the Civil Engineering Commons, and the Risk Analysis Commons

\section{Recommended Citation}

Baheru, Thomas, "Development of Test-Based Wind-Driven Rain Intrusion Model for Hurricane-Induced Building Interior and Contents Damage" (2014). FIU Electronic Theses and Dissertations. 1127.

https://digitalcommons.fiu.edu/etd/1127

This work is brought to you for free and open access by the University Graduate School at FIU Digital Commons. It has been accepted for inclusion in FIU Electronic Theses and Dissertations by an authorized administrator of FIU Digital Commons. For more information, please contact dcc@fiu.edu. 


\title{
FLORIDA INTERNATIONAL UNIVERSITY \\ Miami, Florida
}

\section{DEVELOPMENT OF TEST-BASED WIND-DRIVEN RAIN INTRUSION MODEL \\ FOR HURRICANE-INDUCED BUILDING INTERIOR AND CONTENTS DAMAGE}

\author{
A dissertation submitted in partial fulfillment of the \\ requirements for the degree of \\ DOCTOR OF PHILOSOPHY \\ in \\ CIVIL ENGINEERING \\ by
}

Thomas Baheru

2014 
To: Dean Amir Mirmiran

College of Engineering and Computing

This dissertation, written by Thomas Baheru, and entitled Development of Test-Based Wind-Driven Rain Intrusion Model for Hurricane-Induced Building Interior and Contents Damage, having been approved in respect to style and intellectual content, is referred to you for judgment.

We have read this dissertation and recommend that it be approved.

Forrest Masters

Girma Bitsuamlak

Haiyan Jiang

Atorod Azizinamini

Ioannis Zisis

Arindam Gan Chowdhury, Major Professor

Date of Defense: March 19, 2014

The dissertation of Thomas Baheru is approved.

Dean Amir Mirmiran
College of Engineering and Computing

Florida International University, 2014 
(C) Copyright 2014 by Thomas Baheru All rights reserved. 


\section{DEDICATION}

I dedicate this dissertation to my parents, Alganesh Alemayehu and Seyoum Baheru. 


\section{ACKNOWLEDGMENTS}

I thank my advisor Dr. Arindam Gan Chowdhury, for his support, guidance, and encouragement throughout the years. I would like to thank my committee members, Dr. Girma Bitsuamlak, Dr. Forrest Masters, Dr. Haiyan Jaing, Dr. Ioannis Zisis, and Dr. Atorod Azizinamini for their cooperation and thoughtful guidance in this dissertation work. Special thanks to Dr. Jean-Paul Pinelli and Dr. Ali Tokay for their unreserved contributions in this important research work. I thank Walter Conklin, James Erwin, Roy and all former and present WOW team for their help during my experiments.

The project was supported by the Florida Sea Grant College Program (FSGCP) under Project No.: R/C-D-19. We acknowledge the National Science Foundation, NSF Award No.: CMMI-1234004 and NSF MRI Award No.: CMMI-0923365, for supporting

the simulation of the wind driven rain at the Wall of Wind (WOW). WOW facility construction has been supported by the Florida Center of Excellence in Hurricane Damage Mitigation and Product Development, Department of Energy, Renaissance Re, Roofing Alliance for Progress, and AIR Worldwide.

Finally, I would like to thank my parents, Alganesh Alemayehu and Seyoum Baheru. Without their support, understanding, and love, the completion of this dissertation would not have been possible. 


\section{ABSTRACT OF THE DISSERTATION \\ DEVELOPMENT OF TEST-BASED WIND-DRIVEN RAIN INTRUSION MODEL FOR HURRICANE-INDUCED BUILDING INTERIOR AND CONTENTS \\ DAMAGE \\ by}

Thomas Baheru

Florida International University, 2014

Miami, Florida

Professor Arindam Gan Chowdhury, Major Professor

Major portion of hurricane-induced economic loss originates from damages to building structures. The damages on building structures are typically grouped into three main categories: exterior, interior, and contents damage. Although the latter two types of damages, in most cases, cause more than $50 \%$ of the total loss, little has been done to investigate the physical damage process and unveil the interdependence of interior damage parameters. Building interior and contents damages are mainly due to winddriven rain (WDR) intrusion through building envelope defects, breaches, and other functional openings. The limitation of research works and subsequent knowledge gaps, are in most part due to the complexity of damage phenomena during hurricanes and lack of established measurement methodologies to quantify rainwater intrusion. This dissertation focuses on devising methodologies for large-scale experimental simulation of tropical cyclone WDR and measurements of rainwater intrusion to acquire benchmark test-based data for the development of hurricane-induced building interior and contents damage model. Target WDR parameters derived from tropical cyclone rainfall data were 
used to simulate the WDR characteristics at the Wall of Wind (WOW) facility. The proposed WDR simulation methodology presents detailed procedures for selection of type and number of nozzles formulated based on tropical cyclone WDR study. The simulated WDR was later used to experimentally investigate the mechanisms of rainwater deposition/intrusion in buildings. Test-based dataset of two rainwater intrusion parameters that quantify the distribution of direct impinging raindrops and surface runoff rainwater over building surface - rain admittance factor (RAF) and surface runoff coefficient (SRC), respectively — were developed using common shapes of low-rise buildings. The dataset was applied to a newly formulated WDR estimation model to predict the volume of rainwater ingress through envelope openings such as wall and roof deck breaches and window sill cracks. The validation of the new model using experimental data indicated reasonable estimation of rainwater ingress through envelope defects and breaches during tropical cyclones. The WDR estimation model and experimental dataset of WDR parameters developed in this dissertation work can be used to enhance the prediction capabilities of existing interior damage models such as the Florida Public Hurricane Loss Model (FPHLM). 


\section{TABLE OF CONTENTS}

CHAPTER

PAGE

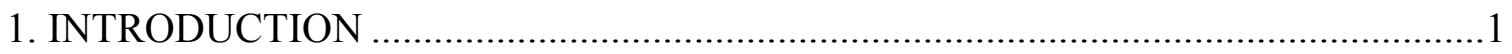

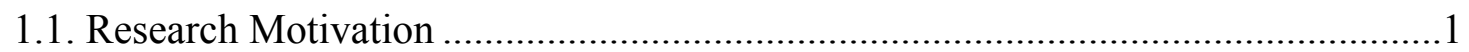

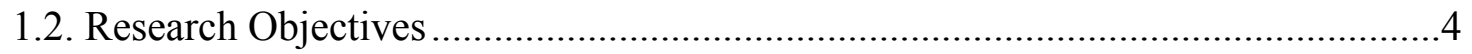

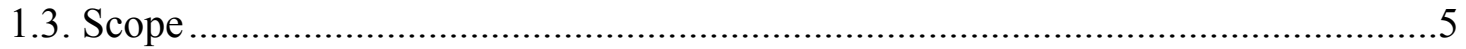

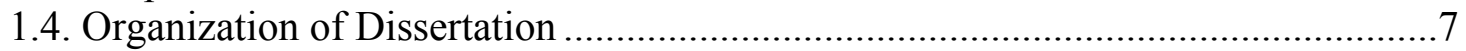

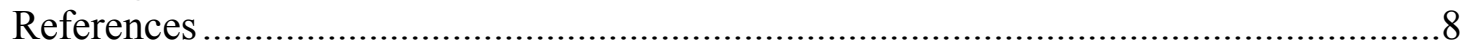

2. SIMULATION OF WIND-DRIVEN RAIN ASSOCIATED WITH TROPICAL STORMS AND HURRICANES USING THE 12-FAN WALL OF WIND ...........9

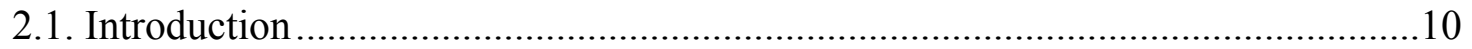

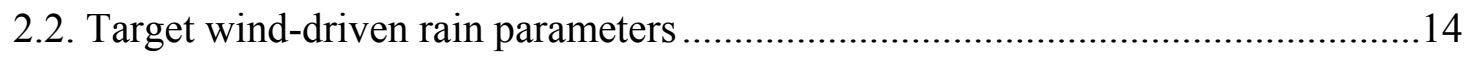

2.2.1 Statistical measures of RSD parameters ..................................................16

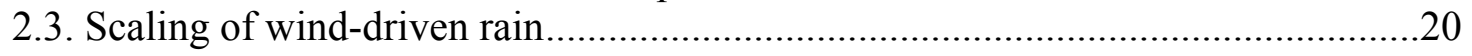

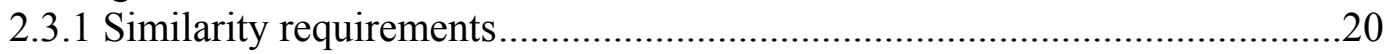

2.3.2 Scaling of wind-driven rain parameters .....................................................2.

2.4. The 12-fan Wall of Wind wind-driven rain simulation device.............................22

2.4.1 Wind and wind-driven rain simulation devices ..........................................22

2.4.2 Simulated wind characteristics ..............................................................26

2.5. Wind-driven rain simulation procedure, results, and discussion ..........................28

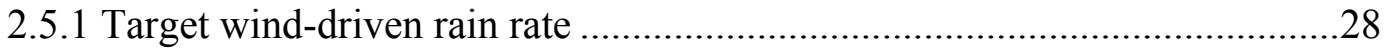

2.5.2 Selection of type and number of spray nozzles .........................................3

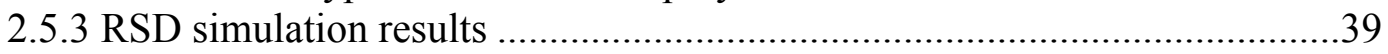

2.5.4 Comparison between current WDR simulation and wind tunnel simulation

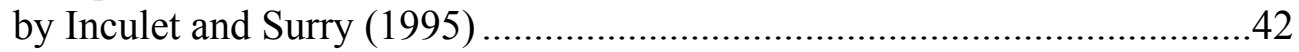

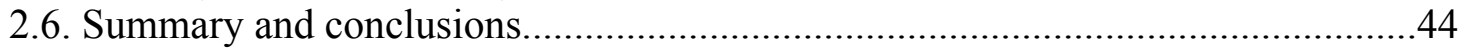

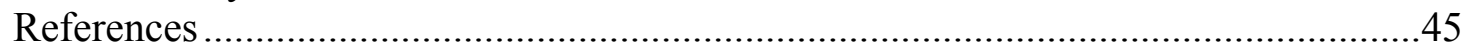

Appendix - A: Raindrop size distribution (RSD) model.....................................49

Appendix - B: Probability density function of RSD parameters...........................52

\section{DISTRIBUTION OF WIND-DRIVEN RAIN DEPOSITION ON LOW-RISE} BUILDINGS: DIRECT IMPINGING RAINDROPS VERSUS SURFACE

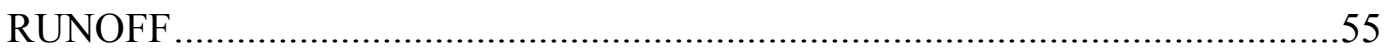

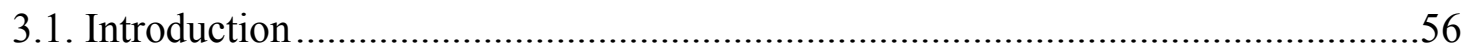

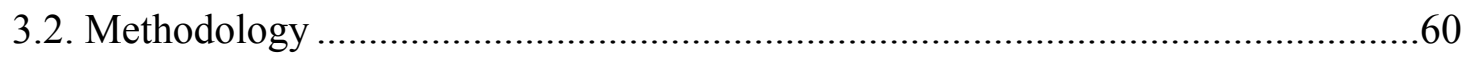

3.2.1 Building models description .................................................................61

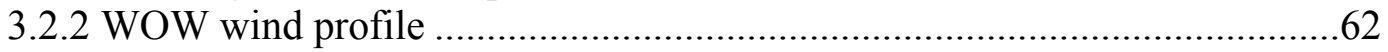

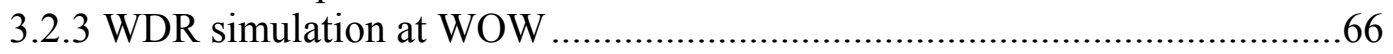

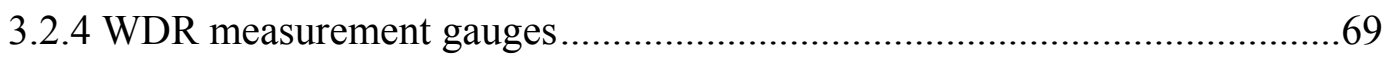

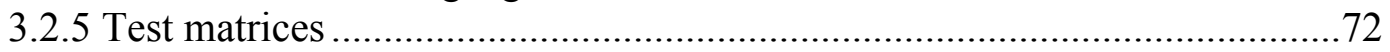

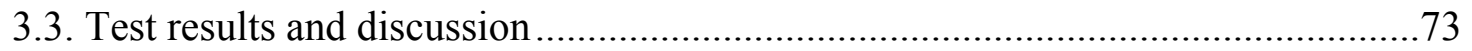

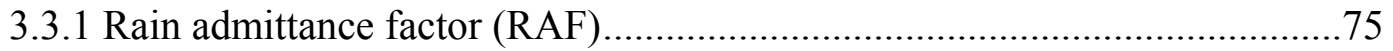

3.3.1.1. Distribution of RAFs..................................................................75 


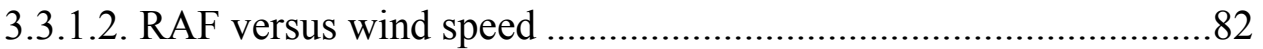

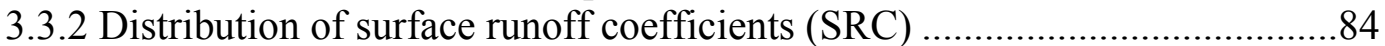

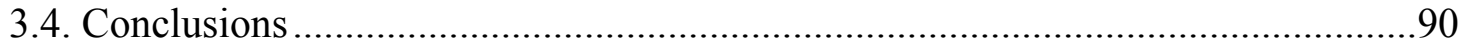

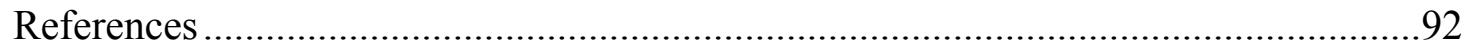

4. ESTIMATION OF WIND-DRIVEN RAIN INTRUSION THROUGH BUILDING ENVELOPE DEFECTS AND BREACHES DURING TROPICAL

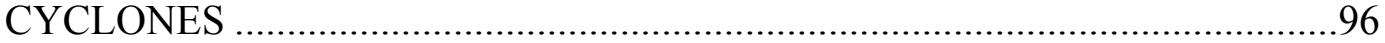

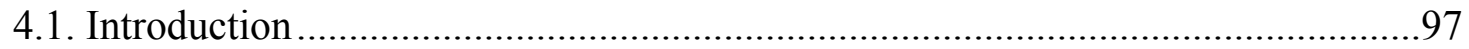

4.2. Wind-driven rain intrusion model.................................................................. 101

4.2.1 WDR intrusion through envelope defects..................................................102

4.2.2 WDR intrusion through envelope breaches ..............................................104

4.3. Development of test-based WDR intrusion data...................................................104

4.3.1 Building model for RAF and SRC measurements ....................................104

4.3.2 Building model for WDR intrusion volume measurements ........................106

4.3.3 12-fan Wall of Wind Flow and WDR characteristics...................................109

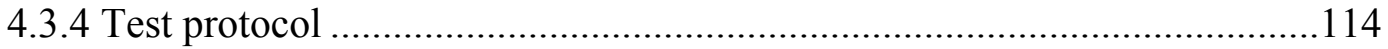

4.4. Results and discussion ............................................................................116

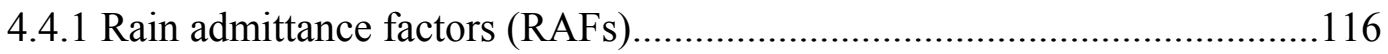

4.4.2 Surface runoff coefficients (SRCs) .........................................................122

4.4.3 Comparison of WDR intrusion volume predicted by the model to the actual volume measured at full scale ......................................................128

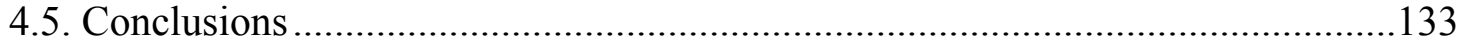

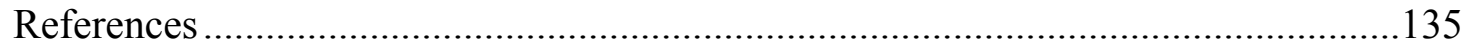

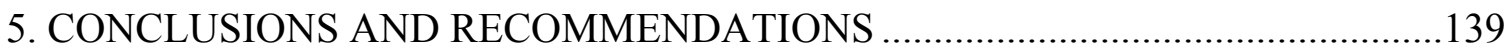

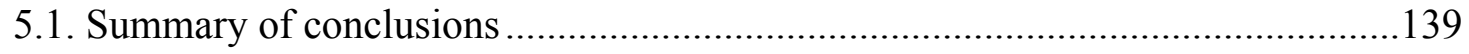

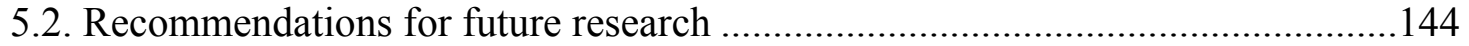




\section{LIST OF TABLES}

TABLE

PAGE

Table 2.1. Synoptic settings of the tropical cyclones (TC) (Tokay et al. 2008) .............. 15

Table 2.2. Statistical measures of RSD parameters based on combined RSD data of the

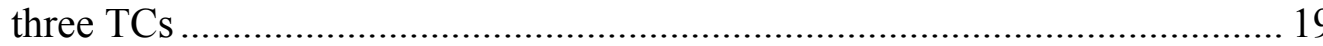

Table 2.3. Nozzle categories based on drop size classification (TeeJet 2011) ................ 34

Table 2.4. Comparison between current WDR simulation and wind tunnel WDR simulation by Inculet and Surry $(1995)$.................................................... 43

Table 3.1 Test protocol for rain admittance factor (RAF) and surface runoff coefficient

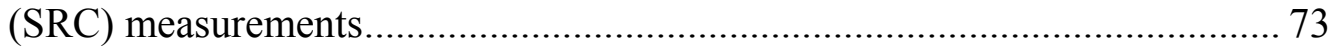

Table 4.1 Rain admittance factor and surface runoff coefficient test parameters ......... 115

Table 4.2 Test matrices for WDR intrusion envelope defects and breaches ................. 116 


\section{LIST OF FIGURES}

FIGURE

PAGE

Figure 1.1 Components of hurricane-induced damage for masonry structures (Pinelli et al. 2008) 2

Figure 2.1 Normalized RSDs: a) Hurricane Alex (2004); b) Hurricane Charley (2004); c) Hurricane Gaston (2004); d) Combined data of the three hurricanes...... 17

Figure 2.2 Statistical plot of the shape parameter (m) of RSD of WDR during the three hurricanes. 18

Figure 2.3 Normalized RSDs in the inter-quartile range of the shape parameter. 19

Figure 2.4 The 12-fan Wall of Wind (WoW): a) Plan view schematic; b) Elevation view with wind speed measurement system in place; c) WDR generating spray nozzles.

Figure 2.5 Instrumentation for WDR simulation: a) PIP and tipping bucket; b)

Pressure sensor.

Figure 2.6 Simulation of atmospheric boundary layer: (a) Wind speed; (b) Turbulence intensity profile.

Figure 2.7 Power-spectral density of longitudinal wind speed, U. 28

Figure 2.8 Liquid-water content versus rain rate..... 30

Figure 2.9 Mass-weighted mean diameter versus rain rate...................................... 30

Figure 2.10 Flow chart of target WDR rate calculations ........................................... 32

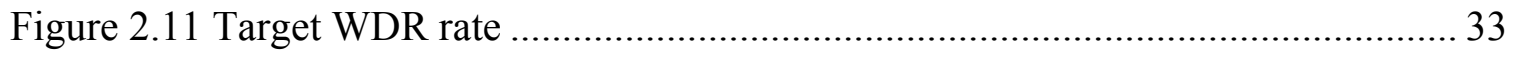

Figure 2.12 TEEJET spray nozzle (courtesy of TEEJET Spray Manual (TeeJet 2011)). 34

Figure 2.13 Flow rate curve for TEEJET 8008 - E nozzle........................................... 35

Figure 2.14 RSD of simulated WDR using TEEJET 8008 - E nozzles ......................... 39

Figure 2.15 Comparison of simulated RSDs along the y-axis .................................. 41

Figure 2.16 Comparison of simulated RSDs along the z-axis ................................. 42

Figure B2.17 Histogram of shape parameter, $m$ of combined data fitted with lognormal distribution. 
Figure B2.18 Probability density functions of shape parameter, $m$ fitted with lognormal distribution.

Figure B2.19 Histogram of slope parameter, $\Lambda$ of combined data fitted with lognormal distribution. 53

Figure B2.20 Probability density functions of slope parameter, $\Lambda$ fitted with lognormal distribution.

Figure B2.21 Histogram of normalizing number concentration, $\log 10 \mathrm{Nw}$ of combined RSD data. 54

Figure B2.22 Histogram of mass-weighted mean diameter, Dmass of combined RSD data

Figure 3.1 Gabel building model with WDR collecting buckets mounted on walls and roof surfaces.

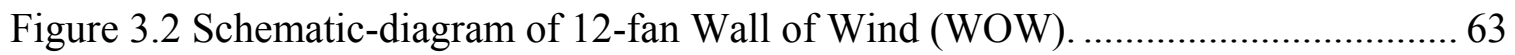

Figure 3.3 12-fan Wall of Wind (WOW) wind speed measurement rake in place........... 65

Figure 3.4 Simulation of atmospheric boundary layer: (a) Wind speed; (b) Turbulence

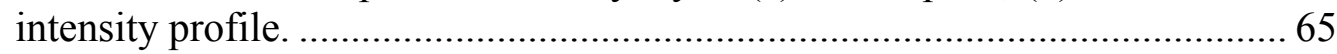

Figure 3.5 Power-spectral density of longitudinal wind speed, U............................. 66

Figure 3.6 12-fan Wall of Wind (WOW) TC WDR generating spray nozzles layout...... 68

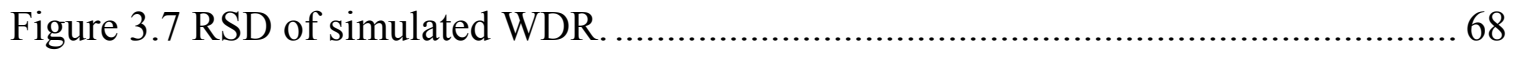

Figure 3.8 WDR rate measurement: (a) Time history of free-field WDR rate; (b)

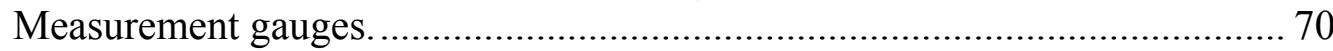

Figure 3.9 Custom-made rainwater measurement gauge......................................... 71

Figure 3.10 Test wind directions and gauge elevation grid for surface runoff measurement. .................................................................................. 73

Figure 3.11 Distribution of RAF on gable building model for (a) $0^{\circ}$, (b) $45^{\circ}$, and (c) $90^{\circ}$ wind directions.

Figure 3.12 Distribution of RAF on flat building model for (a) $0^{\circ}$, (b) $45^{\circ}$, and (c) $90^{\circ}$

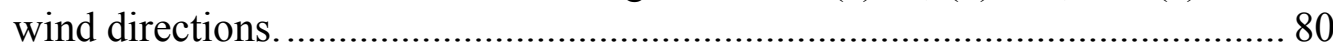

Figure 3.13 Distribution of RAF on hip building model for (a) $0^{\circ}$, (b) $45^{\circ}$, and (c) $90^{\circ}$ wind directions 
Figure 3.14 Rain admittance factor versus wind speed.

Figure 3.15 Distribution of SRC on gable building model for: (a) $0^{\circ}$, (b) $45^{\circ}$, and (c) $90^{\circ}$ wind directions.

Figure 3.16 Distribution of SRC on flat building model for: (a) $0^{\circ}$, (b) $45^{\circ}$, and (c) $90^{\circ}$ wind directions.

Figure 4.1 Large-scale building model with WDR collecting buckets 105

Figure 4.2 (a) Full-scale building model; (b) Rainwater collecting system inside the building model; (c) Roof layout and dimensions of simulated roof deck breach.

Figure 4.3 (a) Simulated window sill crack; (b) WDR measurement system. 109

Figure 4.4 Schematic-diagram of 12-fan Wall of Wind (WOW). 110

Figure 4.5 12-fan Wall of Wind (WOW) wind speed measurement rake in place.

Figure 4.6 Simulation of atmospheric boundary layer: Wind speed and turbulence intensity profile.

Figure 4.7 12-fan Wall of Wind (WOW) TC WDR generating spray nozzles layout.... 114

Figure 4.8 RSD of simulated WDR.

Figure 4.9 Distribution of RAF on gable roof building for (a) $0^{\circ}$, (b) $45^{\circ}$, and (c) $90^{\circ}$ wind directions.

Figure 4.10 Distribution of SRC on gable roof building for (a) $0^{\circ}$, (b) $45^{\circ}$, and (c) $90^{\circ}$ wind directions.

Figure 4.11 WDR intrusion through simulated wall and roof deck breaches for $0^{\circ}$ wind direction.

Figure 4.12 WDR intrusion through simulated wall and roof deck breaches for $45^{\circ}$ wind direction.

Figure 4.13 WDR intrusion through simulated window sill crack. 


\section{INTRODUCTION}

Hurricane induced damages to the built environment led to major economic losses in the past two decades. The average annual loss has been increasing exponentially and reached expected annual loss of 40 billion dollars in year 2010 (NSB 2007). Widespread damages of infrastructures, particularly of, building structures were reported as major contributor of the total economic loss. The need for accurate projection of risk on human life and the nation economy due to annual perils of tropical storms and hurricanes is imperative to foster built environment sustainability and community resiliency. Buildings' vulnerability should be integrated to the probability of hurricanes occurrence and their characteristics to help community and government regulators make informed decision in preparation for future hazards. This requires development of combined algorithm of probabilistic hurricane events, detailed formulation of vulnerability of buildings, and conversion of damage to monetary values. This $\mathrm{PhD}$ dissertation is devoted to study the development of vulnerability model of building structures, specifically building interior components and contents to hurricane related hazard.

\subsection{Research Motivation}

Hurricane-induced damage to low-rise buildings has been reported as cause of major economic loss during hurricane landfall (FEMA 2005; IBHS 2009). The building damages are typically grouped into three main categories: exterior damage (i.e., damage to the building envelope including roof cover, roof sheathing, soffits, roof vents, external walls, windows, and doors), interior damage (i.e., damage to interior walls, ceilings, floor system, fixed furniture, and mechanical and electrical utilities), and building contents

damage (i.e., damage to every interior content which is not attached to the building 
structure). Up to now, researches have been focused on the exterior damage of building as the damages progress from outside to inside (Pinelli et al. 2004; Vickery et al. 2006; Weekes et al. 2009). Documentation of external damage to low-rise building through damage reconnaissance studies and experimental data reinforce this fact (FEMA 1992; FEMA 2005; FEMA 2009; IBHS 2009). However, though the total interior damages incurred high insured and uninsured losses in the past, very little if any test-based data have been developed and they are neglected in most damage surveys. Moreover, recent research conducted on comparison between post-storm recovery cost of exterior and interior hurricane-induced damage has indicated that the interior damage could make up 50 to $100 \%$ of the total damage costs (see Fig. 1.1) (Pinelli et al. 2008; Pita et al. 2012). This high percentage indicates that the accuracy of total loss projection can significantly be affected without realistic physical modeling of the total interior damage in risk prediction models.

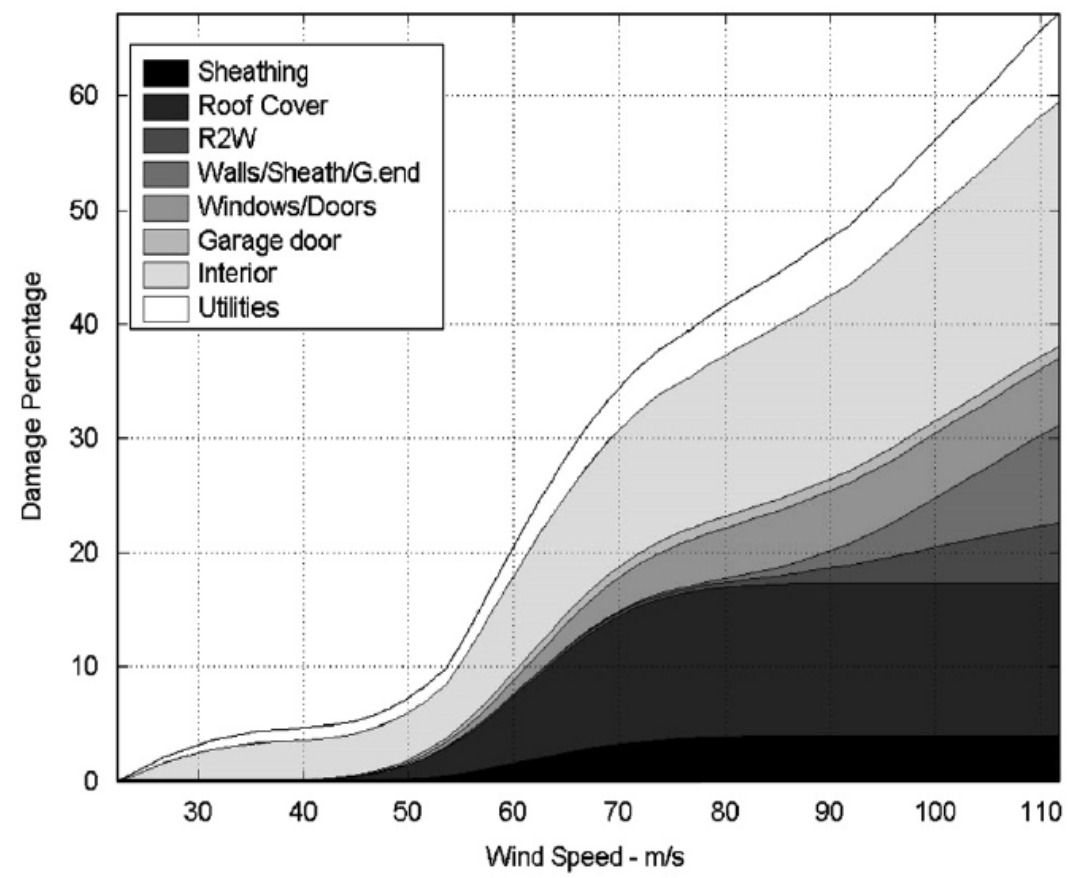

Figure 1.1 Components of hurricane-induced damage for masonry structures (Pinelli et al. 2008) 
Traditionally, due to lack of documented hurricane-induced interior damage data, most catastrophe models estimate the total interior damage as a fraction or percentage of the exterior damage. The fractional coefficients are based on experts' opinion and engineering judgment, which could be highly susceptible to biases and errors. As a result, risk modellers were unable to achieve unbiased risk predictions needed for (a) strengthening the consensus among industry, government regulators and the public on defining reasonable insurance premiums and identifying adequate mitigation measures, and (b) making the requisite policy decisions on the built coastal environment.

Conversely, certain recently developed hurricane risk prediction models (e.g., Florida Public Hurricane Loss Model (FPHLM 4.1) (Pita 2012)) use a physically-based numerical algorithm that incorporates procedural rain water ingress calculations to quantify the economic loss due to building interior damage. This approach provides an additional rainfall model in which the impinging rain probability distribution is separately developed and then combined with envelope defects and breaches to predict the expected interior damage (Pita 2012). However, the procedure involves many assumptions and adjustment factors that account for lack of information on certain variables in the model. The values for these adjustment factors are derived based on either geometrical calculations considering storm direction and building dimensions and orientation, or engineering judgment. These assumptions again could introduce significant error as, in most cases, the economic losses to building interiors and contents exceed $50 \%$ of the total losses.

In addition to the aforementioned adjustment factors, the interior damage models suffer from a lack of available data for validation purposes. Additional data collected 
during the aftermath of storms and through experimentation are required to alleviate the epistemic uncertainty associated with the minimal data sets currently available on the interdependences of the damage variables.

Therefore, it was envisioned that through experimental investigations of the model parameters, the development of physically-based interior damage prediction models could be facilitated. In addition to bridging the existing information gap, this dissertation provides benchmark test-based data on wind-driven rain intrusion and interior damages on single-story residential buildings, which can be used to calibrate and validate the latest loss prediction models. Rather than being the first of several studies, the project aimed at providing an improved WDR intrusion model as a component of building damage model applicable to the existing loss prediction models.

\subsection{Research Objectives}

The overarching goal of the research is to develop test-based vulnerability model on hurricane-induced total building interior damage, a major contributor to hurricane losses to typical residential homes, and use such model to significantly enhance the existing damage prediction models. The study aimed at investigating hurricane wind and wind-driven rain damage to building interiors through experimental investigation of basic damage parameters. The specific objectives are:

i. To simulate realistic wind-driven rain that can represent the tropical cyclone rainfalls for the study of hurricane-induced total interior damage of low-rise residential buildings and thereby develop a testing protocol for investigation of wind-driven rain effects on building structures. 
ii. To develop test-based data on wind-driven rain deposition pattern on the façades of typical low-rise building structures and rainwater intrusion through typical wind speed-dependent external envelope damages and functional openings and infiltration through envelope defects such as cracks for model development and validation purpose.

iii. To develop a wind-driven rain estimation model using the test-based data of rainwater intrusion parameters developed in item (ii) above. The new model will consider the mechanisms of rainwater intrusion in relation to the opening type (envelope breach, functional openings, or defects). The study will further validate the application of the model using experimental data developed on full-scale buildings.

\subsection{Scope}

The hurricane-induced building interior damage study presented herein is focused on the development of test-based vulnerability model through experimental investigation of model parameters and damage observation during laboratory tests. The study comprises of innovative testing of building models under simulated hurricane wind and wind-driven rain to physically investigate damage prediction model parameters and develop test-based wind-driven rain intrusion data. For this purpose, study of tropical cyclone wind-driven rain was reviewed and typical hurricane associated rain characteristics such as raindrop size distributions (RSD) at various rain intensities were identified. The characteristics of wind-driven rain along with realistic turbulent hurricane wind were simulated prior to testing for water intrusion and parameters investigation. 
The experimental study was divided into two stages to obtain the information needed for the advancement of WDR estimation models in predicting the total interior damage loss. These two stages are identified as a parametric study and water intrusion tests. The parametric study is focused on investigation of model adjustment factors mentioned earlier in the problem statement using experimental tests under simulated hurricane wind and wind-driven rain conditions. The tests were conducted on various types and dimensions of building structures so that the test results can fully encompass the missing information and be readily applied to the existing models. Testing to investigate the adjustment factors quantifies the direct impinging raindrops deposition and accumulation of surface runoff rainwater as the two main contributors of wind-driven rain intrusion through building envelope defects and breaches. The testing protocol developed for the study combines the different adjustment factors related to the direct impinging raindrops deposition on building facade in one set and defines the term called rain admittance factor (RAF) and surface runoff coefficients (SRC) and measured on the walls and roof of the building models for different wind directions. This allowed quantifying the RAFs and SRCs, in general, as function of building shape, size and wind direction for the simulated type of storm. The water intrusion due to surface runoff water was investigated as a function of wind direction, perimeter of breached area, and location of breach on the building facade. It is apparent that the amount of direct impinging and runoff water entering through the envelope breach area is dependent on the wind-driven rain intensity, wind speed and location of breach. The study attempted to define these parameters in a most generic way for purpose of their application in WDR estimation model. 
The study primarily sought quantification of expected water intrusion as a function of storm intensity (wind and wind-driven rain intensities), wind direction, and presumed building envelope defects. Investigation of interior damage extent and distribution for a given volume of rain water intrusion is not covered in the current study.

\subsection{Organization of Dissertation}

The dissertation is organized in the following four subsequent chapters.

Chapter 2 presents study of the characteristics of tropical cyclone rainfall and development of wind-driven rain simulation scheme using the 12-fan Wall of Wind facility.

Chapter 3 describes the large-scale testing conducted to characterize the distribution of wind-driven rain deposition during tropical storms and hurricanes. The chapter presents development of test-based data on direct impinging raindrops deposition (or rain admittance factor (RAF)) and surface runoff rainwater accumulation (or surface runoff coefficients (SRC)) for common shapes of buildings.

Chapter 4 presents a WDR estimation model that uses the test-based data to predict the volume of rainwater intrusion through building envelope defects, breaches, and other functional openings. The newly proposed WDR estimation model is validated using experimental rain intrusion data obtained from large-scale experiment.

Chapter 5 summarizes the major findings of the study and suggests future research recommendations. 


\section{References}

FEMA (1992). "Building Performance: Hurricane Andrew in Florida Season." FEMA, ed.

FEMA (2005). "Mitigation Assessment Team Report - Hurricane Charley in Florida; Observations, Recommendations, and Technical Guidance." FEMA 488.

FEMA (2009). "Mitigation Assessment Team Report - Hurricane Ike in Texas and Louisiana; Building Performance Observations, Recommendations, and Technical Guidance." FEMA, ed.

IBHS (2009). "Hurricane Ike - Nature’s Force vs. Structural Strength."

National Science Board (2007). Hurricane warning: the critical need for a national hurricane research initiative. NSB-06-115, 1-36

Pinelli, J.-P., Gurley, K. R., Subramanian, C. S., Hamid, S. S., and Pita, G. L. (2008). "Validation of A Probabilistic Model for Hurricane Insurance Loss Projection in Florida." Reliability Engineering and System Safety, 93, 1896-1905.

Pinelli, J.-P., Simiu, E., Gurley, K., Subramanian, C., Zhang, L., Cope, A., Filliben, J. J., and Hamid, S. (2004). "Hurricane damage prediction model for residential structures." Journal of Structural Engineering, ASCE, 130(11), 1685-1691.

Pita, G. L. (2012). "Hurricane vulnerability of commercial-residential buildings." $P h D$ dissertation Florida Institute of Technology.

Pita, G. L., Pinelli, J.-P., Cocke, S., Gurley, K., Mitrani-Reiser, J., Weekes, J., and Hamid, S. (2012). "Assessment of hurricane-induced internal damage to low-rise buildings in the Florida Public Hurricane Loss Model." Wind Eng. Ind. Aerodyn., 104$106,76-87$.

Vickery, P. J., Skerlj, P. F., Lin, J., Twisdale-Jr., L. A., Young, M. A., and Lavelle, F. M. (2006). "HAZUS-MH Hurricane Model Methodology. II: Damage and Loss Estimation." Natural Hazards Review, ASCE, 7(2), 94-103.

Weekes, J., Balderrama, J., Gurley, K., Pinelli, J.-P., Pita, G., and Hamid, S. "Physical Damage Modeling of Commercial-Residential Structures in Hurricane Winds." Proc., the 11th American Conference on Wind Engineering. 


\title{
2. SIMULATION OF WIND-DRIVEN RAIN ASSOCIATED WITH TROPICAL STORMS AND HURRICANES USING THE 12-FAN WALL OF WIND
}

\author{
Thomas Baheru ${ }^{1}$, Arindam Gan Chowdhury ${ }^{* 1}$, Girma Bitsuamlak ${ }^{2}$, Forrest J. Masters ${ }^{3}$, \\ Ali Tokay ${ }^{4}$ \\ ${ }^{1}$ Department of Civil and Environmental Engineering, Florida International University, Miami, FL, USA \\ ${ }^{2}$ Department of Civil and Environmental Engineering, Western University, London, ON, Canada \\ ${ }^{3}$ Department of Civil and Coastal Eng., University of Florida, Gainesville, FL, USA \\ ${ }^{4}$ Joint Center for Earth Systems Technology, University of Maryland, Baltimore; NASA Goddard Space \\ Flight Center, Greenbelt, Maryland, USA
}

\section{(Accepted for publication in Building and Environment journal)}

Abstract. Wind-driven rain (WDR) is among the important environmental variables that affect the performance and durability of building enclosure systems. Although the need to investigate multi-level effects of WDR on building structures has increased through time, the available methods of investigation have been generally limited to field study and application of computational fluid dynamics. This paper investigates the parameters of tropical storm and hurricane-level WDR and presents a methodology of large-scale experimental simulation of WDR that may complement the two other investigation methods. Tropical cyclone WDR data acquired through National Aeronautics and Space Administrations' Tropical Rainfall Measuring Mission ground validation program were used to study the characteristics of tropical storm and hurricane-level WDR and derive the values of target parameters, which were later used in the experimental simulation process. Procedure for determination of target WDR rate, simulation of raindrop size distribution and its integral parameters, and selection of type and number of nozzles are discussed in detail. Similarity requirements and important scaling considerations of WDR

\footnotetext{
*Corresponding author, Associate Prof., E-mail: chowdhur@fiu.edu
} 
simulation were addressed. The procedure was used to simulate WDR using the 12-fan Wall of Wind facility at Florida International University. The experimental simulation results, presented herein, demonstrated satisfactory representation of target rainfall intensity and raindrop size distribution in the test setup. The WDR simulation methodology presented herein may be used, in general, for simulation of WDR in various types of testing facilities to address the environmental performance of buildings, building systems, and components and experimentally evaluate water intrusion in buildings during tropical storms and hurricanes.

Keywords: large-scale testing; low-rise building; raindrop size distribution; tropical cyclone rainfall; wind driven rain; Wall of Wind

\subsection{Introduction}

Wind-driven rain (WDR) is an important environmental variable that affects the performance and durability of building enclosure systems. Its multi-level impact ranges from weakening the building envelope through deterioration of roof covers and wall claddings to damage of building interior components and contents in extreme weather conditions. WDR intrusion through building envelope defects and breaches during tropical storms and hurricanes, as indicated in recent years post-storm reports, contributed to a major portion of the total property losses through interior damages (FEMA 2005). WDR penetration through building envelope has been a persistent problem during such windstorms, affecting long term functionality of building enclosure systems (Mullens et al. 2006; van de Lindt et al. 2007). Even under normal weather conditions, the deposition of raindrops on building façades alters the hygrothermal dynamics of building enclosure system and significantly affects the overall HAM (Heat, 
Air, and Moisture) transfer performance and energy consumption of buildings (Blocken et al. 2007). In spite of the wide spectrum of impacts, up to now, the available methods of investigation of WDR effects on building structures have been generally limited to field studies to characterize raindrop size distribution (Friedrich et al. 2013; Friedrich et al. 2012), application of numerical and/or computational fluid dynamics to model rain deposition (Blocken and Carmeliet 2012; Blocken et al. 2005; Choi 1993; Choi 1994) and laboratory experiments assessing the performance of single building components (Bitsuamlak et al. 2009; Lopez et al. 2011; Salzano et al. 2010). A systematic approach to recreate WDR in full-scale experimentation in high wind events has not been developed. There is scarcity of field and experimentally measured WDR data to validate WDRbuilding interaction information produced through numerical approaches (Blocken and Carmeliet 2007; Hangan 1999). Adequate investigation of WDR impacts entails the development of experimental environment that would simulate WDR effects under controllable and repeatable testing conditions.

Having the turbulent wind as a major cause of WDR impact, the extent of any sort of WDR effects on buildings is determined by the two important quantities: volume of rainwater per unit volume of air and its rate of deposition onto the building surface. Raindrop size distribution (RSD), defined as the number of raindrops $N(D)$ within a specific drop size range per unit volume of air, and velocity of raindrops are the parameters of WDR that are used in derivation of total volume of rainwater and its rate of deposition, respectively. Also, in high wind conditions such as tropical storms and hurricanes, the rate of deposition and subsequent impact is predominantly dependent on the nature of the wind and wind-induced pressure. Physical simulation of WDR to 
reproduce WDR effects and develop useable test-based data of rainwater deposition, as well as intrusion through building envelope, needs to ensure the realistic representation of the parameters of wind and WDR in the experimental setup. In past, many attempts were made to simulate WDR in both wind tunnel and large scale testing facilities. Inculet (2001) simulated WDR in a $5 \mathrm{~m} \times 4 \mathrm{~m}$ wind tunnel at the Western University, Ontario, Canada. Model scale RSD based on Marshall and Palmer (1948) model was used as a target to simulate WDR at various rain rates. Drop size and velocity scaling approach was implemented to derive the target cumulative percentage volume of rainwater versus drop diameters. Lopez (2011) studied the simulation of WDR at full scale using the Full-Scale Test Facility at the Insurance Institute for Business \& Home Safety (IBHS). The study characterized the nature of WDR associated with super-cell thunderstorms and hurricanes based on field data acquired through the Verification of the Origins of Rotation in Tornadoes Experiment 2 (VORTEX2) project and the Florida Coastal Monitoring Program (FCMP). An RSD model suggested by Best (1950) and a model derived from field data were used to validate the full-scale simulation. Bitsuamlak et al. (2009) investigated the potential to simulate WDR at full scale using the 6-fan Wall of Wind hurricane simulator at the International Hurricane Research Center, FIU. The study used the building code recommendation of flow uniformity check to investigate the overall RSD representation in the experimental setup. Knasiak et al. (2005) simulated horizontal rain and studied the spatial uniformity of the flow at low and high rain rates as function of spray height. The study indicated that the increase in height of nozzles placement results in a more homogenous representation of RSD (Knasiak et al. 2005). 
The WDR intrusion problem during tropical storms and hurricanes is a complex phenomenon. The wind induced pressure causes damage to the building external envelope and creates a pathway to WDR intrusion along with the existing envelope defects. Total volume of rainwater ingress largely depends on the nature of wind and WDR. The aerodynamic pressure distribution and raindrops impact pattern are two intertwined processes leading to the total volume of WDR intrusion through openings located on the building envelope. Quantification of water volume and subsequent effects and the development of mitigation strategies to reduce rainwater penetration through building envelope require understanding of this complex process. Holistic testing of building models to investigate WDR intrusion requires the realistic simulation of both wind and rain characteristics in an experimental setup.

The purpose of the current study is to characterize the nature of WDR associated with tropical storms and hurricanes and develop a simulation methodology, which would allow testing building models under realistic WDR conditions. Identifying representative values of target WDR parameters, scaling laws, systematic simulation procedure and simulation results are discussed in subsequent sections. The simulation of tropical cyclone and hurricane associated WDR was performed at the Wall of Wind facility at FIU as described in this paper. The WDR simulation methodology presented herein may be used, in general, for simulation of WDR in various types of testing facilities to address the environmental performance of buildings, building systems, and components. Such simulation will also facilitate future study of rainwater intrusion problems in buildings and development of test-based WDR data and mitigation techniques to minimize water and moisture intrusion. 


\subsection{Target wind-driven rain parameters}

Characteristics of rain associated with tropical storms and hurricanes have been studied by many researchers (Lopez 2011; Merceret 1974; Tokay et al. 2008; Willis and Tattelman 1989). The characteristic RSD (and its integral parameters, e.g. liquid-water content and rain rate) of WDR is mainly determined by the physical processes including aggregation and/or riming among ice crystals aloft and drops collision which cause drops to break-up/defragment and coalesce. In addition to imparting inertial acceleration onto the raindrops, the variable wind velocity plays important role in the process through mixing the drops and increasing the probability of collision. In the current study, the nature of RSD of WDR during tropical storms and hurricanes was studied using a set of data acquired through the National Aeronautics and Space Administrations' Tropical Rainfall Measuring Mission (TRMM) ground validation program at Wallops station, Wallops Island, VA, during Hurricanes Alex, Charley, and Gaston (2004). Although the trace paths of Hurricane Alex and Charley did not pass across Wallops Island, they caused significant wind and rainfall at the measuring station while crossing nearby states and cities. On the contrary, after it degraded to tropical storm, Hurricane Gaston crossed the state of Virginia and caused high rainfall at the measurement site. The detailed synoptic setting of these hurricanes can be found on the National Hurricane Center Tropical Prediction Center web page and is also briefly discussed in Tokay et al. (2008). The RSD and rain rate data were collected using impact type of disdrometers and tippingbucket rain gauges, respectively. Table 2.1 presents parameters of the three hurricanes in relation to the measurement data collected at Wallops Island, VA. 
Table 2.1. Synoptic settings of the tropical cyclones (TC) (Tokay et al. 2008)

\begin{tabular}{lccccc}
\hline $\begin{array}{c}\text { Hurricane } \\
\text { Name }\end{array}$ & $\begin{array}{c}\text { Max wind } \\
\text { speed (mph) }\end{array}$ & $\begin{array}{c}\text { Lowest surface } \\
\text { pressure (mb) }\end{array}$ & $\begin{array}{c}\text { Disdrometer } \\
\text { Rainfall (mm) }\end{array}$ & $\begin{array}{c}\text { Rain Gauge } \\
\text { Rainfall (mm) }\end{array}$ & $\begin{array}{c}\text { Disdrometer } \\
\text { rainy minutes }\end{array}$ \\
\hline Alex (2004) & 98 & 972 & 42 & 42 & 338 \\
Charley (2004) & 69 & 1000 & 70 & 75 & 713 \\
Gaston (2004) & 40 & 1000 & 15 & 18 & 279 \\
\hline
\end{tabular}

Recent research suggest that the RSD of WDR associated with tropical cyclone (TC) is better represented using a three parameter gamma distribution (see Eq. (1)) (Bringi et al. 2003; Tokay et al. 2008; Willis and Tattelman 1989). A simplified derivation of the gamma model of RSD, Eq. (1), is presented in Appendix-A for the sake of completeness, however, the interested reader may refer to Testud et al. (2001), Willis (1984), and Sekhon and Srivastava (1971) for further explanations and mathematical modeling of RSD.

$$
\frac{N(D)}{N_{w}}=f(m)\left(\frac{D}{D_{\text {mass }}}\right)^{m} \exp \left(-(4+\mathrm{m}) \frac{D}{D_{\text {mass }}}\right)
$$

Equation (1) represents the dimensionless form of the RSD spectrum, where, $N(D) / N_{w}$ is the normalized RSD, $D$ is the diameter of raindrops, $D_{\text {mass }}$ is the mass-weighted mean diameter, $m$ is the shape parameter, and $f(m)$ is given by

$$
f(m)=\frac{6}{4^{4}} \frac{(4+m)^{m+4}}{\Gamma(m+4)}
$$

where, $\Gamma$ is the gamma function.

Note that Eq. (1) is independent of the rain rate or any other integral parameter of RSD. The shape parameter, $m$, defines the non-dimensional spectrum of raindrop size distribution. The mass-weighted mean diameter, $D_{\text {mass }}$, and the intercept parameter or 
normalizing number concentration, $N_{w}$, are required to convert the non-dimensional RSD to a dimensional form. $D_{\text {mass }}$ is estimated based on rain rate $(R R) . N_{w}$ can be estimated based on $D_{\text {mass }}$ and liquid-water content $(W)$, the latter being a function of the rain rate. These relationships are discussed later in more details.

\subsubsection{Statistical measures of RSD parameters}

The RSD data collected during the three hurricanes were averaged over two minutes to calculate the normalized RSD and normalized diameter. The averaging time of two minutes was selected based on Bringi et al. (2003) as the time for which a rain event could be characterized by a specific average rain rate.
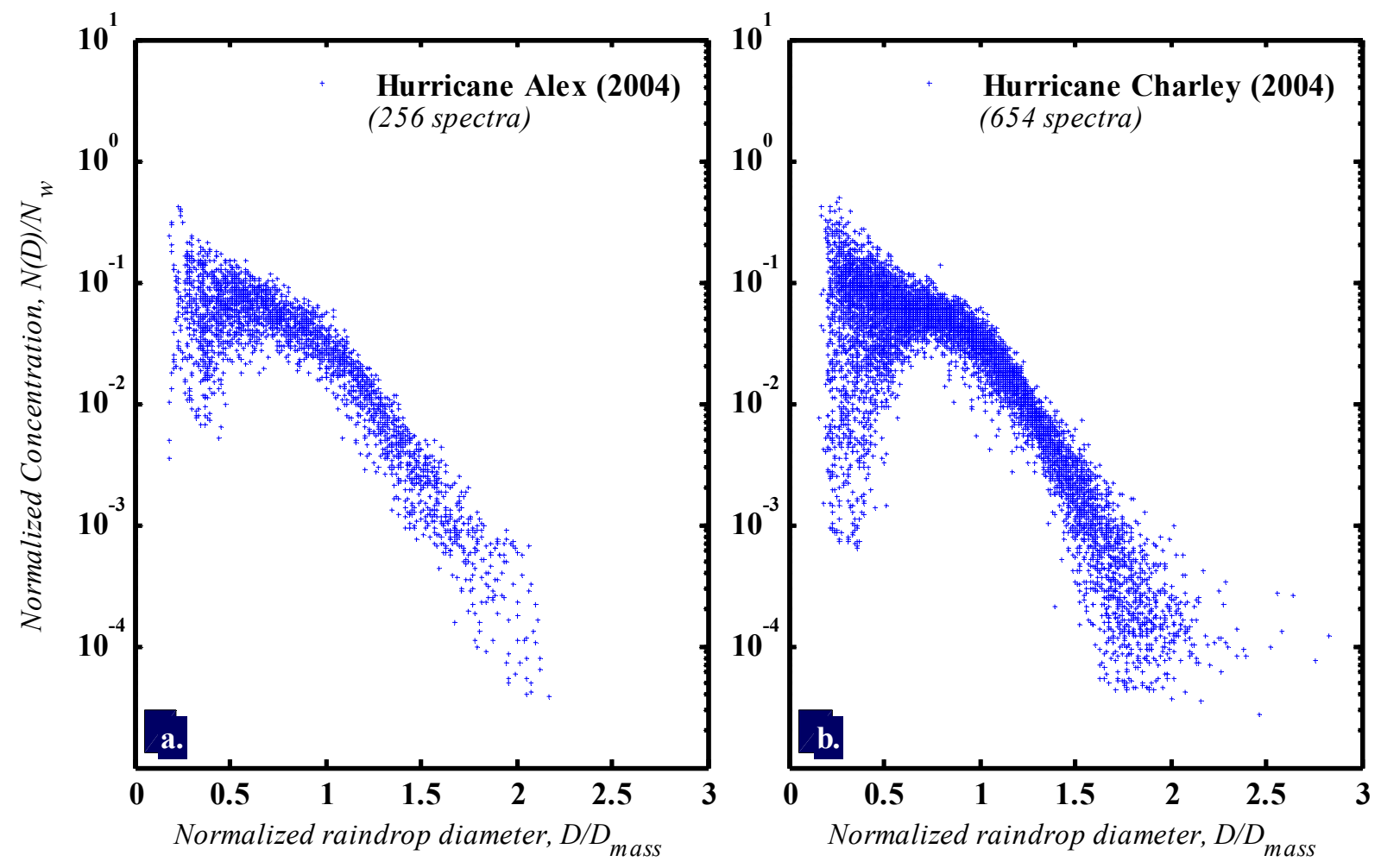

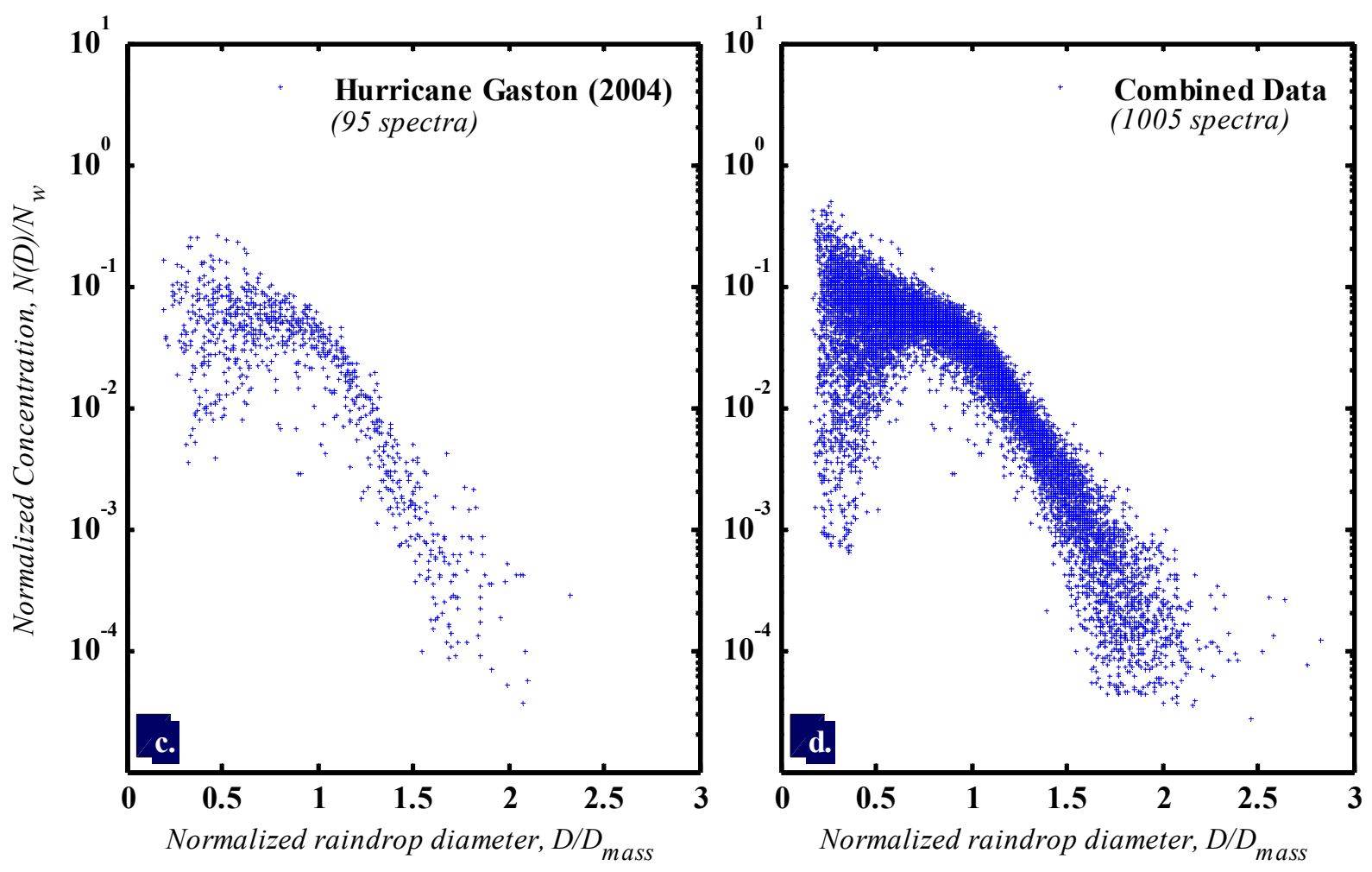

Figure 2.1 Normalized RSDs: a) Hurricane Alex (2004); b) Hurricane Charley (2004); c) Hurricane Gaston (2004); d) Combined data of the three hurricanes.

Figure 2.1a-c present the dimensionless RSD spectra of the three hurricanes while

Fig. 2.1d shows the spectral plot of aggregate data from the three hurricanes. The fact that the normalized RSD is independent of any measured dimensional quantities of WDR allowed combining the RSD data from the three hurricanes to identify the underlying nature of TC WDR with a better confidence level or minimized statistical error. The shape parameter for each two-minute RSD data was estimated using the Probability Plot Correlation Coefficient (PPCC) method. Based on the data analysis, the nature of the following parameters was investigated to formulate a set of target values for simulation purpose (see Figure B2.17-B2.22 of Appendix-B).

- Probability density function of the shape parameter, $m$

- Probability density function of the slope parameter, $\Lambda$ (see Appendix - A) 
- Probability density function of the intercept parameter, $\log _{10}\left(N_{w}\right)$

- Probability density function of the mass-weighted mean diameter, $D_{\text {mass }}$

The RSD data collected during Hurricane Alex, Charley, and Gaston provided sample sizes of 256, 654, and 95 2-minute RSD spectra, respectively. Figure 2.2 shows the statistical plot of shape parameters of the three hurricane RSDs. Although combining the three RSDs data increased the total number of outliers in the combined dataset (see Fig. 2.2), the inter-quartile range was found to be smaller than that of Hurricane Charley, which had more than $50 \%$ contribution to the combined RSD data. The normalized RSD spectra in the inter-quartile range are shown in Figure 2.3, with the average normalized RSD found based on the average shape parameter, $m$, of the combined dataset. For engineering application, it is recommended that a good representation of the RSD spectra in laboratory rain simulation shall fall in this inter-quartile region, which is equivalent to the width of about half of the standard deviation $(\approx \pm 0.5 \sigma)$ over the mean shape parameters (see Table 2.2).

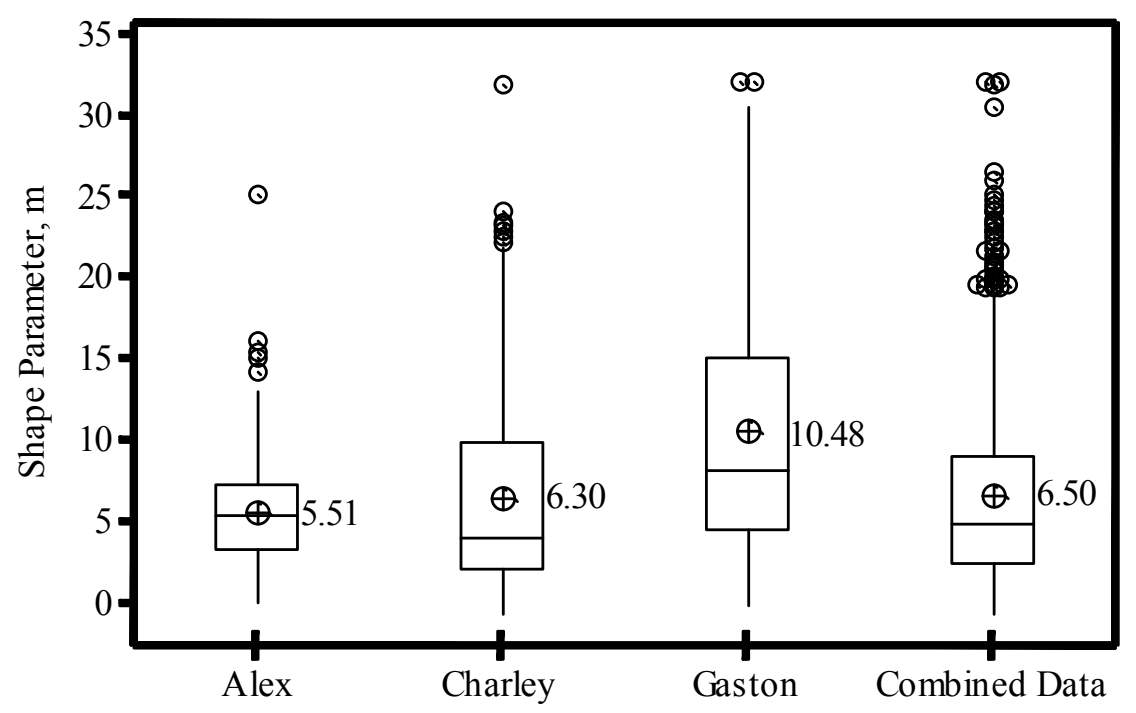

Figure 2.2 Statistical plot of the shape parameter (m) of RSD of WDR during the three hurricanes. 


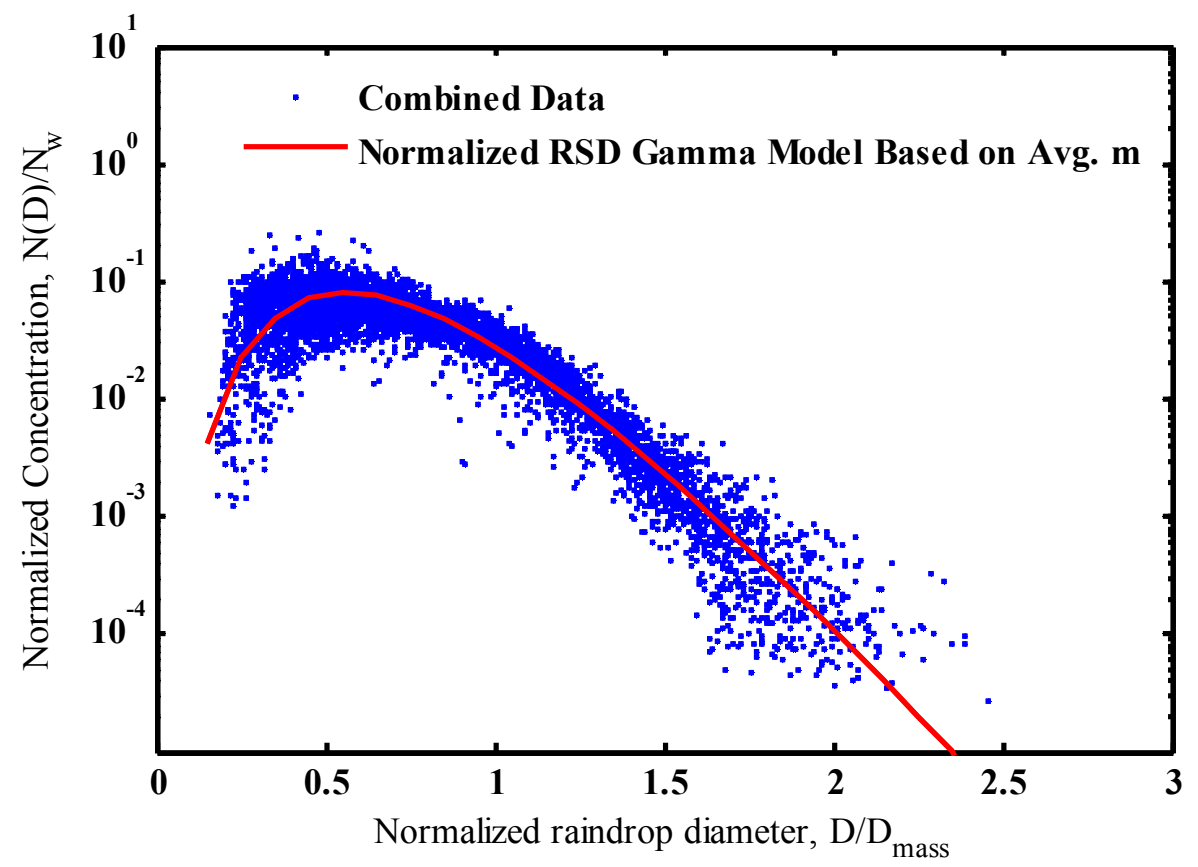

Figure 2.3 Normalized RSDs in the inter-quartile range of the shape parameter.

The statistical analysis of RSD parameters based on data collected during the three hurricanes indicated that the shape and slope parameters have lognormal distribution with mean values of 6.50 and 10.06, respectively (Fig. B2.17-B2.20 of Appendix - B). The histograms of $D_{\text {mass }}$ and $N_{w}$ based on the entire RSD data are shown in Figs. B2.21 and B2.22 of Appendix B. Table 2.2 shows the statistical measures of RSD parameters of TC WDR based on the combined data set.

Table 2.2. Statistical measures of RSD parameters based on combined RSD data of the three TCs

\begin{tabular}{lccccccc}
\hline & Mean & StDev & Min., Max. & Median & IQR* & Skewness & Kurtosis \\
\hline Shape, $m$ & 6.50 & 5.54 & $-0.70,32.00$ & 4.80 & 6.65 & 1.40 & 2.03 \\
Slope, $\Lambda$ & 10.06 & 7.88 & $1.84,65.55$ & 7.91 & 7.46 & 2.59 & 10.16 \\
$\log _{10} N_{w}$ & 3.67 & 0.42 & $2.47,4.71$ & 3.74 & 0.66 & -0.42 & -0.58 \\
$D_{\text {mass }}$ & 1.20 & 0.30 & $0.53,2.22$ & 1.18 & 0.43 & 0.35 & -0.17 \\
\hline
\end{tabular}

*Inter-quartile Range 


\subsection{Scaling of wind-driven rain}

\subsubsection{Similarity requirements}

The three main forces governing the motion of a raindrop are gravitational force, wind-induced inertial acceleration force, and viscous friction force. Having the primary flow governing forces, the similarity requirements between model and prototype for experimental simulation of WDR can be derived either using the classical BuckinghamPi theorem or flow governing equations. Derivation of similarity requirements using flow governing equations is presented in Inculet (2001). Water to air density ratio, Reynolds number (Re), and Froude number (Fr) are the three non-dimensional parameters controlling the similitude of WDR flow in various scales. While the density ratio similarity requirement is being satisfied by default, the challenge remains in fulfilling the other two requirements. Experimental or model scale simulation of wind and WDR usually requires a tradeoff between the two similarity requirements based on their effect on the test result. For example, a Froude number based simulation of WDR in a scaled experimental setup will result in Reynolds number similitude violation between model and full-scale given by

$$
R e_{m s}=\lambda_{v}^{3} R e_{f s}
$$

where $\lambda_{v}$ is the velocity scale and the subscripts $f_{s}$ and $m s$ refer to full-scale and modelscale, respectively.

Raindrops in WDR flow field are subjected to critical flow condition in the high relative velocity zone where the Re is very high. The typical Re for raindrops during tropical storms and hurricanes ranges between $10^{2}$ to $10^{5}$ with corresponding drag force 
coefficients of $C_{d}=1.057$ to 0.45 , for small and large drops, respectively (Foote and Toit 1969; Morsi and Alexander 1972). An increase in Re causes a minor change in the trajectory of raindrops if the critical Re is not exceeded. On the other hand, scaling down the WDR flow field decreases Re, causing an increase in the drag force and drag coefficient due to the steep negative slope of the drag force coefficient in the low $\operatorname{Re}$ region. This could cause raindrops to follow different trajectories and result in an unrealistic wetting pattern on building façade in laboratory testing using WDR simulated at small scale. In general, this suggests that experimental simulation of WDR shall be performed at large scales.

\subsubsection{Scaling of wind-driven rain parameters}

In order to examine the scaling of the integral parameters of WDR, velocity and length-scale $\left(\lambda_{V}=V_{m s} / V_{f s}\right.$ and $\left.\lambda_{L}=L_{m s} / L_{f s}\right)$ were applied to the raindrop size distribution, $N(D)$, and drop diameter $(D)$ as follows:

$$
D_{m s}=\lambda_{L} D_{f s} ; \quad N_{m s}=\frac{N_{f s}}{\lambda_{L}{ }^{4}}
$$

Equation (4) shows that in down-scaling of WDR flow field, the raindrop number concentration per unit volume of air increases by the fourth power of the length-scale inverse while the raindrop sizes are reduced by multiplying with the length-scale. Using Eq. (4) one can show that the rain rate in model and full-scale are related to the velocity scale. The liquid-water content per unit volume of air, which is the integral of raindrop mass spectrum, however, remains the same between the model scale and prototype. 


\subsection{The 12-fan Wall of Wind wind-driven rain simulation device}

\subsubsection{Wind and wind-driven rain simulation devices}

The WDR simulation reported in this paper was performed using the 12-fan Wall of Wind (WOW) facility at FIU capable of generating tropical storm and hurricane wind speeds. The 12 electric fans are arranged in two-row by six-column pattern to produce a wind field $6 \mathrm{~m}(20 \mathrm{ft})$ wide and $4.25 \mathrm{~m}$ (14ft) high, allowing aerodynamic testing of largescale building models. A contraction section is used downwind of the array of 12 fans to facilitate mixing up of the flow and attaining uniform flow field with high wind speeds. The vertical flow directing vanes at the exit of the contraction zone guide the flow in the longitudinal direction. A $9.75 \mathrm{~m}$ (32ft) long flow simulation box downwind of the contraction provides the required fetch length and confines the flow to develop the desired atmospheric boundary flow characteristics. A suburban mean wind speed profile is generated using triangular-shape spires and floor roughness (see Fig. 2.4). The optimal shape and size of the spires and floor roughness were determined through a rigorous trialand-error procedure of wind profile measurements in the small-scale version of the 12fan Wall of Wind (scale of 1:15) (Aly et al. 2011). Based on the scaled model results, spires and roughness elements were constructed and installed in the full scale 12-fan WOW (see Figs. 2.4a and 2.4b).

Detailed temporal and spatial measurements of wind speed and turbulence intensity were conducted using a vertical rake system built specifically for wind measurement purposes. The rake system consisted of pressure tubes mounted at various elevations in the wind field and connected to a 16-channel Scanivalve DSA pressure scanner to record differential pressure time histories that were converted to instantaneous 
wind speeds. In addition to the pressure scanner, eight Cobra Probes were mounted on the measurement mast to capture the turbulence characteristics of the flow field in the three major directions. Figure $2.4 \mathrm{~b}$ shows the wind profile measurement setup with measurement rake placed at $6.1 \mathrm{~m}(20 \mathrm{ft})$ from the exit of the flow simulation box.
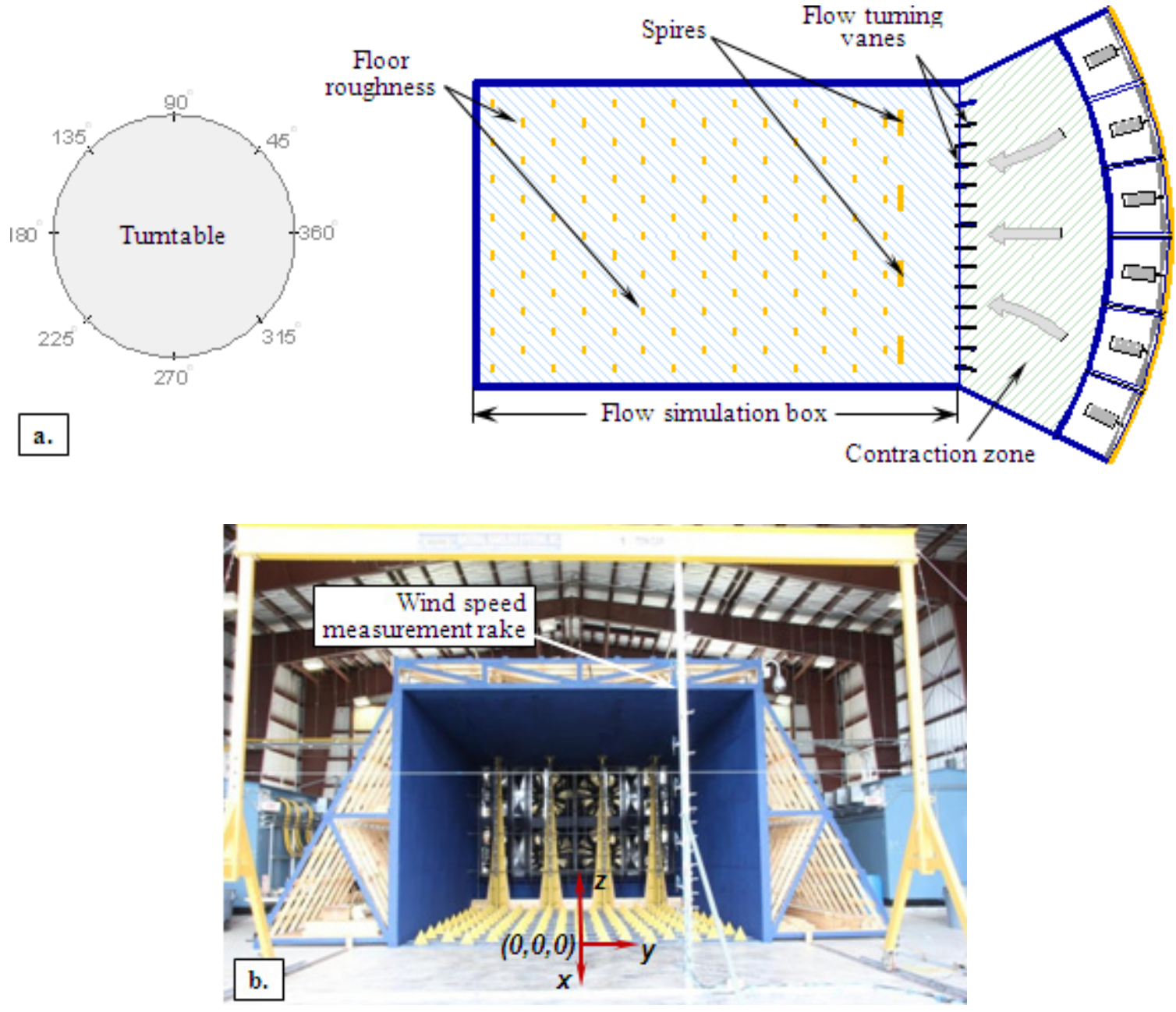


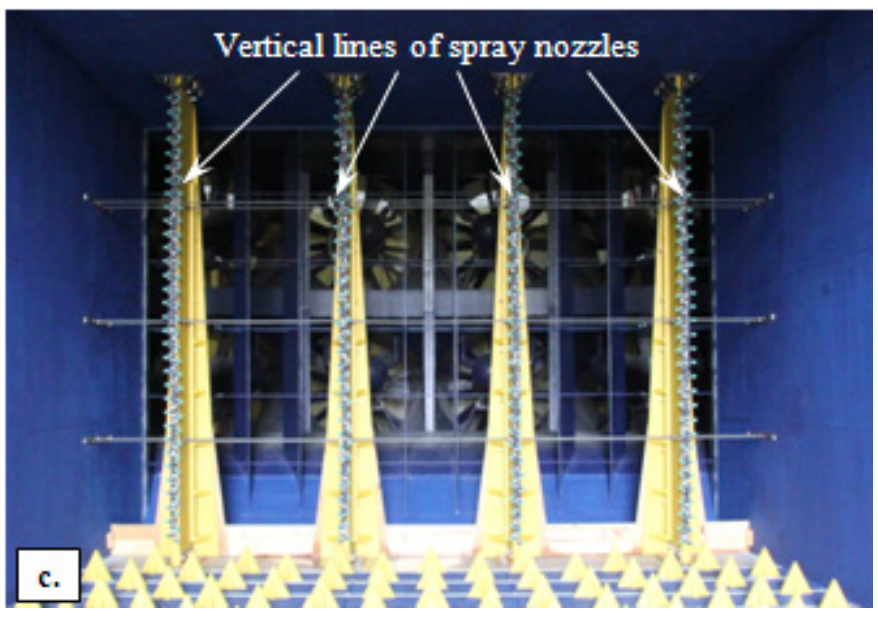

Figure 2.4 The 12-fan Wall of Wind (WoW): a) Plan view schematic; b) Elevation view with wind speed measurement system in place; c) WDR generating spray nozzles.

The WDR at the 12-fan WOW is generated using a plumbing system consisting of four vertical lines (with spray nozzles) attached to the front of the frame supporting the spires (See Fig. 2.4c). The lines are fed from a common horizontal pipe running over the top of the flow simulation box. The horizontal pipe is connected to a main water supply line of diameter $50.8 \mathrm{~mm}$ (2.0 in), supplying water at a constant rate of about $5 \mathrm{~m}^{3} / \mathrm{hr}$ and with a pressure of $345 \mathrm{KPa}(50 \mathrm{psi})$. Equally spaced TeeJet full cone spray nozzles are installed along the length of the vertical lines to generate the desired rain rate at the testing section (i.e., the turn table location). A detailed procedure on how to select the type and number of nozzles based on the target WDR rate and nozzles' capacity is presented in section 5 .

A precipitation imaging probe (PIP) mounted on the measurement rake was used to measure the raindrop size distribution of simulated WDR at different locations within the flow field. The PIP measures the distribution of raindrop sizes using an optical array of probes illuminating an array of $64100 \mu \mathrm{m}$ diameter photodiodes which allow detecting raindrop size range of 100 to $6200 \mu \mathrm{m}$. The raindrops interrupt the light as they 
pass through a laser beam cross-section and their size and count are determined through scanning of the light intensity on the 64 diodes at a frequency rate equal to the ratio of the lateral velocity of sample air volume (wind speed) to the size resolution of the PIP (100 $\mu \mathrm{m})$. The effective laser beam area (sample area), which is a product of effective array width (EAW) and depth of field (DOF), is used to detect the raindrops based on their size and closeness to the focal point. The raindrop number concentration per unit volume of air is calculated as number count from the PIP, $n(D)$, per sample volume, $S V$, which is dependent on size of raindrop.

$$
N(D)=\frac{n(D)}{S V}
$$

In Eq. 5, the sample volume for each class of raindrop sizes is calculated as

$$
S V=E A W \cdot D O F \cdot(U \cdot t)
$$

where $U$ is the wind speed and $t$ is the sampling time.

In addition to the PIP, two TB3 tipping bucket rain gauges were installed on the ground to measure the rain rate during the simulation. Each tipping bucket registers a pulse for every $0.254 \mathrm{~mm}(0.01 \mathrm{in})$ rainfall and records the time history data to ML1-FL data logger. Two flow pressure sensors were also installed at the mid height of two of the four vertical spray lines to monitor the flow pressure during the simulation. 


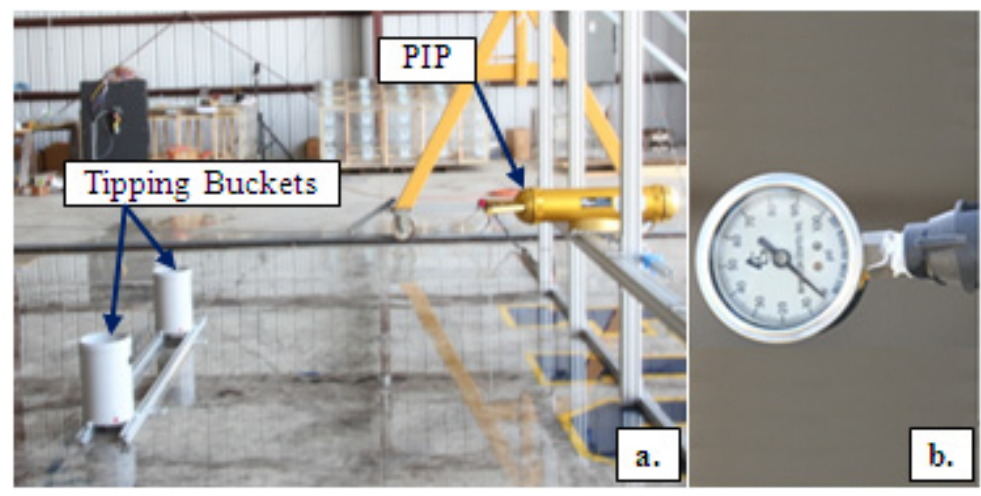

Figure 2.5 Instrumentation for WDR simulation: a) PIP and tipping bucket; b) Pressure sensor.

\subsubsection{Simulated wind characteristics}

Wind characteristics (wind speed and turbulence intensity) simulation was performed prior to the WDR simulation. Model-scale wind speed of $20.1 \mathrm{~m} / \mathrm{sec}$ (45 mph) at a height of $0.91 \mathrm{~m}(3 \mathrm{ft})$ was selected as target wind speed for the simulation of WDR in the testing setup. Based on preselected length scale, $\lambda_{\mathrm{L}}$, of 1:4 and a velocity scale, $\lambda_{\mathrm{V}}$, of 1:2, the target wind speed corresponds to full-scale $40.2 \mathrm{~m} / \mathrm{sec}(90 \mathrm{mph})$ at $3.66 \mathrm{~m}$ (12ft) height. Figure 2.6a shows the wind speed profile along the centerline of the flow field for the selected target wind speed in the suburban terrain. The mean wind speed profile for the target wind speed corresponds to a 1/4.2 power-law coefficient (the target suburban terrain coefficient being $1 / 4.0$ ). The measured mean wind speed at the target height was $20.84 \mathrm{~m} / \mathrm{sec}(46.6 \mathrm{mph})$. The turbulence intensity at the corresponding height was $13.67 \%$. The turbulence intensities were lower than the full-scale target values due to the missing low frequency fluctuations in the simulation (see Fig 2.7). The use of such partial turbulence simulation method, focusing mainly on correctly simulated high frequency turbulence fluctuations, has been shown to be effective for the aerodynamic 
testing of low-rise buildings such as the Silsoe model tested by Richards et al. (2007) and the scaled model WOW tested by Fu et al. (2012) andYeo and Chowdhury (2013).
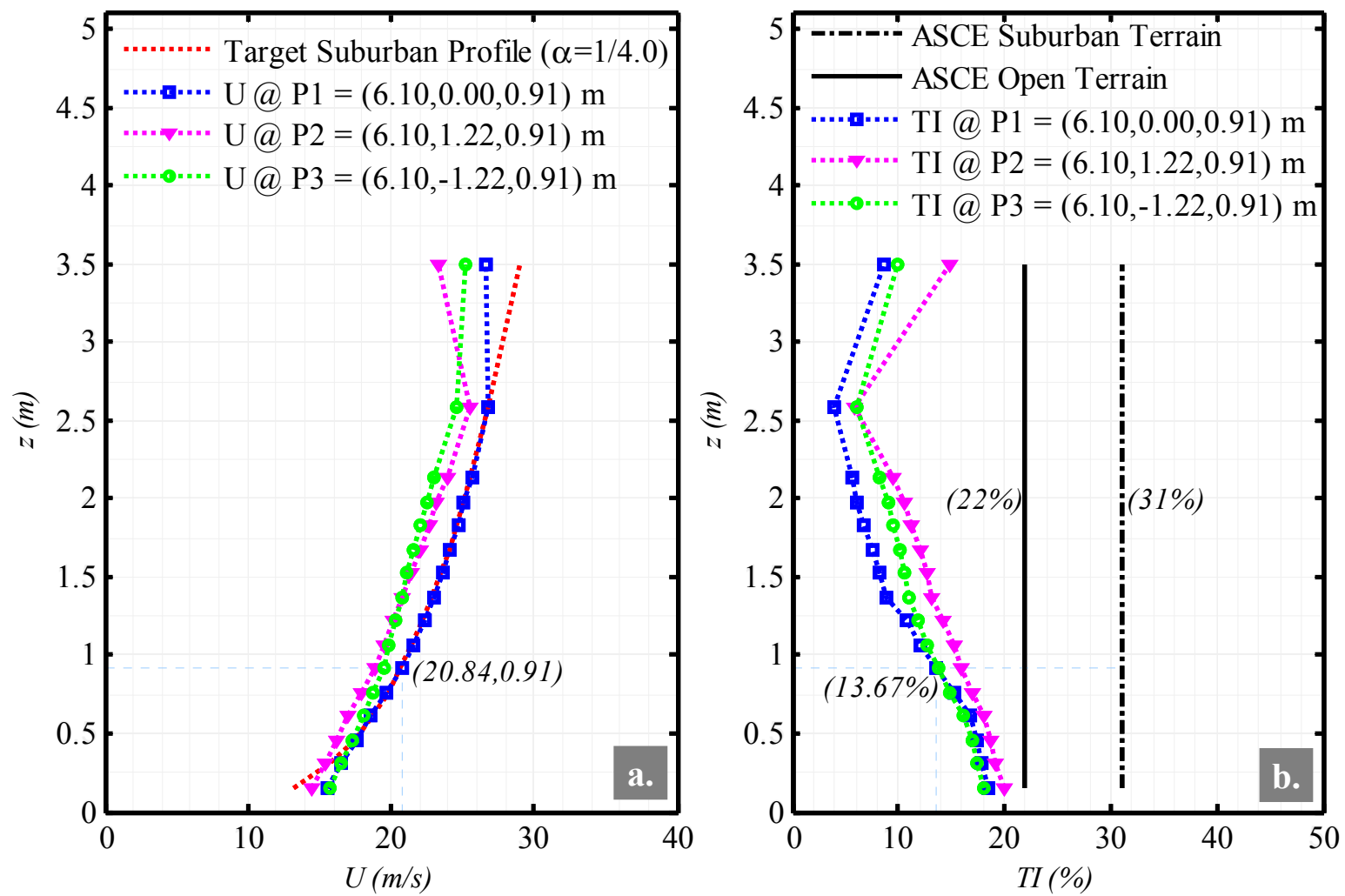

Figure 2.6 Simulation of atmospheric boundary layer: (a) Wind speed; (b) Turbulence intensity profile. 


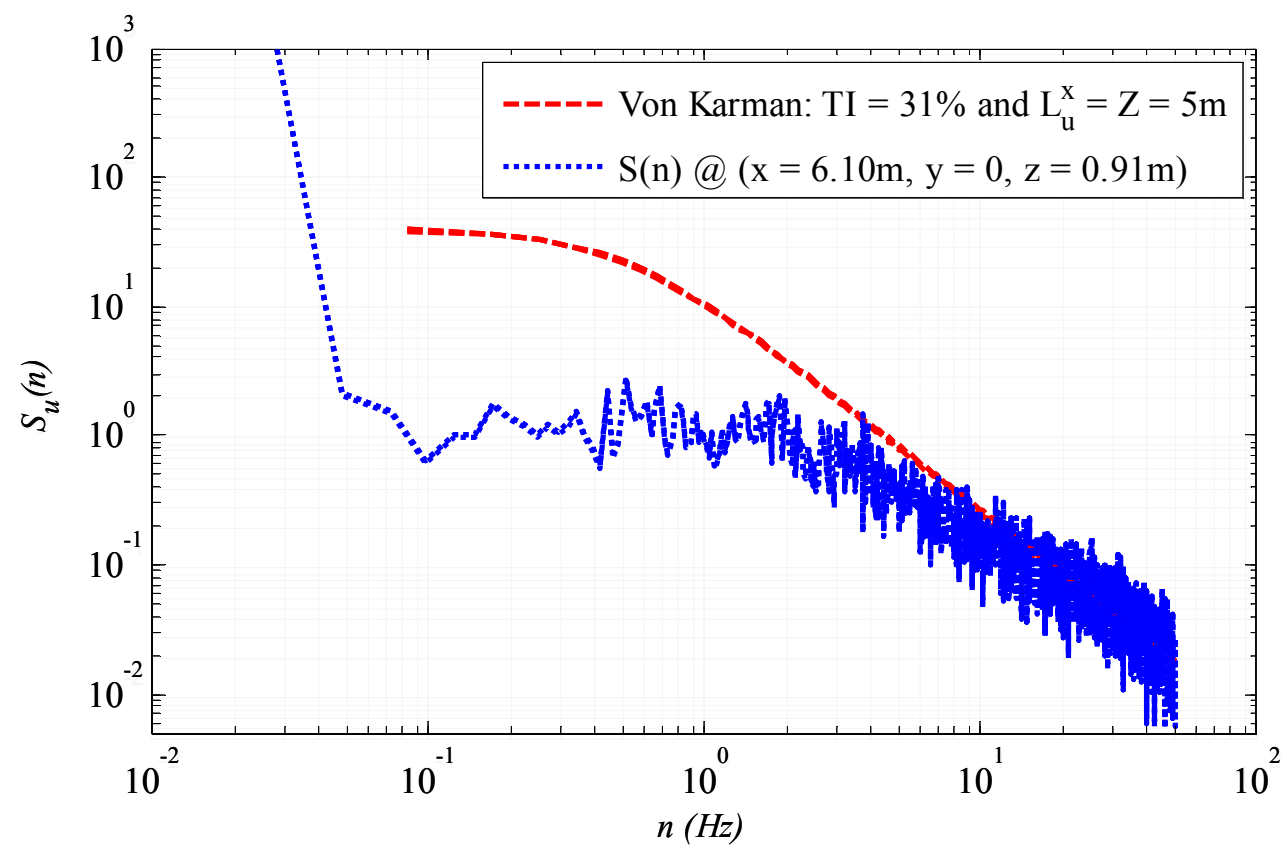

Figure 2.7 Power-spectral density of longitudinal wind speed, U.

\subsection{Wind-driven rain simulation procedure, results, and discussion}

\subsubsection{Target wind-driven rain rate}

The WDR rate (sometimes referred as vertical rain rate: mass flux of raindrops passing through a unit vertical area) is a function of raindrop size distribution (RSD) and raindrop lateral velocities or wind speed. The target WDR rate can only be defined in relation to the wind speed as in most practical applications the lateral velocities of rain drops are considered to be equal to the wind speed, assuming no slippage of wind flow around the raindrop surface. However, in the field of climatology, it is customary to relate the RSD rather with horizontal rain rate as raindrops fall with constant velocities once they attain their terminal velocities. For this reason and the lack of well documented simultaneously measured wind and WDR rate data during tropical cyclones (TC), the target WDR rate is derived based on horizontal rain rate (mass flux of raindrops passing through a unit horizontal area). For the purpose of simulation of WDR in the 
experimental setup, the horizontal rain rate was first selected from TC rain rate spectra. A detailed statistical analysis and estimation of probability density functions of horizontal rain rate during tropical storms and various categories of hurricanes were reported by Lonfat et al. (2004). Note that the frequency distribution of azimuthally averaged rain rate varies with radial distance from the storm center. The frequency distribution of azimuthally averaged rain rate for different categories of storms within the $500 \mathrm{~km}$ radial distance is given on Figure 10b of Lonfat et al. (2004). For the purpose of WDR simulation, an approximate 90 percentile of rain rate, $25.40 \mathrm{~mm} / \mathrm{hr}(1.0 \mathrm{in} / \mathrm{hr})$, was selected as a target horizontal rain rate for the current simulation.

The liquid water content per unit volume of air, $W$, the characteristic number concentration, $N_{w}$, and the mass-weighted mean diameter, $D_{\text {mass }}$, were estimated based on the selected target rain rate and using an empirical formula derived from combined RSD data of the three hurricanes indicated in Table 2.1. Figure 2.8 shows the relationship between $W$ and the horizontal rain rate $\left(R R_{h}\right)$. A similar $R R_{h}-W$ equation was suggested by Willis and Tattelman (1989) based on rainfall data collected during tropical storms and hurricanes. Figure 2.9 shows the combined data based on the hurricanes indicated in Table 2.1 and the equation for the best fit curve relating $D_{\text {mass }}$ and $R R_{h}$. 


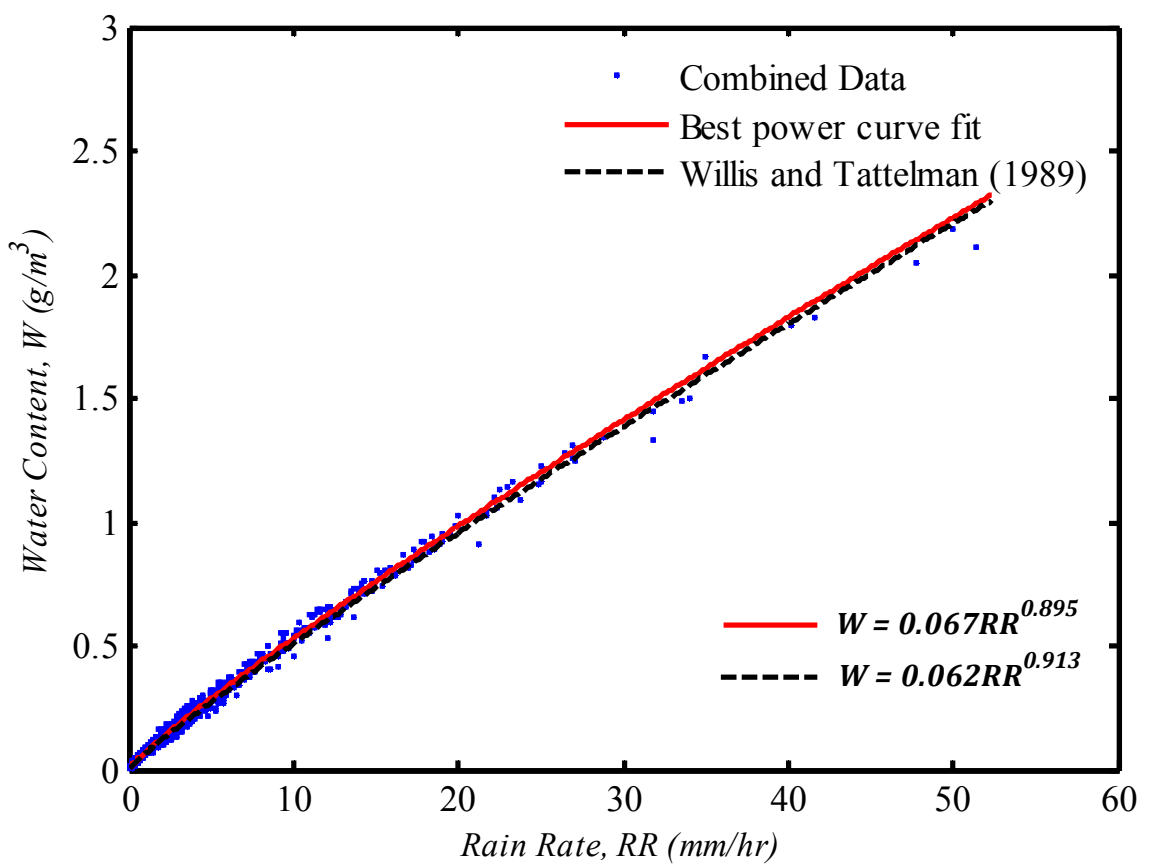

Figure 2.8 Liquid-water content versus rain rate

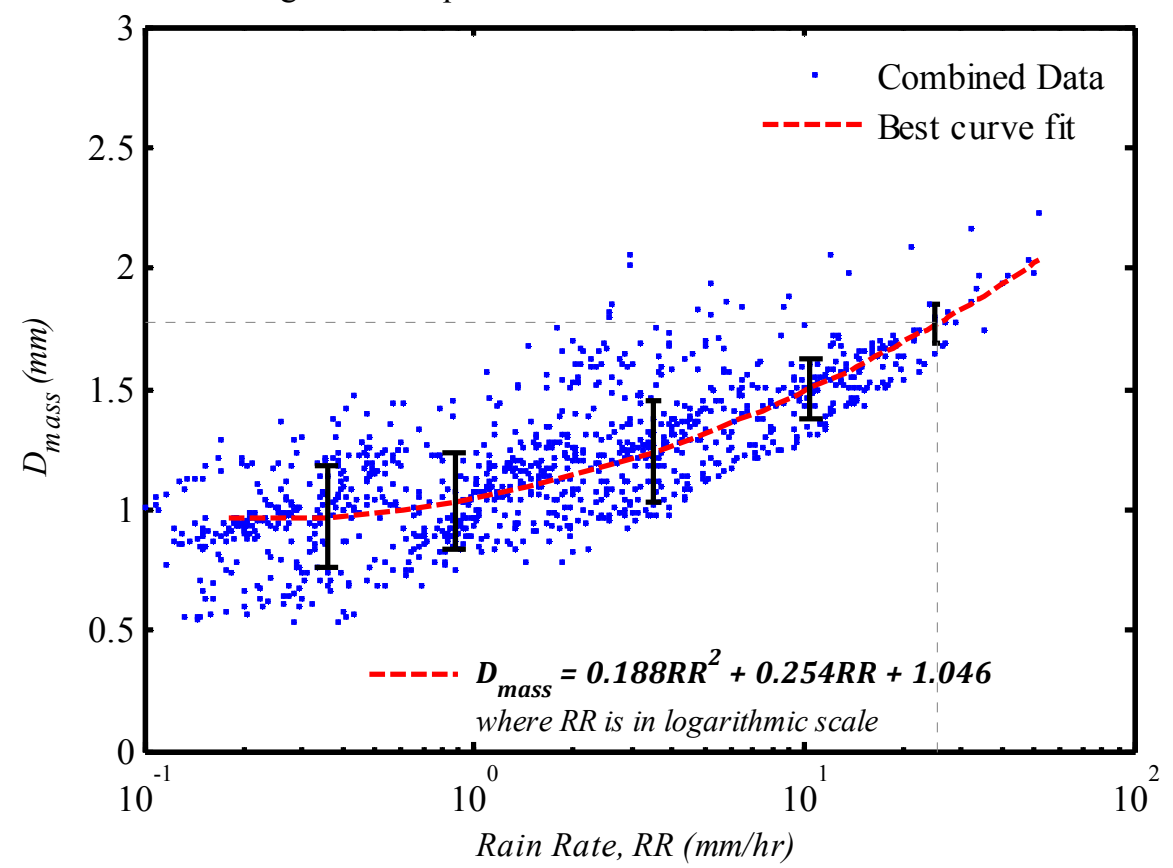

Figure 2.9 Mass-weighted mean diameter versus rain rate.

Figure 2.10 summarizes the procedure for obtaining the target WDR rate. The steps are as follows (the numbering shown in Fig. 2.10 corresponds to these steps):

Using the selected target horizontal rain rate of $25.4 \mathrm{~mm} / \mathrm{hr}(1.0 \mathrm{in} / \mathrm{hr})$ the liquid water 
content, $W$ of $1.21 \mathrm{~g} / \mathrm{m}^{3}$ and mass-weighted mean diameter, $D_{\text {mass }}$ of $1.77 \mathrm{~mm}$ are estimated using Fig. 2.8 and Fig. 2.9, respectively. (2) Using $W=1.21 \mathrm{~g} / \mathrm{m}^{3}$ and $D_{\text {mass }}=$ $1.77 \mathrm{~mm}, N_{w}$ is estimated as $10.05 \times 10^{3} / \mathrm{m}^{3} \mathrm{~mm}$ using Eq. 6 of Appendix A. (3) Using the estimated $N_{w}$ and $D_{\text {mass }}$ values the normalized target RSD shown in Fig. 2.3 (red line, $m=6.50$ ) was converted to full-scale dimensional RSD for a diameter range of up to 6.0 mm. (4) The estimation of the target full-scale dimensional RSD needs the determination of the cut-off maximum raindrop diameter such that the integration of the corresponding mass flux spectrum (see Eq. 15, Appendix-A) reproduces the preselected target horizontal rain rate. A piecewise integration method was used to determine the cut-off maximum raindrop diameter such that the area under the mass flux spectrum produced the preselected horizontal rain rate of $25.4 \mathrm{~mm} / \mathrm{hr}(1.0 \mathrm{in} / \mathrm{hr})$. (5) The cut-off maximum raindrop diameter thus obtained was $3.50 \mathrm{~mm}$, which was used to truncate the full-scale dimensional RSD with an arbitrary maximum raindrop diameter to the target full-scale dimensional RSD. The physical significance of the estimated cut-off maximum raindrop diameter was validated by the findings of Tokay et al. (2008) who reported that the maximum raindrop size during tropical cyclone rainfall rarely exceeds $4.0 \mathrm{~mm}$. (6) The target full-scale RSD with $D_{\max }=3.50 \mathrm{~mm}$ was converted to target model-scale RSD by using the scaling laws presented in Section 3 (see Sec. 3.2). (7) The wind driven rain rates (termed as vertical rain rates) for a range of wind speeds were obtained through the integration of the product of the model-scale mass concentration spectrum and the lateral velocity of the drops. Note that for wind driven rain simulation the lateral velocity of drops is assumed to be equal to the wind speed (as opposed to the terminal velocity of rain drops used to estimate the horizontal rain rate). Figure 2.11 shows the final results of 
the target WDR rate as a function of wind speed. The WDR simulation at the Wall of Wind (WOW) was conducted at preselected model-scale wind speed of $U=20.1 \mathrm{~m} / \mathrm{sec}$ $(45 \mathrm{mph})$ at a height of $0.91 \mathrm{~m}(3.0 \mathrm{ft})$ (refer to subsection 1.4.1 for more details). This wind speed corresponds to a full-scale wind speed of $40.2 \mathrm{~m} / \mathrm{sec}(90 \mathrm{mph})$ at a height of $3.64 \mathrm{~m}(12.0 \mathrm{ft})$. Based on Fig. 2.11, the corresponding model-scale target WDR rate was found to be $R_{\mathrm{v}}=89.41 \mathrm{~mm} / \mathrm{hr}(3.52 \mathrm{in} / \mathrm{hr})$. The following section describes the process for selection of type and number of spray nozzles to reproduce the target model-scale WDR rate.
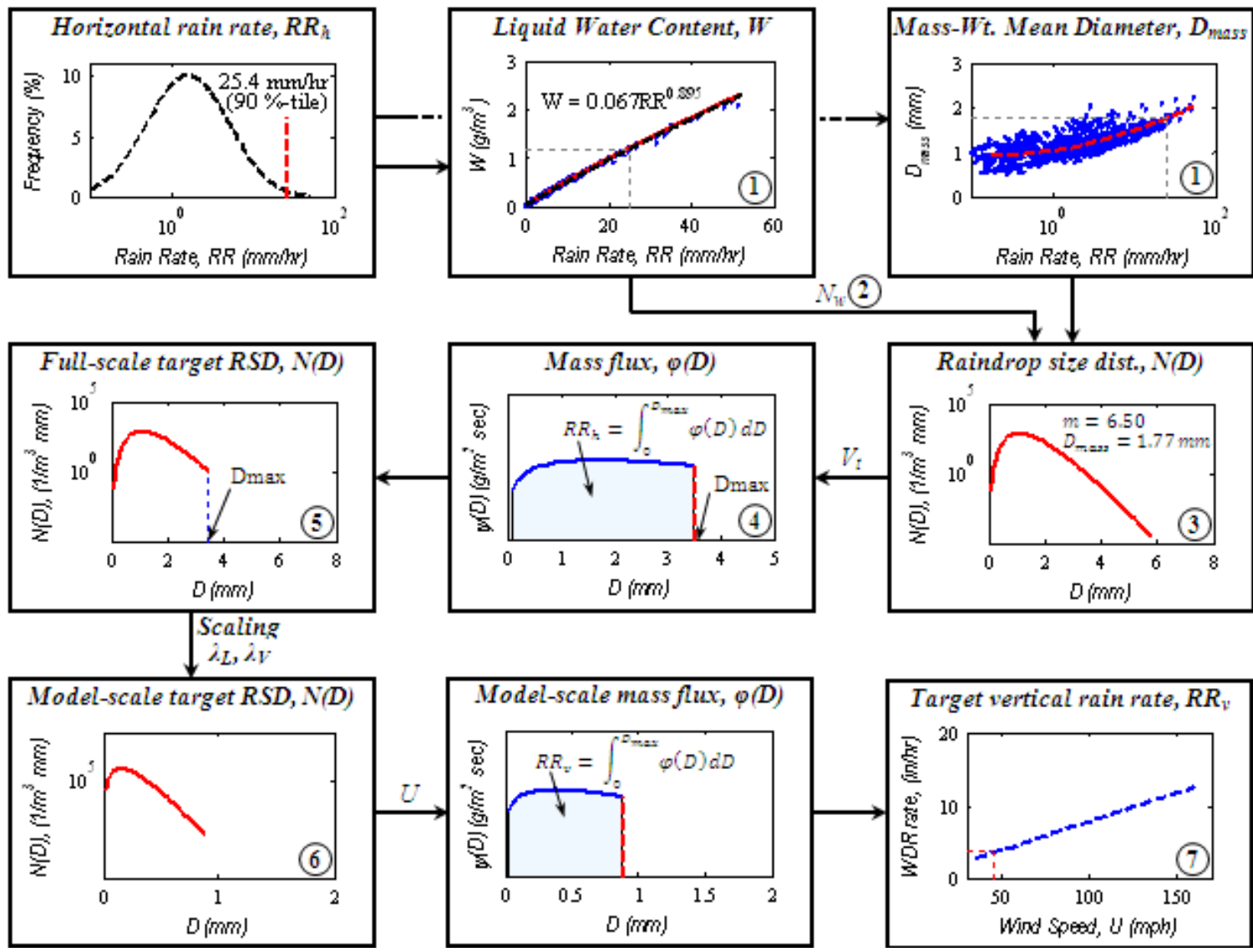

Figure 2.10 Flow chart of target WDR rate calculations 


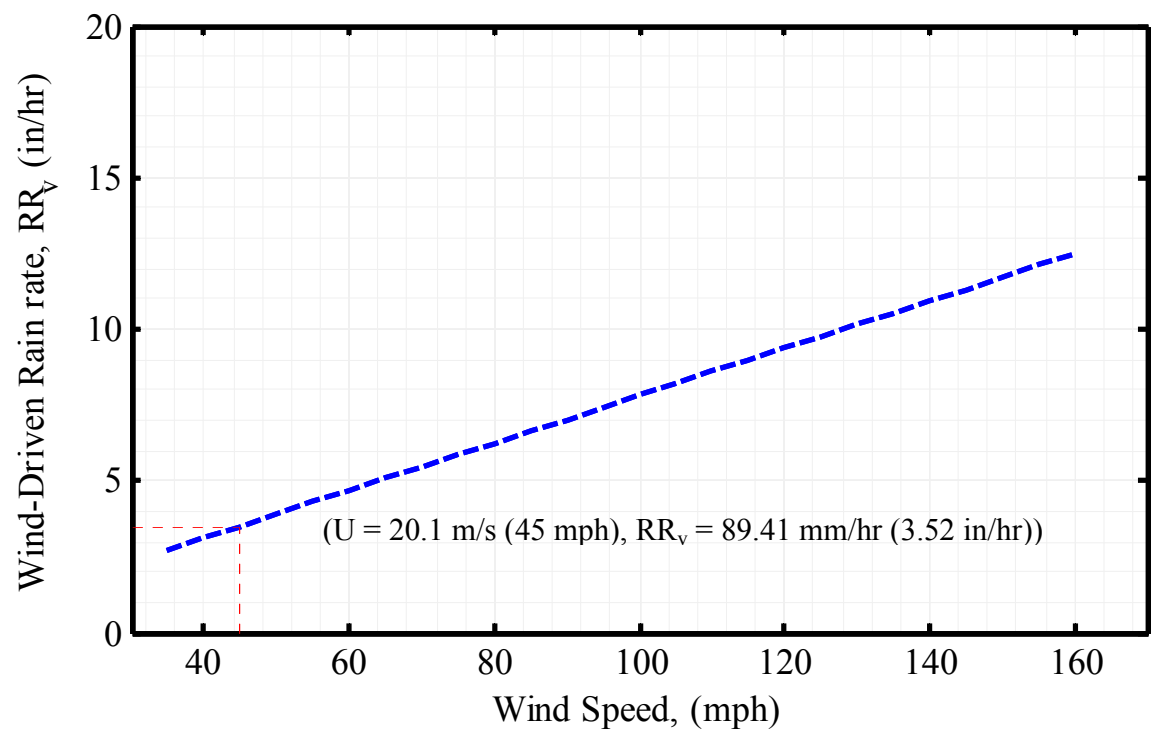

Figure 2.11 Target WDR rate

\subsubsection{Selection of type and number of spray nozzles}

Simulation of WDR with the desired characteristics requires the selection of an appropriate spray nozzle type (opening shape and size) and arrangement/spacing in the test setup. Although the WDR flow at some distance downstream of the nozzle rack is affected by the turbulent wind, the RSD is mainly dependent on the type of spray nozzles used to generate the liquid-water particles. Commercially available spray nozzles are categorized by their type, flow rate capacity at a specified pressure, spray pattern, drop sizes, and spray angle. Figure 2.12 shows a typical TEEJET nozzle with nomenclature tips used to identify nozzle types. The nozzle type is determined by the orifice geometry and the nomenclature is based on the shape or pattern of the emerging water particles, which are referred either as flat, full cone, or hollow cone (for example: Fig. 2.12 shows $X R$, namely, extended range flat spray). The spray angle defines the angle that the water drop flow pattern makes at the nozzle orifice, which determines the spacing required to develop a uniform flow when the nozzles are arranged in a horizontal setup to simulate 
vertically falling raindrops. However, for WDR simulation the spray angle is of less importance as the spray nozzles are spaced vertically.
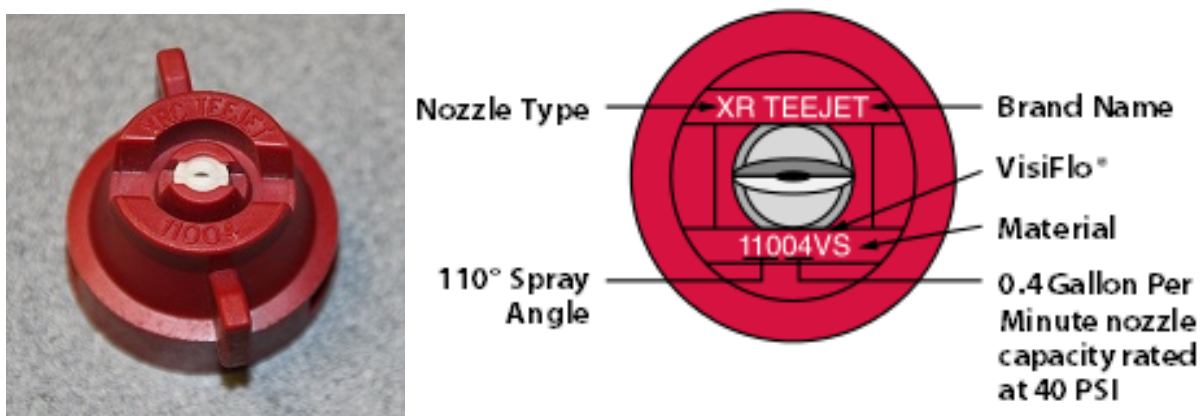

Figure 2.12 TEEJET spray nozzle (courtesy of TEEJET Spray Manual (TeeJet 2011)).

The drop size distribution and flow rate capacity are the two important quantities that dictate the selection of nozzle type for WDR simulation. The median-volume diameter, $D_{o}$, is an integral parameter of the drop size distribution which characterizes the nature of the drop sizes that a nozzle type can generate. Based on the median-volume diameter that they generate, commercially available nozzles are usually categorized with qualitative terms of drop size distribution such as fine, medium, coarse, etc. Table 2.3 demonstrates TEEJET nozzle type classification based on the median-volume diameter that they produce.

\begin{tabular}{lcc}
\multicolumn{2}{l}{ Table 2.3. Nozzle categories based on drop size classification (TeeJet 2011) } \\
\hline Category & Symbol & Approximate $\boldsymbol{D}_{\boldsymbol{o}}(\mathbf{m m})$ \\
\hline Extremely Fine & $X F$ & $\approx 0.05$ \\
Very Fine & $V F$ & $<0.136$ \\
Fine & $F$ & $0.136-0.177$ \\
Medium & $M$ & $0.177-0.218$ \\
Coarse & $C$ & $0.218-0.349$ \\
Very Coarse & $V C$ & $0.349-0.428$ \\
Extremely Coarse & $E C$ & $0.428-0.622$ \\
Ultra Coarse & $U C$ & $>0.622$ \\
\hline
\end{tabular}


Based on the estimated target mass-weighted mean diameter, full-scale mean target median-volume diameter of $1.71 \mathrm{~mm}\left(D_{o}=1.70 \mathrm{~mm}\right)$ is calculated using Eq. 11 of Appendix - A. For simulation of WDR with adopted length-scale of 1:4, the target median-volume diameter, $D_{o}$, in the model-scale becomes $1.70 / 4=0.425 \mathrm{~mm}$. Referring to Table 2.3 , the nozzle type that can produce very coarse drop size $(V C)$ was selected for the simulation.

The flow rate capacity of a single nozzle is usually given as a function of pressure. Among the available nozzle types that can produce very coarse $(V C)$ drop sizes, TEEJET extended range flat spray nozzle (TEEJET 8008 - E) was used in this simulation. The flow rate curve of TEEJET 8008 - E nozzle as a function of pressure is shown in Fig. 2.13 where $Q_{r e f}=0.182 \mathrm{~m}^{3} / \mathrm{hr}(0.8 \mathrm{gpm})$ and $P_{r e f}=275.8 \mathrm{KPa}(40 \mathrm{psi})$.

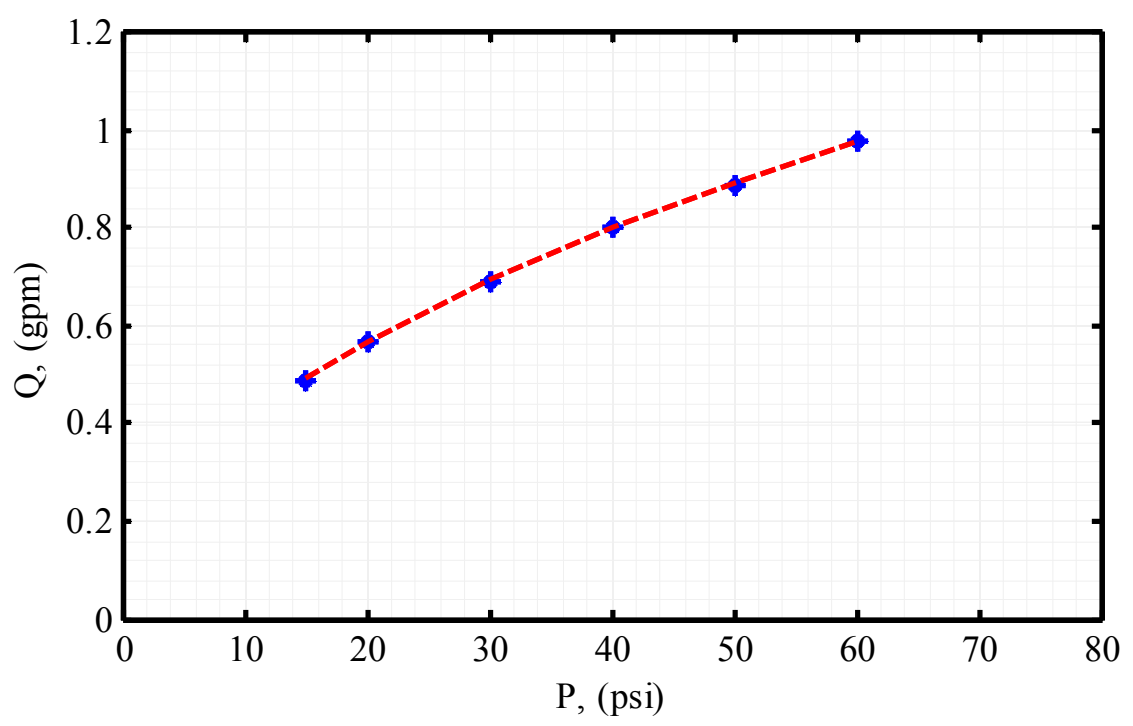

Figure 2.13 Flow rate curve for TEEJET 8008 - E nozzle.

The total number of nozzles was determined based on the need to generate the target WDR rate for a given wind speed. The volume of water sprayed from the nozzles can be 
estimated as the cumulative volume of water from all spray nozzles. The discharge rate from a single nozzle is calculated using the spray nozzle flow rate curve of Fig. 2.13 as:

$$
Q_{\text {nozzle }}=Q_{\text {ref }}\left(\frac{P_{\text {measured }}}{P_{\text {ref }}}\right)^{0.50}
$$

The value of $P_{\text {measured }}$ was read from pressure sensors installed at the nozzle tip along the vertical spray lines. The total number of nozzles per vertical spray line was then estimated as

$$
\text { Number of Nozzles }=f \cdot \frac{R R_{v} \cdot A}{Q_{\text {nozzle }}}
$$

where $R R_{v}$, is the target vertical rain rate and $A$ is the vertical cross-sectional area covered by a single spray line. The factor, $f$, was introduced to account for the loss of water volume between the nozzles location to the testing section. The number of nozzles per vertical spray line for this simulation was determined using an iterative procedure to meet the target WDR rate at the preselected target wind speed (see Fig 2.11). The steps of the iterative procedure are discussed as follows for general use of WDR simulation:

1. To initiate the iterative procedure $P_{\text {measured }}$ was assumed to be $40 \mathrm{psi}$, which corresponded to $Q_{\text {nozzle }}=0.182 \mathrm{~m}^{3} / \mathrm{hr}(0.8 \mathrm{gpm})$ based on the flow rate curve for TEEJET $8008-E$ nozzle. Initially $f$ was assumed to be unity and Eq. 8 was used to determine the number of nozzles per vertical spray lines.

2. Having the number of nozzles, the actual pressure was measured after installation of the number of nozzles on each vertical spray line. The number of nozzles per vertical line was then revised using Eq. 8 based on the new estimated nozzle flow rate, $Q_{\text {nozzle }}$ (given by Eq. 7). 
3. Based on PIP measurement of drop size distribution, the WDR rate at the testing section was determined. For the current simulation this rate was found to be much less than at the nozzle section due to the loss of water drops between the nozzle racks to the testing section. The factor $f$ in Eq. 8 was obtained by dividing the target WDR rate by the measured WDR rate at the test section. Based on the $f$ value, the number of nozzles per spray line was increased using Eq. 8 to account for the loss.

4. Steps 2 and 3 were repeated till the WDR rate at the testing section matched closely the target WDR rate, $R R_{v}$.

Assuming the reference pressure and flow rate at the nozzles' tip, Eq. 8 resulted in a value of 3.14 indicating three nozzles per spray line for the selected target wind speed $(20.1 \mathrm{~m} / \mathrm{s}(45 \mathrm{mph}))$ and WDR rate $89.4 \mathrm{~mm} / \mathrm{hr}(3.52 \mathrm{in} / \mathrm{hr}))$. A pressure of $358.5 \mathrm{KPa}$ (52 psi) was read after installing the three TEEJET $8008-E$ nozzles per vertical spray. Using Eq. 7, the nozzle discharge rate was $0.207 \mathrm{~m}^{3} / \mathrm{hr}(12632.0 \mathrm{in} / \mathrm{hr})$ based on $P_{\text {measured }}$ $=358.5 \mathrm{KPa}$. Based on $Q_{\text {nozzle }}=0.207 \mathrm{~cm}^{3} / \mathrm{hr}(12632.0 \mathrm{in} / \mathrm{hr})$, Eq. 8 resulted in a value of 2.78 showing that the required number of nozzles per spray lines still remained as three. Figure 2.14 presents raindrop size distribution (RSD) measured using the three nozzles per spray line. Note that the RSD was based on PIP measurements of drop sizes between 0.2 to $1.0 \mathrm{~mm}$. This was the range for which reliable calibration could be obtained for the PIP instrument based on DMT spinning disk calibrator. For drop sizes less than $0.2 \mathrm{~mm}$, fluctuating calibration readings were obtained and considered unreliable. For drop sizes more than $1.0 \mathrm{~mm}$, the number count of drops measured by the PIP was very low $(\leq 10)$ 
and was neglected. Also, it is unlikely for a nozzle with median-volume diameter of $0.349-0.428 \mathrm{~mm}$ (Table 2.3 ) to produce a drop size larger than $1.0 \mathrm{~mm}$ given that the volume contribution increases with drop diameter to the third power.

Based on the RSD, the estimated WDR rate at the testing section using three TEEJET $8008-E$ nozzles per vertical spray line was found to be $54.86 \mathrm{~mm} / \mathrm{hr}(2.16$ $\mathrm{in} / \mathrm{hr}$ ). The lower WDR rate result at the testing section indicated the need to increase the value of $f$ from unity to the value not less than the ratio of target rain rate to measured: $3.52 / 2.16=1.63$. Considering the nearest integer a new value of $f=2$ was used which resulted in about seven nozzles per spray line using Eq. 8. Figure 2.14 shows the comparison of the RSD measured using seven and three nozzles per spray line. The increased number of nozzles per spray line resulted in a WDR rate of $113.28 \mathrm{~mm} / \mathrm{hr}(4.46$ $\mathrm{in} / \mathrm{hr}$ ) and liquid-water content of $W=1.60 \mathrm{~g} / \mathrm{m}^{3}$, as compared to the target values of $R R_{v}$ $=89.41 \mathrm{~mm} / \mathrm{hr}(3.52 \mathrm{in} / \mathrm{hr})$ and $W=1.21 \mathrm{~g} / \mathrm{m}^{3}$. Figure 2.14 shows that RSD measurement indicated a better match with the target gamma model for medium size drops $(0.2 \leq D \leq$ $0.6 \mathrm{~mm}$ ), while higher number concentrations were measured for large size drops $(\mathrm{D}>$ $0.6 \mathrm{~mm}$ ). High concentration of large size drops caused the increase in WDR rate and liquid-water content as compared to the target values. The simulation of the WDR using seven nozzles per spray line was considered to be satisfactory as this setup resulted is the closest simulation of the target WDR rate and liquid-water content. The RSD measurements of simulated WDR at the target wind speed, and detailed discussion including investigation of spatial characteristics of RSD in the flow field, are presented in the next subsection. 


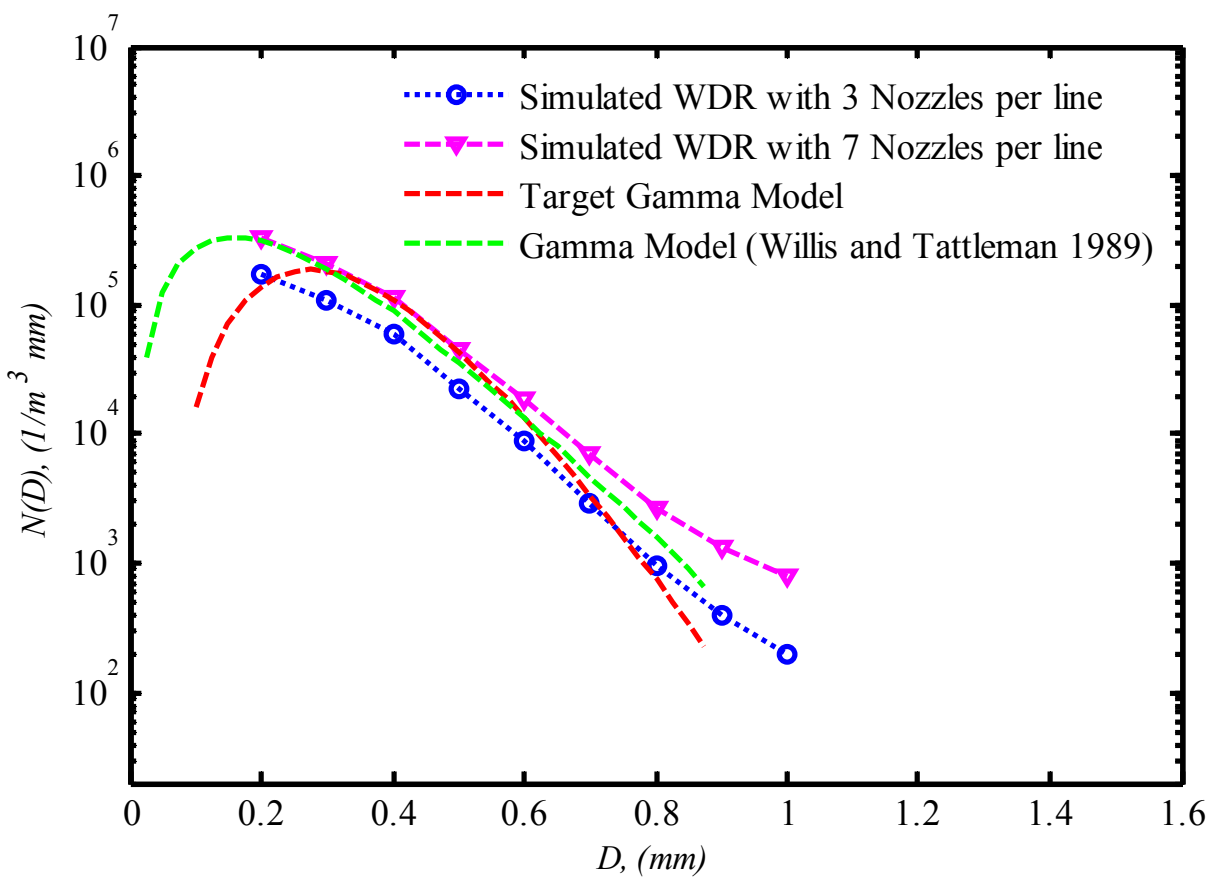

Figure 2.14 RSD of simulated WDR using TEEJET 8008 - E nozzles

\subsubsection{RSD simulation results}

Following the determination of number of nozzles and their placement in the testing setup, a series of WDR tests were conducted to obtain RSD measurements at different locations within the flow field and investigate the spatial representation of target RSD parameters. Each test was performed for a duration of 5 minutes using a wind speed of $20.1 \mathrm{~m} / \mathrm{sec}(45 \mathrm{mph})$ and WDR rate of $113.28 \mathrm{~mm} / \mathrm{hr}(4.46 \mathrm{in} / \mathrm{hr})$. Figure 2.15 shows the comparison between RSD measurements taken across the flow field at $(x, y, z)=$ $(6.10,0.0,0.76),(6.10,1.22,0.76)$ and $(6.10,-1.22,0.76) \mathrm{m}$, and the target RSD corresponding to a WDR rate of $R R_{v}=89.41 \mathrm{~mm} / \mathrm{hr}(3.52 \mathrm{in} / \mathrm{hr})$ and wind speed of $\mathrm{U}=$ $20.1 \mathrm{~m} / \mathrm{sec}(45 \mathrm{mph})$ (See Fig. $2.4 \mathrm{~b}$ for $(0,0,0)$ coordinate). The figure also shows the comparison of target values and their experimental counterparts for parameters such as: shape parameter, $m$, of the best-fit gamma distribution, estimated using the PPCC 
method; slope, $\Lambda$; number concentration, $N_{w}$; and mass-weighted mean diameter, $D_{\text {mass }}$. The RSD measurement at the center of the flow (simulated RSD@ $@$ 1) indicated a better match with the target gamma model as compared to the RSD measurements taken at 1.22 m (4 ft) on either side of the centerline (simulated RSD@ P2, simulated RSD@ P3). The differences are likely due to the deficits in wind speed and turbulence intensity profiles for points P2 and P3 (see Fig. 2.6). The fact that the sampling volume of RSD measurement using the PIP depends on the wind speed might cause inevitable propagation of wind speed deficit to be reflected in the RSD data across the flow field. Despite the differences in the RSD plots across the flow field, the RSD parameters for all three points $\mathrm{P} 1, \mathrm{P} 2$, and $\mathrm{P} 3$ showed reasonable agreement with their target values. For the centerline point $\mathrm{P} 1$, the shape parameter of the simulated RSD, $m$, was found to be within half standard deviation $\left(\bar{m} \pm 0.5 \sigma_{m}\right)$ while the slope was within one standard deviation $\left(\bar{\Lambda} \pm 1.0 \sigma_{\Lambda}\right)$ about the target mean values. For point $\mathrm{P} 1$, the number concentration, $N_{w}$, and mass-weighted mean diameter, $D_{\text {mass }}$, closely matched the target mean values ( $N_{w}: 6.38$ versus 6.41 and $D_{\text {mass }}$ : 0.48 versus 0.44 ). The maximum differences of the RSD parameters across the flow field were (compared to P1 values): $7.5 \%$ for $m, 10 \%$ for $\Lambda, 12 \%$ for $N_{w}$, and $8 \%$ for $D_{\text {mass. }}$ Note that the RSD of WDR simulated using TEEJET $8008-E$ nozzles also closely matched with the gamma model suggested by Willis and Tattelman (1989), which is characterized by smaller value of shape parameter and high $D_{\text {mass }}$. 


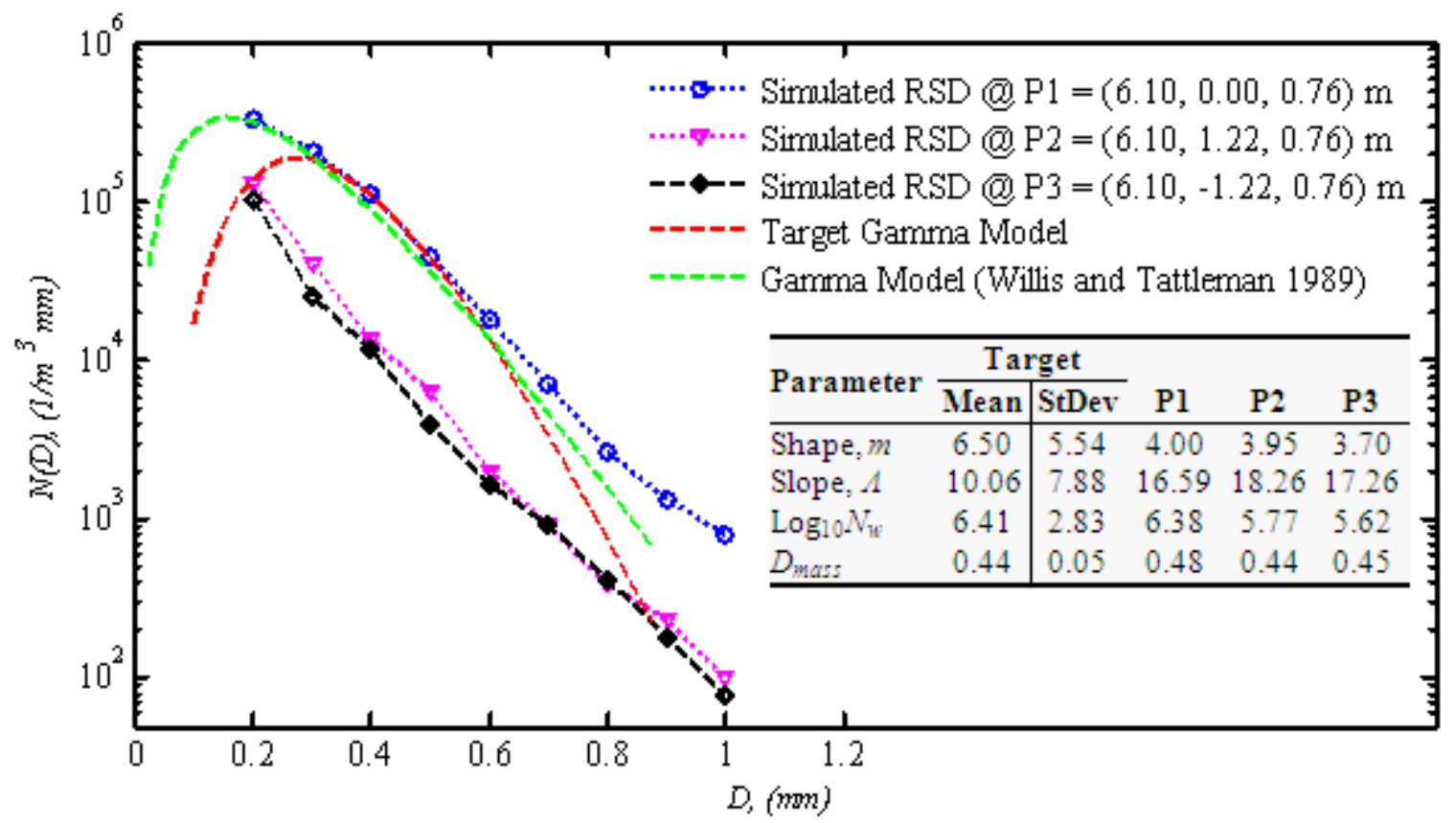

Figure 2.15 Comparison of simulated RSDs along the y-axis

Figure 2.16 shows the spatial representation of RSD parameters along the vertical axis (z-axis) at the centerline. Similar to the lateral variability, there were differences in RSDs for the two points P1 and P4. However, RSD parameters for these points showed reasonable agreement with their target values. For point $\mathrm{P} 4$, the shape parameter, $m$, was found to be within half standard deviation, while the slope was close to within one standard deviation about the target mean values. For point P4, the number concentration, $N_{w}$, and mass-weighted mean diameter, $D_{\text {mass }}$, closely matched the target mean values ( $N_{w}: 6.04$ versus 6.41 and $D_{\text {mass }}: 0.43$ versus 0.44 ). 


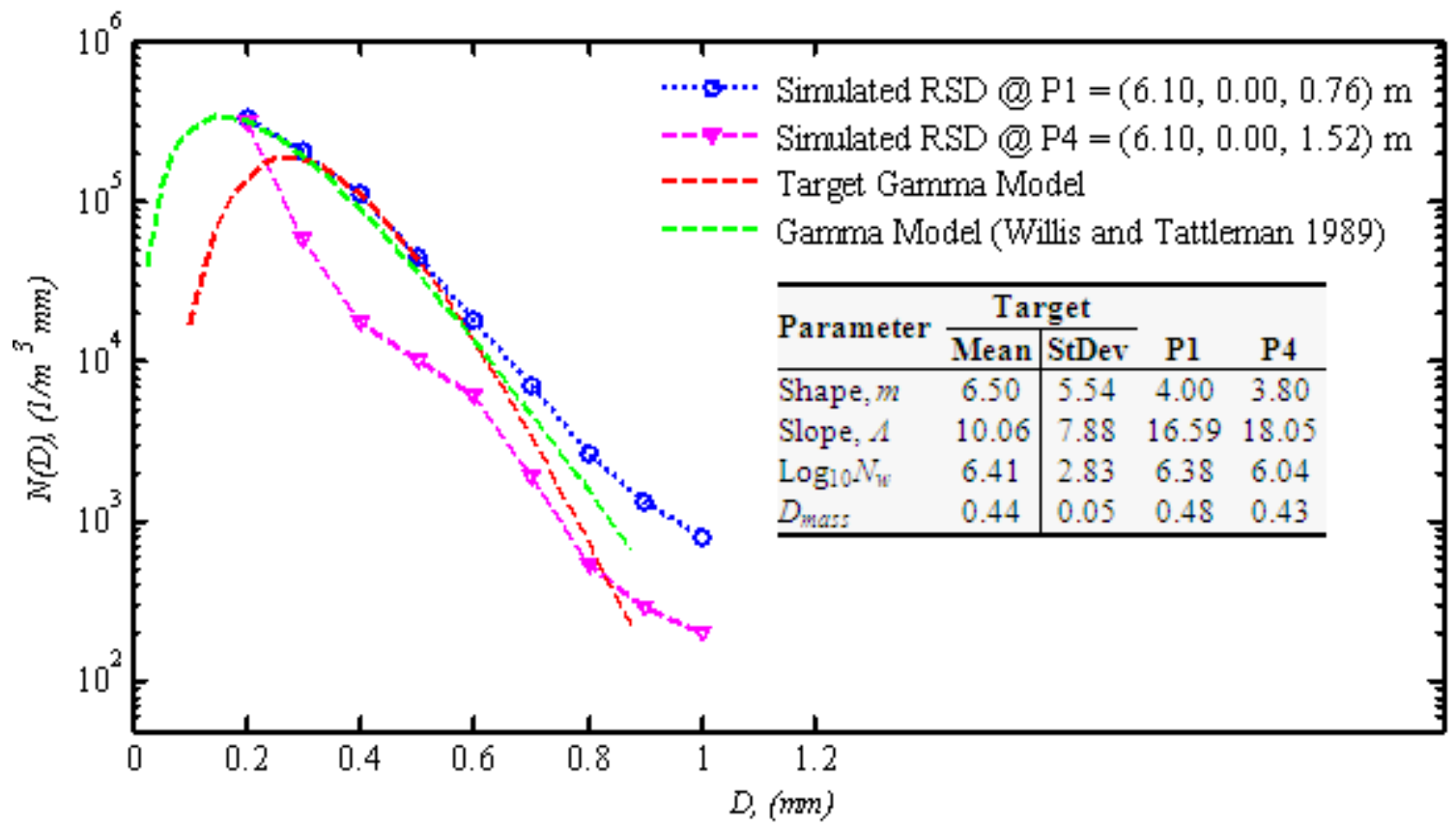

Figure 2.16 Comparison of simulated RSDs along the z-axis

Reasonable spatial homogeneity of the RSD parameters measured across the lateral and vertical sections of the flow field suggested the adequacy of simulated WDR to be used in investigation of WDR effects on building structures using building models. However, the scale of the model should be such that the model should be completely immersed within the flow field test section area for which this spatial homogeneity of WDR simulation has been investigated in this paper.

\subsubsection{Comparison between current WDR simulation and wind tunnel simulation by Inculet and Surry (1995)}

Table 4 presents detailed comparison of the current WDR simulation and the wind tunnel simulation by Inculet and Surry (1995), noting the similarities and differences and the suitability ranges of the approaches. 
Table 2.4. Comparison between current WDR simulation and wind tunnel WDR simulation by Inculet and Surry (1995)

\section{WDR simulation using proposed methodology}

- Froude number (Fr) similarity requirement was used.

- The raindrop size distribution (RSD) was modeled using the three-parameter gamma distribution, which can represent both tropical cyclone and non-tropical cyclone RSDs.

- The target model-scale RSD was determined by applying length-scale directly to drop size, $\mathrm{D}$, and number concentration, N(D). The velocity-scale was used to determine model-scale velocity of raindrops. This approach helped to determine the target WDR rate ahead of simulation.

- Open jet simulation of WDR presented difficulty in attaining spatial homogeneity of RSD within the flow field.

- Small drop sizes, corresponding to $1 \mathrm{~mm}$ diameter at full scale, were simulated using scaling.

- Nozzles were installed on a vertical section reducing the fetch length required to simulate target RSD for both, low and high wind speeds.

- RSD measurement was conducted for raindrops passing through vertical area, which allowed counting of raindrops as driven by horizontal wind. This is important for WDR simulation with high wind speed (in cases of tropical storms and hurricanes) to minimize error.

\section{WDR simulation by Inculet and Surry (1995)}

Froude number (Fr) similarity requirement was used.

Exponential raindrop size distribution suggested by Marshall and Palmer (1948) was used as fullscale target RSD. The exponential distribution is a special case of gamma distribution with shape parameter equal to unity, representing rare cases of RSD during tropical cyclone.

The target RSD was determined through scaling of terminal velocity of raindrops and an equivalent RSD quantity was introduced as a product of number concentration, $\mathrm{n}(\mathrm{d})$ and terminal velocity $\mathrm{V}_{\mathrm{t}}$. The number concentration, $\mathrm{n}(\mathrm{d})$ is not scaled, which makes it difficult to calculate the target rain rate at model scale.

Simulation of WDR using closed wind tunnel allowed achievement of RSD homogeneity within the flow field.

It was noted that small drops could not be simulated due to small length-scale (length-scale $=1: 64)$. As mentioned by Inculet and Surry (1995), this could cause significant errors in the desired rain rate and test results.

Nozzles were installed on the ceiling of the wind tunnel (horizontal layout). Such layout requires longer fetch length in order to produce properly mixed drop sizes. The requirement of fetch length increases with wind speed, limiting the simulation method to a lower wind speed only.

RSD measurement was conducted for raindrops passing through a horizontal area. Such measurement is only suitable for low wind speed tests and the accuracy of measurements at higher wind speeds can be compromised (Blocken and Carmeliet 2004). 


\subsection{Summary and conclusions}

The current paper presented the characterization of tropical cyclone (TC) wind driven rain (WDR) based on field measurements of raindrop size distribution (RSD) collected during 2004-05 north Atlantic hurricane seasons. The RSD of TC WDR is characterized by a three-parameter gamma distribution with defined physical ranges of distribution parameters (shape, scale, and intercept parameters), which depicted lognormal distributions. Mean and standard deviation of the parameters of gamma model were derived using statistical analysis of combined RSD data of Hurricane Alex, Charley, and Gaston (2004) and used as set of target values for simulation of WDR in the experimental setup. Experiment scale simulation of WDR requires similitude of water to air density ratio, Reynolds number $(\mathrm{Re})$, and Froude number $(\mathrm{Fr})$ similarity requirements between model- and full-scales. Although Froude number (Fr) similarity requirement between model and prototype scale was employed in simulation of WDR, the increase in wind-induced drag force on individual raindrop in low Reynolds number ( $\mathrm{Re})$ region suggested that experimental simulation of WDR shall be performed at large scales.

A procedural method of estimating target WDR rate as a function of test wind speed based on target RSD and rain rate was presented for simulation of WDR in experimental setups. The target median volume diameter dictated the selection of the type of nozzle to reproduce RSD of TC WDR. An iterative procedure was used to estimate the number of nozzles required to produce the target WDR rate in the test setup. The adequacy of the simulated WDR was investigated by comparing RSD parameters with their target values. The measured RSD parameters were found to be within the statistical limits showing reasonable simulation. The test results showed reasonable spatial 
homogeneity of the RSD parameters measured across the lateral and vertical sections of the flow field. This suggested the adequacy of the WDR simulation for the investigation of water intrusion effects on low rise building structures using large-scale building models. Such study will address rainwater intrusion problems in buildings and facilitate the development of test-based WDR data and mitigation techniques to minimize water and moisture intrusion and reduce losses of building contents during hurricanes.

\section{References}

Aly, A. M., Chowdhury, A. G., and Bitsuamlak, G. (2011). "Wind profile management and blockage assessment for a new 12-fan Wall of Wind facility at FIU." Wind and Structures, 14(4), 1-16.

Best, A. C. (1950). "The size distribution of raindrops." Quarterly Journal of the Royal Meteorological Society, 76(327), 16-36.

Bitsuamlak, G. T., Chowdhury, A. G., and Sambare, D. (2009). "Application of a fullscale testing facility for assessing wind-driven-rain intrusion." Building and Environment 44, 2430-2441.

Blocken, B., and Carmeliet, J. (2004). "A review of wind-driven rain research in building science." J. Wind Eng. Ind. Aerodyn., 92, 1079-1130.

Blocken, B., and Carmeliet, J. (2007). "Validation of CFD simulations of wind-driven rain on a low-rise building facade." Building and Environment, 42, 2530-2548.

Blocken, B., and Carmeliet, J. (2012). "A simplified numerical model for rainwater runoff on building facades: Possibilities and limitations." Building and Environment, 53(0), 59-73.

Blocken, B., Carmeliet, J., and Poesen, J. (2005). "Numerical simulation of the winddriven rainfall distribution over small-scale topography in space and time." Journal of Hydrology, 315, 252-273.

Blocken, B., Roels, S., and Carmeliet, J. (2007). "A combined CFD-HAM approach for wind-driven rain on building facades." J. Wind Eng. Ind. Aerodyn., 95, 585-607.

Bringi, V. N., Chandrasekar, V., Hubbert, J., Gorgucci, E., Randeu, W. L., and Schoenhuber, M. (2003). "Raindrop Size Distribution in Different Climatic Regimes 
from Disdrometer and Dual-Polarized Radar Analysis." Journal of the Atmospheric Sciences, 60(2), 354-365.

Choi, E. C. C. (1993). "Simulation of wind-driven rain around a building." J. Wind Eng. Ind. Aerodyn., 46\&47, 721-729.

Choi, E. C. C. (1994). "Determination of wind-driven rain intensity on building faces." $J$. Wind Eng. Ind. Aerodyn., 51, 55-69.

FEMA (2005). "Mitigation Assessment Team Report - Hurricane Charley in Florida; Observations, Recommendations, and Technical Guidance." FEMA 488.

Foote, G. B., and Toit, P. S. D. (1969). "Terminal Velocity of Raindrops Aloft." Journal of Applied Meterology, 8, 249-253.

Friedrich, K., Higgins, S., Masters, F. J., and Lopez, C. R. (2013). "Articulating and Stationary PARSIVEL Disdrometer Measurements in Conditions with Strong Winds and Heavy Rainfall." Journal of Atmospheric and Oceanic Technology, (in Press).

Friedrich, K., Kalina, E. A., Masters, F. J., and Lopez, C. R. (2012). "Drop-Size Distributions in Thunderstorms Measured by Optical Disdrometers during VORTEX2." Monthly Weather Review, 141(4), 1182-1203.

Fu, T.-C., Aly, A. M., Chowdhury, A. G., Bitsuamlak, G., Yeo, D., and Simiu, E. (2012). "A proposed technique for determining aerodynamic pressures on residential homes." Wind and Structures, 15(1), 27-41.

Hangan, H. (1999). "Wind-driven rain studies. A C-FD-E approach." J. Wind Eng. Ind. Aerodyn., 81, 323-331.

Inculet, D. R. (2001). "The design of cladding against wind-driven rain." University of Western Ontario.

Inculet D, Surry D. (1995). Simulation of wind-driven rain and wetting patterns on buildings. Prepared for Housing Innovation Division, Canadian Housing Information Center (CHIC), Technical Series 96-213, Canada Mortgage and Housing Corporation, Ottawa.

Knasiak, K., Schick, R. J., and Kalata, W. (2005). "Multiscale design of rain simulator." Spray Analysis and Research Services, Spray Systems Co. Wheaton, IL.

Lonfat, M., Frank D. Marks, J., and Chen, S. S. (2004). "Precipitation Distribution in Tropical Cyclones Using the Tropical Rainfall Measuring Mission (TRMM) Microwave Imager: A Global Perspective." Monthly Weather Review, American Meteorological Society, 132, 1645-1660. 
Lopez, C., Masters, F. J., and Bolton, S. (2011). "Water penetration resistance of residential window and wall systems subjected to steady and unsteady wind loading." Building and Environment, 46, 1329-1342.

Lopez, C. R. (2011). "Measurement, analysis, and simulation of wind-driven rain." University of Florida.

Marshall, J. S., and Palmer, W. M. K. (1948). "The distribution of raindrops with size." Journal of Meteorology, 5(4), 165-166.

Merceret, F. J. (1974). "On the Size Distribution of Raindrops in Hurricane Ginger." Monthly Weather Review, 102(10), 714-716.

Morsi, S. A., and Alexander, A. J. (1972). "An investigation of particle trajectories in two-phase flow systems." Journal of Fluid Mechanics, 55, 193-208.

Mullens, M., Hoekstra, B., Nahmens, I., and Martinez, F. (2006). "Water Intrusion in Central Florida Homes During Hurricane Jeanne in September 2004." Technical report, University of Central Florida Housing Constructability LabOrlando, FL.

Richards, P. J., Hoxey, R. P., Connell, B. D., and Lander, D. P. (2007). "Wind-tunnel modelling of the Silsoe Cube." J. Wind Eng. Ind. Aerodyn., 95, 1384-1399.

Salzano, C. T., Masters, F. J., and Katsaros, J. D. (2010). "Water penetration resistance of residential window installation options for hurricane-prone areas." Building and Environment, 45, 1373-1388.

Sekhon, R. S., and Srivastava, R. C. (1971). "Doppler Radar Observations of Drop-Size Distributions in a Thunderstorm." Journal of the Atmospheric Sciences, 28(6), 983994.

TeeJet (2011). "TeeJet Technologies Catalog 51." S. S. Co., ed.Wheaton, Illinois USA.

Testud, J., Oury, S., Black, R. A., Amayenc, P., and Dou, X. (2001). "The Concept of "Normalized" Distribution to Describe Raindrop Spectra: A Tool for Cloud Physics and Cloud Remote Sensing." Journal of Applied Meteorology, 40(6), 1118-1140.

Tokay, A., Bashor, P. G., Habib, E., and Kasparis, T. (2008). "Raindrop size distribution measurements in tropical cyclones." Monthly Weather Review, American Meteorological Society, 136(May 2008), 1669-1685.

van de Lindt, J., Graettinger, A., Gupta, R., Skaggs, T., Pryor, S., and Fridley, K. (2007). "Performance of Wood-Frame Structures during Hurricane Katrina." Journal of Performance of Constructed Facilities, 21(2), 108-116.

Willis, P. T. (1984). "Functional Fits to Some Observed Drop Size Distributions and Parameterization of Rain." Journal of the Atmospheric Sciences, 41(9), 1648-1661. 
Willis, P. T., and Tattelman, P. (1989). "Drop-size distributions associated with intense rainfall." J. Appl. Meter., 28, 3-15.

Yeo, D., and Chowdhury, A. (2013). "Simplified Wind Flow Model for the Estimation of Aerodynamic Effects on Small Structures." Journal of Engineering Mechanics, 139(3), 367-375. 


\section{Appendix - A: Raindrop size distribution (RSD) model}

The general gamma distribution for RSD can be expressed as

$$
N(D)=\frac{\Lambda^{r} D^{r-1} \exp (-\Lambda D)}{\Gamma(r)}
$$

where $D$ is the diameter, $N(D) d D$ is the number of drops of diameter between $D$ and $D+d D$ in a unit volume of air, and $\Lambda$ and $r$ are the scale and shape parameters, respectively. Equation (1) can be rewritten by replacing $r$ with $m+4$ ( $m$ being a measure of the shape parameter):

$$
N(D)=\frac{\Lambda^{m+4} D^{m+3} \exp (-\Lambda D)}{\Gamma(m+4)}
$$

The parameters of gamma distribution are inter-related and expressed in terms of measured quantities as the underlying characteristics of RSD largely depends on drops' deformation and defragmentation as they fall in turbulent air (Bringi et al. 2003; Ulbrich 1983; Villermaux and Bossa 2009). For example, the scale parameter $\Lambda$ is expressed in terms of the mass-weighted mean diameter $D_{\text {mass }}$ and the shape parameter, $m$ :

$$
\Lambda=\frac{4+m}{D_{\text {mass }}}
$$

The mass-weighted mean diameter, $D_{\text {mass }}$ is defined as the ratio of the fourth to the third order moment of raindrop size distribution and is calculated as

$$
D_{\text {mass }}=\frac{\sum D^{4} N(D)}{\sum D^{3} N(D)}
$$

Substituting Eq. 3 into Eq. 2

$$
N(D)=\frac{D^{3}}{D_{\text {mass }}} \frac{(4+\mathrm{m})^{m+4}\left(\frac{D}{D_{\text {mass }}}\right)^{m} \exp \left(-(4+\mathrm{m}) \frac{D}{D_{\text {mass }}}\right)}{\Gamma(m+4)}
$$


where, $D / D_{\text {mass }}$ is the normalized diameter and a generalized normalizing number concentration/intercept parameter is introduced as a function of liquid-water content $(\mathrm{W})$ (Testud et al. 2001):

$$
N_{w}=\frac{4^{4}}{\pi \rho_{w}}\left(\frac{W}{D_{\text {mass }}}\right)
$$

Note that the normalizing number concentration/intercept is the coefficient equivalent to the intercept of the exponential distribution in Eq. 5, which can be derived by setting $m$ to zero. The water content is calculated as

$$
W=\frac{\pi}{6} \rho_{w} E\left[D^{3}\right]
$$

The cubic diameter term in Eq. 5 can be substituted by the expected cubic diameter as shown in the water content equation above (see Eq. 7), which would allow formation of normalized RSD independent of rain rate and/or any other integral parameter. Thus, substituting Eq. 6 and 7 into Eq. 5 gives

$$
\frac{N(D)}{N_{w}}=\frac{6}{4^{4}} \frac{(4+\mathrm{m})^{m+4}\left(\frac{D}{D_{\text {mass }}}\right)^{m} \exp \left(-(4+\mathrm{m}) \frac{D}{D_{\text {mass }}}\right)}{\Gamma(m+4)}
$$

Hence,

$$
\frac{N(D)}{N_{w}}=f(m)\left(\frac{D}{D_{\text {mass }}}\right)^{m} \exp \left(-(4+\mathrm{m}) \frac{D}{D_{\text {mass }}}\right),
$$

where

$$
f(m)=\frac{6}{4^{4}} \frac{(4+m)^{m+4}}{\Gamma(m+4)}
$$

Equation 9 is the dimensionless form of RSD spectrum, which is independent of the rain rate. The term $N(D) / N_{w}$ represents normalized RSD and $m$ is a measure of the shape 
parameter. The relation between normalized median volume diameter $D_{o}$ and $D_{\text {mass }}$ is given as (Gorgucci et al. 2002):

$$
\frac{D_{o}}{D_{\text {mass }}}=\frac{3.67+m}{4+\mathrm{m}}
$$

The mass concentration spectrum, $m(D)$, can readily be calculated considering the mass of each drop and number concentration as

$$
m(D)=N(D) \cdot \rho_{w} \frac{\pi}{6} D^{3}
$$

where $\rho_{w}$ is density of water. The liquid-water content per unit volume of air, $W$, is estimated through integration of mass concentration spectrum

$$
W=\int_{0}^{\infty} m(D) d D
$$

The mass flux of raindrops through a unit area is estimated using the velocity of drops as given in Eq. 13.

$$
\varphi(D)=m(D) \cdot V
$$

The rain rate can be determined by integrating the mass flux as

$$
R R=3600 \int_{0}^{\infty} \varphi(D) d D
$$

The use of terminal velocity in Eq. 14 will result in horizontal rain rate (rain flux passing through horizontal area or vertically falling rain) while the lateral velocity of drops (which is assumed to be equal to the wind speed for all sizes of drops) will produce the WDR rate. 


\section{Appendix - B: Probability density function of RSD parameters}

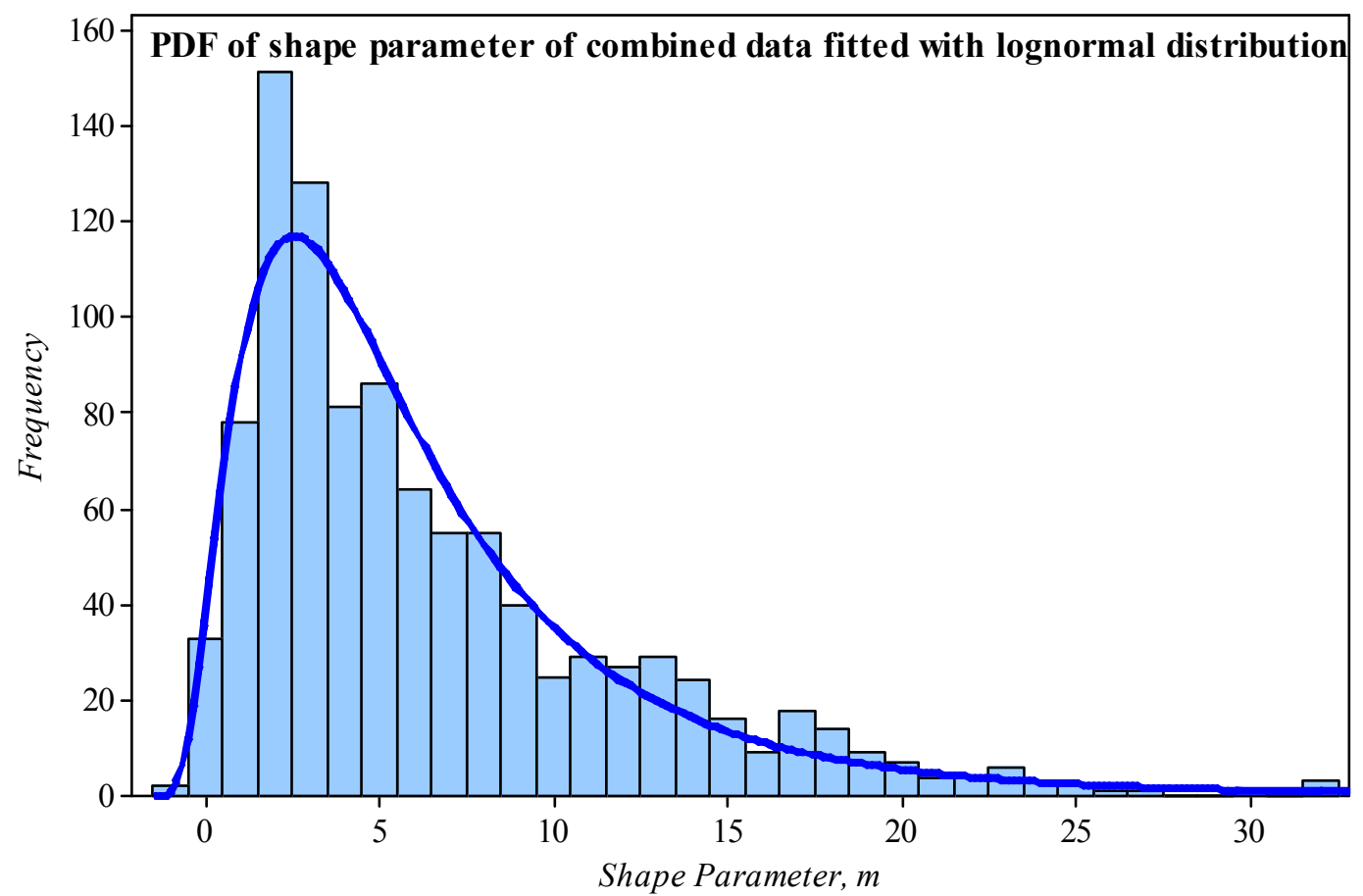

Figure B2.17 Histogram of shape parameter, $m$ of combined data fitted with lognormal distribution.

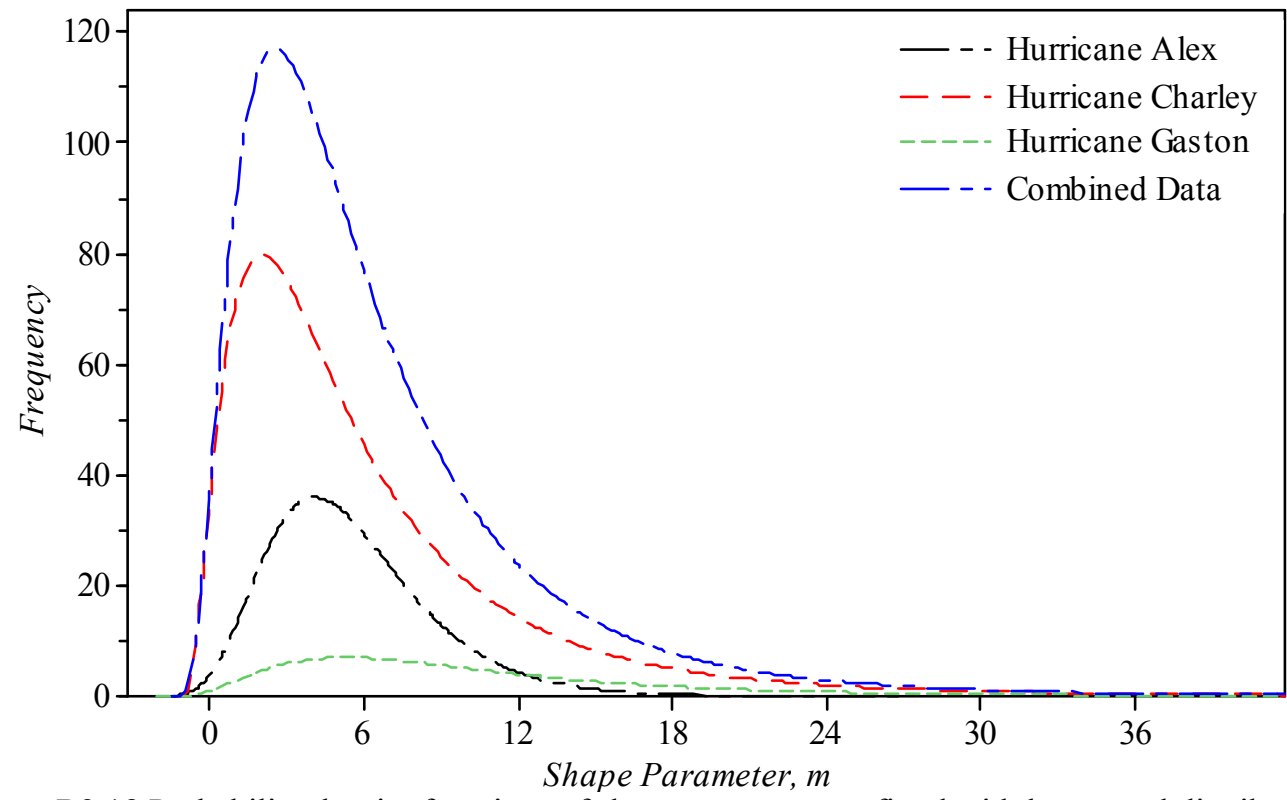

Figure B2.18 Probability density functions of shape parameter, $m$ fitted with lognormal distribution. 


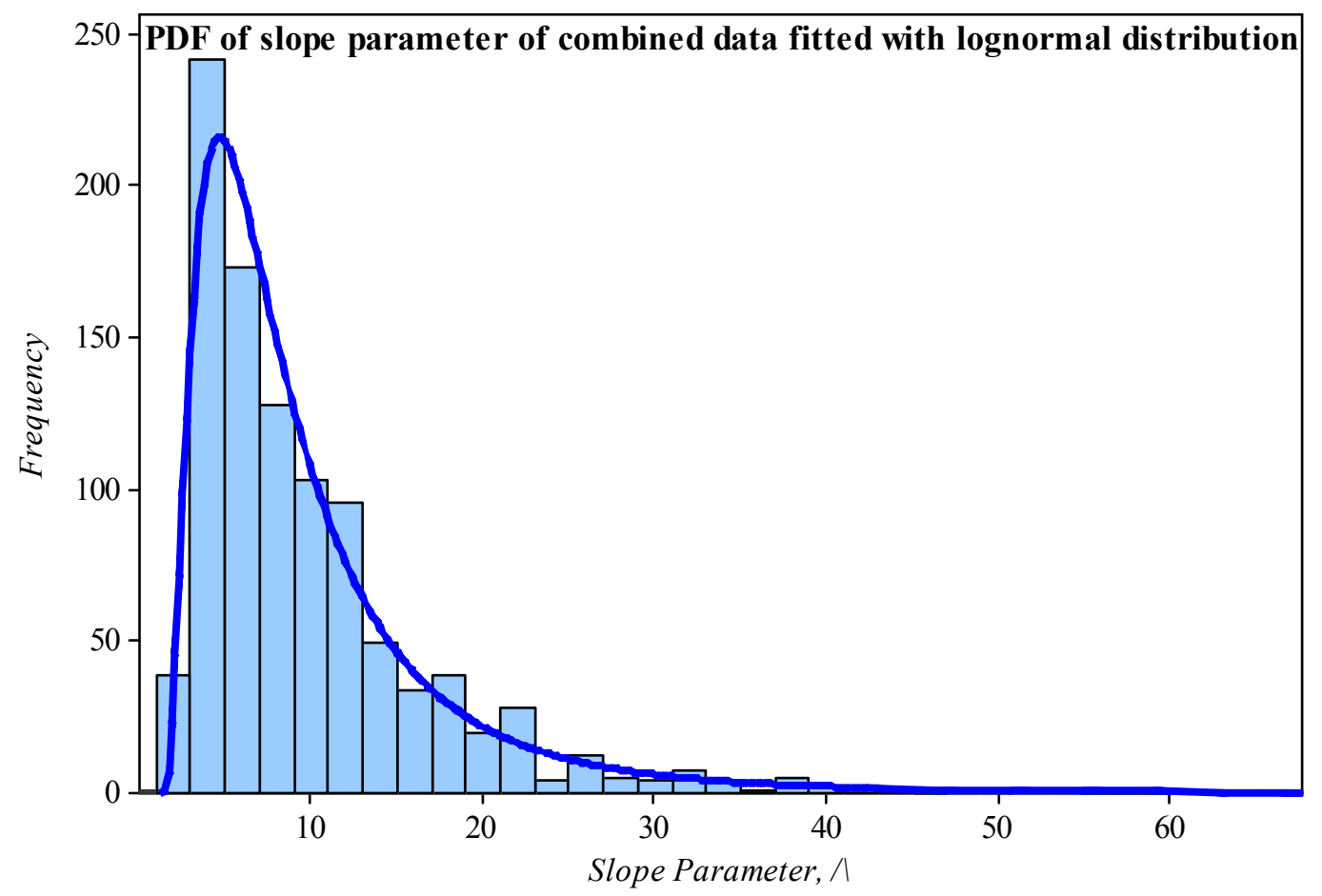

Figure B2.19 Histogram of slope parameter, $\Lambda$ of combined data fitted with lognormal distribution.

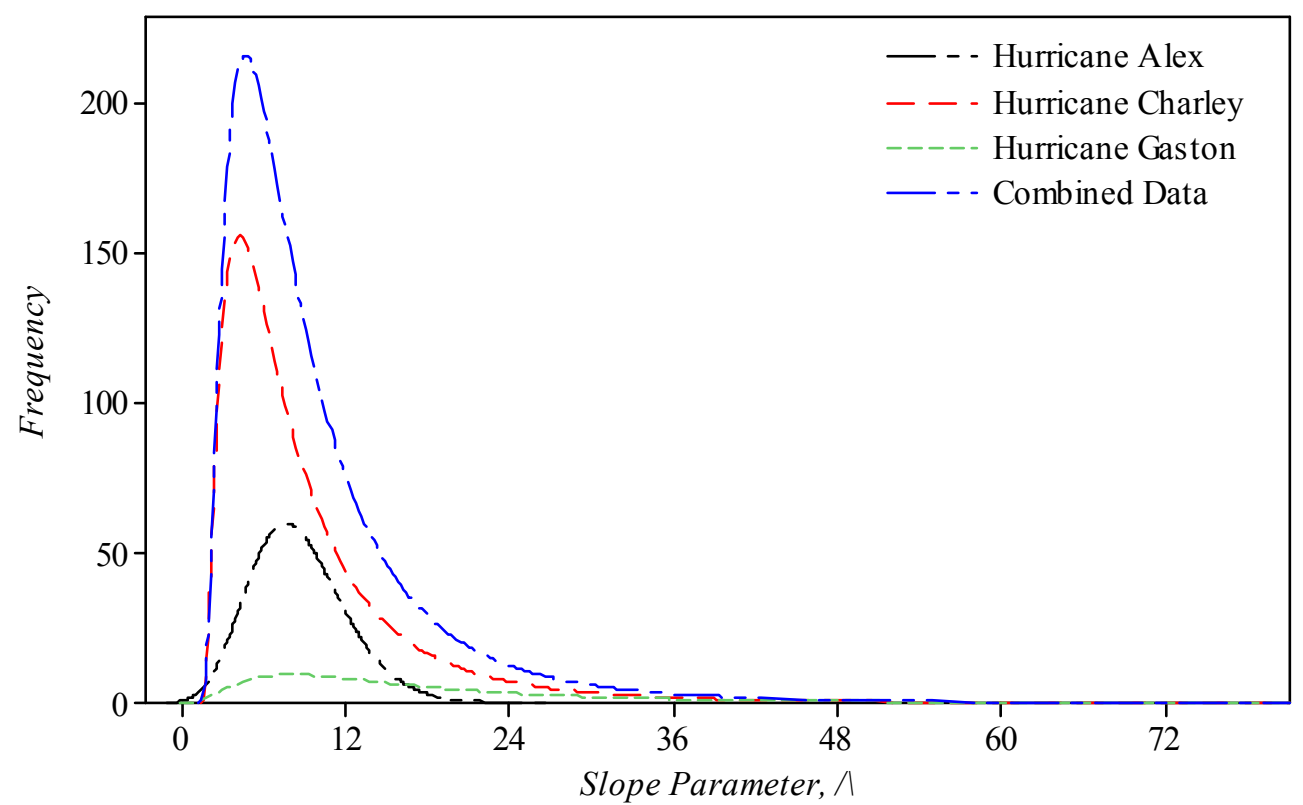

Figure B2.20 Probability density functions of slope parameter, $\Lambda$ fitted with lognormal distribution. 


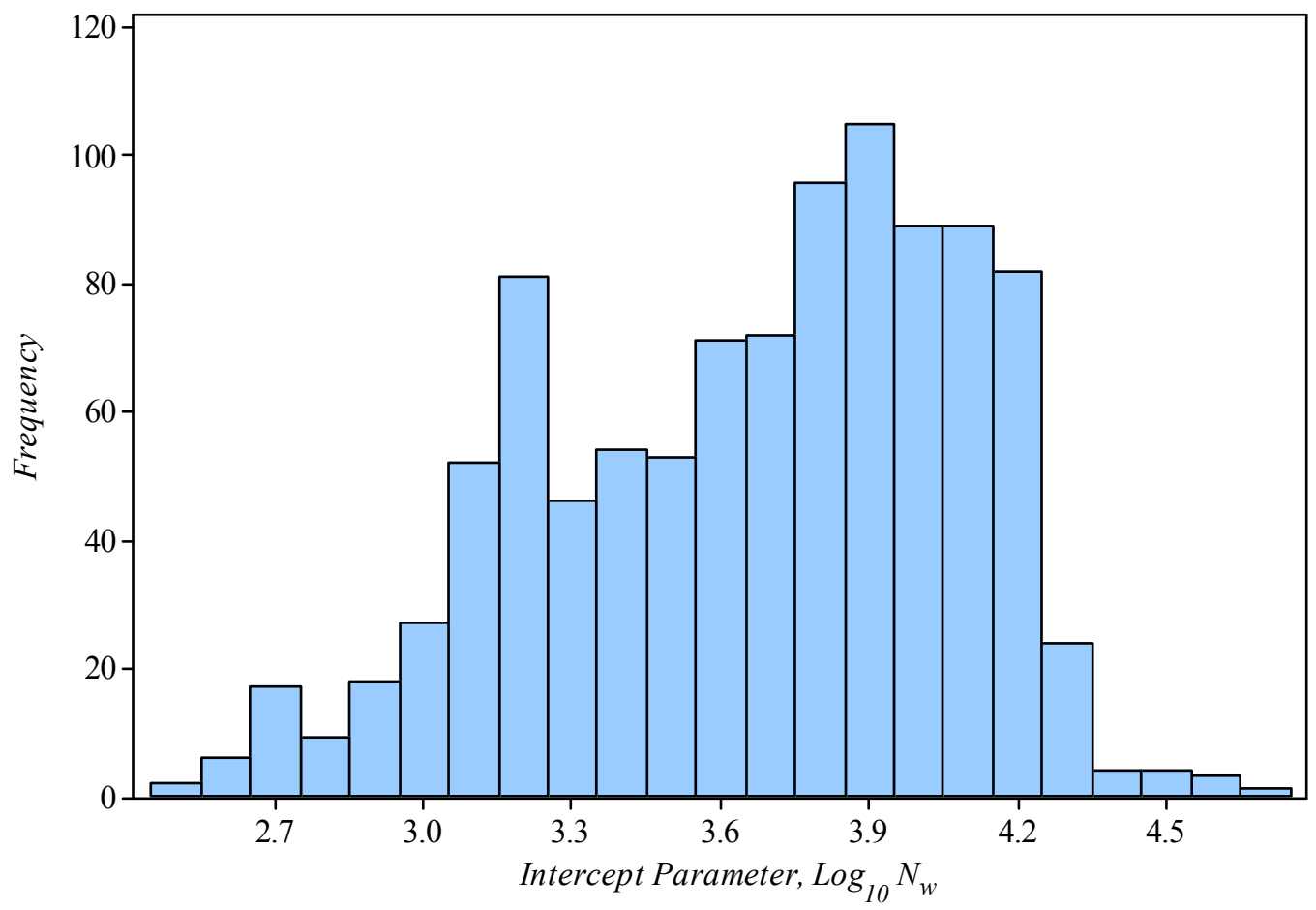

Figure B2.21 Histogram of normalizing number concentration, $\log _{10} N_{w}$ of combined RSD data.

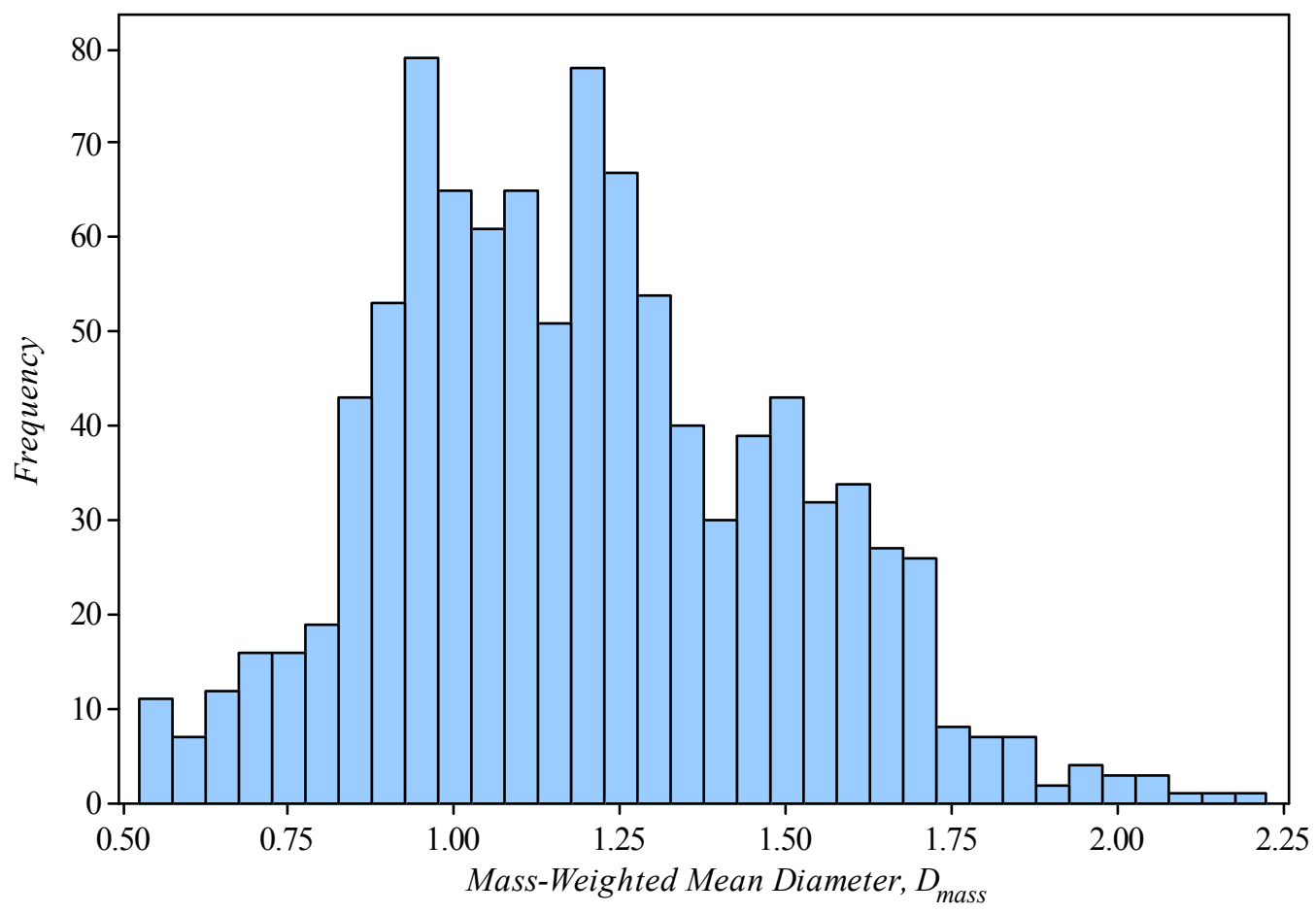

Figure B2.22 Histogram of mass-weighted mean diameter, $\mathrm{D}_{\text {mass }}$ of combined RSD data 


\title{
3. DISTRIBUTION OF WIND-DRIVEN RAIN DEPOSITION ON LOW-RISE BUILDINGS: DIRECT IMPINGING RAINDROPS VERSUS SURFACE RUNOFF
}

\author{
Thomas Baheru ${ }^{1}$, Arindam Gan Chowdhury ${ }^{1 *}$, Jean -Paul Pinelli ${ }^{2}$, Girma Bitsuamlak ${ }^{3}$ \\ ${ }^{1}$ Department of Civil and Environmental Engineering and International Hurricane Research Center, Florida \\ International University, Miami, FL, USA \\ ${ }^{2}$ Department of Civil Engineering, Florida Institute of Technology, Melbourne, FL, USA \\ ${ }^{3}$ Department of Civil and Environmental Engineering, Western University, London, ON, Canada
}

(A paper under review for the journal of Wind Engineering and Industrial Aerodynamics)

Abstract. Wind-driven rain (WDR) effects on various components of a building facade are dependent on the total volume of rainwater deposition. The total volume of WDR deposition at a specific location on the building facade has contributions from both directly impinging raindrops and accumulated surface runoff. The distribution of WDR deposition over the building surface is dependent on the nature of the storm and on the aerodynamic shape of the building. This paper presents an experimental study conducted to investigate the distribution of WDR deposition on the external facade of low-rise buildings. Two parameters that quantify the distribution of direct impinging raindrops and surface runoff rainwater over the building surface — rain admittance factor (RAF) and surface runoff coefficient (SRC), respectively — were measured separately under simulated WDR conditions. Test-based RAF and SRC datasets were developed for three types of building models (gable, flat, and hip-roof buildings) tested for various wind directions. Test results indicated a higher concentration of direct impinging raindrop deposition on windward vertical surfaces of the building when compared to the horizontal roof components. The test results also demonstrated that the leading edge/corner regions of the buildings received less volume surface runoff rainwater, and the rainwater *Corresponding author, Associate Prof., E-mail: chowdhur@fiu.edu 
accumulation increases toward the leeward surfaces. The test-based RAF and SRC data developed in this work may be used for estimation of WDR deposition on façades of lowrise buildings as well as water intrusion through building envelope breaches, openings, and defects.

Keywords: Impinging rain; Large-scale testing; Low-rise building; Raindrop size distribution; Surface runoff; Wind-driven rain; Wall of Wind

\subsection{Introduction}

Wind-driven rain (WDR) intrusion through building envelope defects and breaches is a major source of damage to building interior components and contents during hurricane landfall. High wind pressure and wind-borne debris can cause major breaches to external building envelope. These breaches along with existing envelope defects and openings (e.g., soffit vents) form pathways for WDR to enter into the building enclosure system and cause damage to building interior components and contents (Bitsuamlak et al. 2009; Chowdhury et al. 2012). Some of the interior building damages caused by WDR intrusion during hurricanes include soaking of roof and wall insulations, weakening of gypsum boards and total collapse of ceilings, rotting of floor systems, and destruction of contents (FEMA 2005). In the past, such building damages contributed significantly to the total loss together with subsequent losses due to short and long term functional disruption of buildings. The extent of building interior damages due to WDR intrusion is dependent on the total volume of WDR ingress through building envelope defects, openings, and breaches. The total volume has contributions from both directly impinging raindrops onto the opening area and accumulated surface runoff 
rainwater coming from nearby undamaged envelope surface. Currently available models for estimation of the total volume of WDR intrusion through a given opening on a building facade use distribution of WDR deposition on the surface of the building envelope (Dao and Lindt 2010; Pita et al. 2012). However, the accuracy of such models has been limited due to the scarcity of available field and experimental data on distribution of rainwater deposition over building surfaces. The current study experimentally investigated the distribution of WDR deposition on the façade of low-rise buildings with various roof shapes.

The total volume and mechanism of rainwater deposition on various components of a building façade vary with the exposure to the incident WDR. The wetting pattern caused by impinging raindrops on the building envelope is mainly governed by the interaction of wind, wind-driven raindrops, and aerodynamic shape of the building structure. The rain admittance factor (RAF) is a coefficient that quantifies the distribution of impinging raindrops on building envelope as a function of building shape, location on the building façade, and wind direction (Straube and Burnett 2000). The trajectory of raindrops and their final destination on a building façade is also dependent on the raindrop size, implying the importance of raindrop size distribution in measurements of RAF. Similarly, the volume of surface runoff rainwater at a given location on a building façade is expressed through surface runoff coefficient (SRC) which quantifies the accumulated surface rainwater (total surface rainwater volume leftover from splashing and surface absorption) (Blocken and Carmeliet, 2012). The surface runoff rainwater over the building façade is affected by surface wettability, the absorption capacity of building envelope material, surface roughness, surface tension, gravity, and wind action. 
Various field measurements and numerical studies have been conducted to quantify the distribution of WDR deposition on building facades as direct impinging raindrops and surface runoff rainwater. Nore et al. (2007) conducted field measurements of WDR deposition on a low-rise building located in Trondheim, Norway. The study was focused on quantifying the distribution of WDR deposition (direct impinging rain) in relation to wind speed, wind direction, and rain intensity. Detailed measurement dataset including free-field WDR rate, WDR deposition on building façade, wind speed, wind direction, horizontal rain intensity, and building and topographic descriptions were provided for model development and validation purpose. A similar field measurement of WDR deposition as a result of direct impinging raindrops were reported by Blocken and Carmeliet (2005) using the VIELT building of Laboratory of Building Physics at Catholic University of Leuven, Belgium. The field data of impinging WDR deposition were used to develop high-resolution dataset of WDR coefficients (analogous of RAF) to be used in estimation of WDR deposition using numerical methods. Van-Mook (2002) measured the rainwater accumulation on the west façade of the main building at the Eindhoven University of Technology (TUE), Netherlands. WDR coefficients were estimated at two locations on the building façade. Results showed wide dispersion of WDR coefficients as a function of reference wind velocity and horizontal rain rate (Van-Mook 1999; VanMook 2002). A more extensive study of WDR deposition on building façade was conducted by Ge and Krpan (2009) on existing five low-rise and three high-rise buildings located in British Columbia, Canada. The study was aimed at improving the adequacy and use of local building WDR exposure data which are used in designing of building envelopes. The field measurement data by Ge and Krpan (2009) suggested that the 
distribution of WDR coefficients could vary with rain events. The study also indicated that the presence of roof overhang significantly reduced the WDR coefficients on the building façades and the shedding effect of the overhang depends on the wind and rain characteristics (Ge and Krpan 2007; Ge and Krpan 2009). Comprehensive review of some early-time field measurements of WDR deposition on building façades are presented by Blocken and Carmeliet (2004); Straube (1998). In general, the field measurements showed that the top and side corners/edges of building walls receive large volume of direct impinging raindrops which is largely attributed to the deflection of raindrops caused by the driving wind action as the consequence of the presence of the building itself. Contrary to field measurements of direct impinging raindrops, measurements of surface runoff rainwater on existing building façade are scarce. Detailed review of surface runoff rainwater measurements on building façade is presented by Blocken and Carmeliet (2012); Blocken et al. (2013).

In addition to the field measurements, the distributions of direct impinging raindrops and surface runoff WDR deposition on building facades were investigated using numerical and/or computational fluid dynamics (CFD) approach by many researchers including Choi (1993); Choi (1994); Kubilay et al. (2013), Blocken and Carmeliet (2002); Blocken and Carmeliet (2007); Hangan (1999); Karagiozis et al. (1997); Van den Brande et al. (2013). Distribution patterns of WDR deposition conforming to the field measurements were reported by these authors using the CFD method. Although the CFD approach produced valuable information on volume and mechanism of WDR deposition on building facades, experimental and field measurement data are scarce to validate the findings based on the numerical analyses. 
Therefore, it is the purpose of the current study to develop test-based dataset of RAF and SRC distribution on the facades of commonly available shapes of low-rise buildings. Such database can be used to develop a more accurate method of estimation of WDR deposition on building façade as well as water intrusion through building envelope defects, openings, and breaches. Moreover, understanding of WDR deposition patterns and accumulation mechanisms will facilitate the development of damage mitigation strategies to reduce the building enclosure and interior damages during tropical storms and hurricanes. Section 2 presents the methodology used to develop test-based data of RAF and SRC distributions on the facades of building models. It is accompanied by detailed descriptions of the testing setup, simulation of atmospheric boundary layer (ABL) wind profile and tropical cyclone (TC) WDR using the Florida International University's (FIU) 12-fan Wall of Wind (WOW) facility, capable of simulating hurricane wind speeds, instrumentation, and testing protocol for estimating RAF and SRC distribution. Section 3 discusses the test results followed by some important deductions. The conclusions of the study along with summarized major findings are presented in Section 4.

\subsection{Methodology}

The test setup to produce test-based RAF and SRC data was carefully designed in order to ensure the realistic representation of test results. Prior to collecting test data, typical hurricane wind and WDR characteristics were simulated in the test setup based on target characteristics obtained from field data collected during hurricanes (Tokay et al. 2008; Yu and Chowdhury 2009; Yu et al. 2008). A length scale of $\lambda_{L}=1: 4$ and velocity 
scale of $\lambda_{V}=1: 2$ were used between model and prototype considering the wind flow field dimensions and tropical cyclone WDR simulation at Wall of Wind. The following subsections describe the test setup in detail.

\subsubsection{Building models description}

Test-based WDR deposition parameters - RAF and SRC - data were developed on facades of building models with three types of roof shapes: gable, flat, and hip. The test buildings were built with double acrylic wall and roof covers attached to an internal wooden framing system. Each building model had a base plan dimensions of $1.52 \times 2.30$

$\mathrm{m}^{2}\left(5.0 \times 7.5 \mathrm{ft}^{2}\right)$ and eave height of $0.76 \mathrm{~m}(2.5 \mathrm{ft})$ assuming the same length scale of 1:4. A 5:12 roof pitch was used for both gable and hip roofs with overhang length of 7.62 cm (3.0 in) on all sides. The length-scale and model building dimensions were selected based on the need to minimize blockage within the flow field (maximum blockage was $9.78 \%$ for the gable building). The percentage of blockage was checked against tolerable limits as investigated by Bitsuamlak et al. (2010) and Aly et al. (2011), who reported that up to $16 \%$ blockage in an open-jet facility doesn't necessarily require pressure measurement corrections. The double acrylic wall and roof claddings were designed with grid-format of openings used to mount WDR collecting buckets. Figure 3.1 shows the gable building model with opening layout and detailing. 


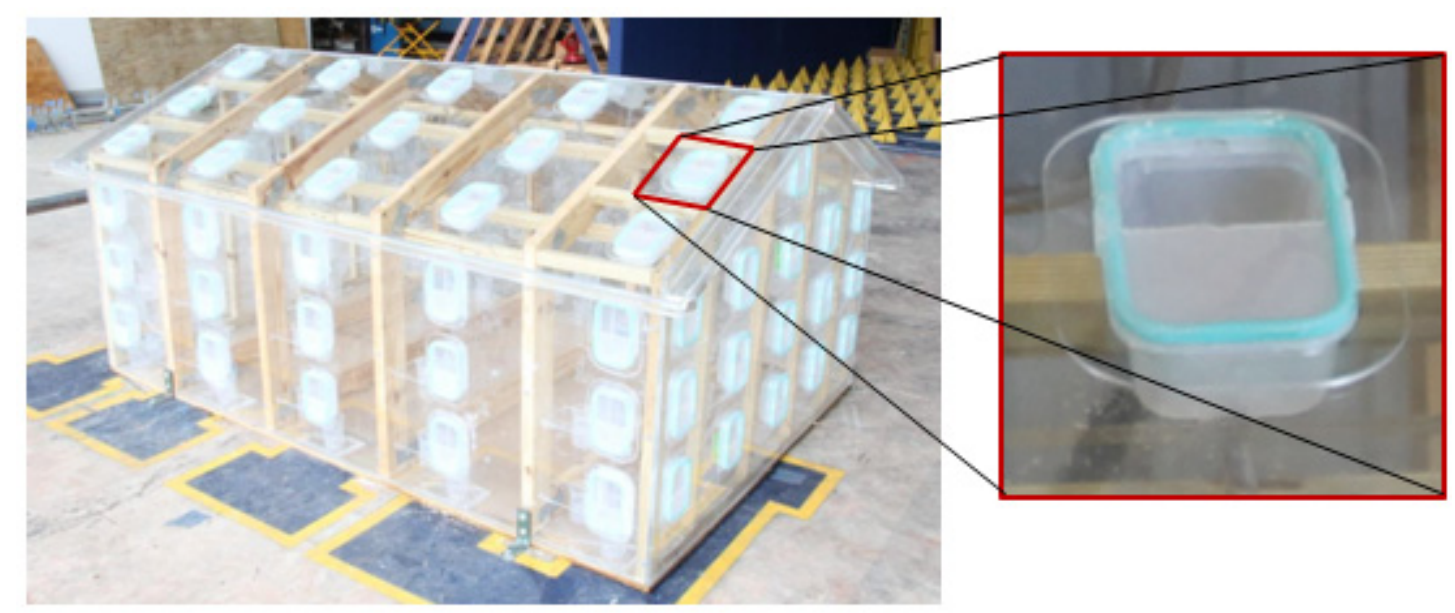

Figure 3.1 Gabel building model with WDR collecting buckets mounted on walls and roof surfaces.

\subsubsection{WOW wind profile}

The WDR tests for the current study were performed using FIU's 12-fan Wall of Wind. The atmospheric boundary layer (ABL) wind flow was simulated using traditional passive wind flow simulation scheme of using vertical spires and floor roughness. Twelve giant fans each driven by 700 horse-power electric motor and arranged in tworows of convex arc produce air flow field big enough to test low-rise building models at large scale (flow field dimensions of $6.10 \mathrm{~m}(20 \mathrm{ft})$ wide and $4.28 \mathrm{~m}(14 \mathrm{ft})$ high). The wind flow produced from each fan merges into a contraction zone designed to generate a uniform flow with desired high wind speed. Vertical flow straighteners installed at the exit of the contraction zone direct the flow in the longitudinal direction suppressing the lateral air speed induced by the shape of the contraction zone. A $9.75 \mathrm{~m}$ (32ft) long flow simulation box downstream of the contraction zone confines the flow and provides the required fetch length to develop the desired ABL flow characteristics. The triangular spires and floor roughness elements crafted through rigorous trial-and-error procedure 
generate the flow turbulence and vertical profile of mean wind speed. Figure 3.2 presents the schematic view of 12-fan WOW.

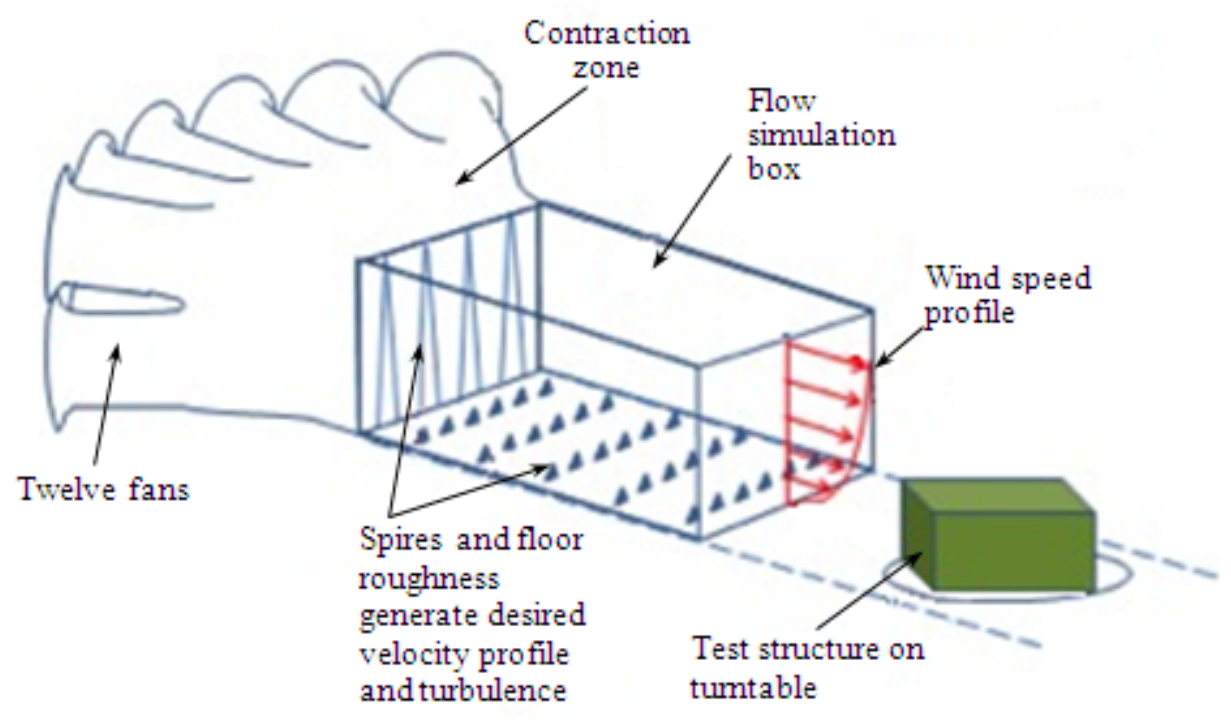

Figure 3.2 Schematic-diagram of 12-fan Wall of Wind (WOW).

Suburban wind profile with a target power-law coefficient of $\alpha=1 / 4.0$ was simulated in the experimental setup for testing of WDR deposition on low-rise building models. The wind speed and turbulence intensity measurements were conducted using a vertical rake system built specifically for wind measurement purpose. The rake system consisted of pressure tubes mounted at various elevations on a vertical mast in the wind field and connected to a 16-channel Scanivalve DSA pressure scanner to record differential pressure time histories that were converted to instantaneous wind speeds. In addition to the pressure sensors, eight Cobra Probes were mounted on the measurement mast to capture the turbulence characteristics of the flow in the three major directions. Figure 3.3 shows the wind profile measurement setup with measurement rake placed at the testing section (at $6.10 \mathrm{~m}$ (20ft) from the exit of the flow simulation box). 
Spatial wind speed measurements at WOW indicated a close match between target and simulated wind speed profiles. Figure 3.4a presents the wind speed profiles at three coordinate locations, $(x, y)=(6.10,0.0),(6.10,1.22)$, and $(6.10,-1.22) \mathrm{m}$, across the flow field and the target suburban profile corresponding to $\alpha=1 / 4.0$ (see Fig 3.3 for $(0,0$, 0) coordinate). The centerline mean and 3-sec gust wind speeds (for 50\% throttle of the fans' motor power used in the current study) were $27.40 \mathrm{~m} / \mathrm{s}(61.30 \mathrm{mph})$ and $29.30 \mathrm{~m} / \mathrm{s}$ $(65.54 \mathrm{mph})$ at the mean-roof-height of the test building $(\mathrm{z}=0.91 \mathrm{~m}(3.0 \mathrm{ft}))$. The powerlaw coefficients for the three coordinate locations were found to be $\alpha=1 / 4.21,1 / 4.10$, and 1/5.54, respectively. Minor deficits in mean wind speed profiles were observed for measurements taken laterally at $y= \pm 1.22 \mathrm{~m}(4.0 \mathrm{ft})$. For example, the mean-roof-height mean wind speeds at $\mathrm{y}= \pm 1.22 \mathrm{~m}(4.0 \mathrm{ft})$ were $25.25 \mathrm{~m} / \mathrm{s}(56.48 \mathrm{mph})$ and $25.90 \mathrm{~m} / \mathrm{s}$ (57.94 $\mathrm{mph}$ ) as compared to $27.40 \mathrm{~m} / \mathrm{s}(61.30 \mathrm{mph})$ centerline mean wind speed depicting corresponding deficits of $7.8 \%$ and $5.5 \%$, respectively. The mean-roof-height turbulence intensities at the three coordinate locations were $13.93 \%, 15.77 \%$, and $13.47 \%$, respectively (see Fig $3.4 \mathrm{~b}$ for the turbulence intensity profiles at corresponding coordinates). Partial turbulence simulation approach is used at the WOW (Fu et al. (2012); Yeo and Chowdhury (2013). The WOW turbulence intensities are lower than their ABL counterparts due to the missing low frequency fluctuations in the flow as portrayed in the longitudinal wind speed power spectrum of Figure 3.5. The use of such partial turbulence simulation method, focusing mainly on correctly simulated high frequency turbulence fluctuations, has been proven to be adequate for aerodynamic testing of large-scale low-rise building models such as that of the Silsoe cubic building tested by Aly et al. (2011) and Richards et al. (2007). 
In addition to the longitudinal flow characteristics, the Cobra Probe measurements indicated that the centerline transverse and vertical turbulence intensities at $z=1.07 \mathrm{~m}$ (3.50 ft) were $10.10 \%$ and $9.33 \%$, respectively.

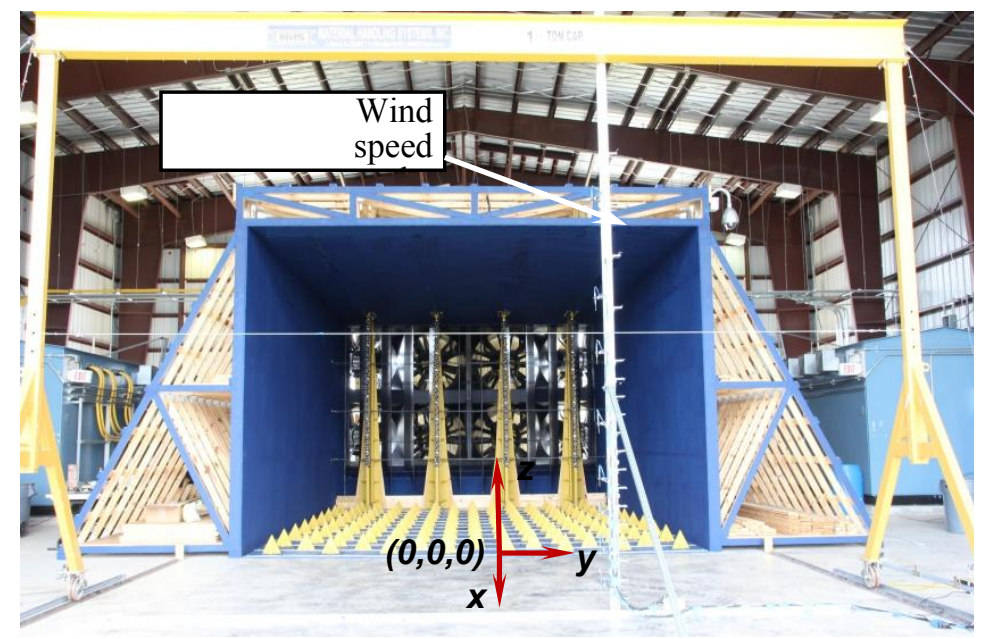

Figure 3.3 12-fan Wall of Wind (WOW) wind speed measurement rake in place.
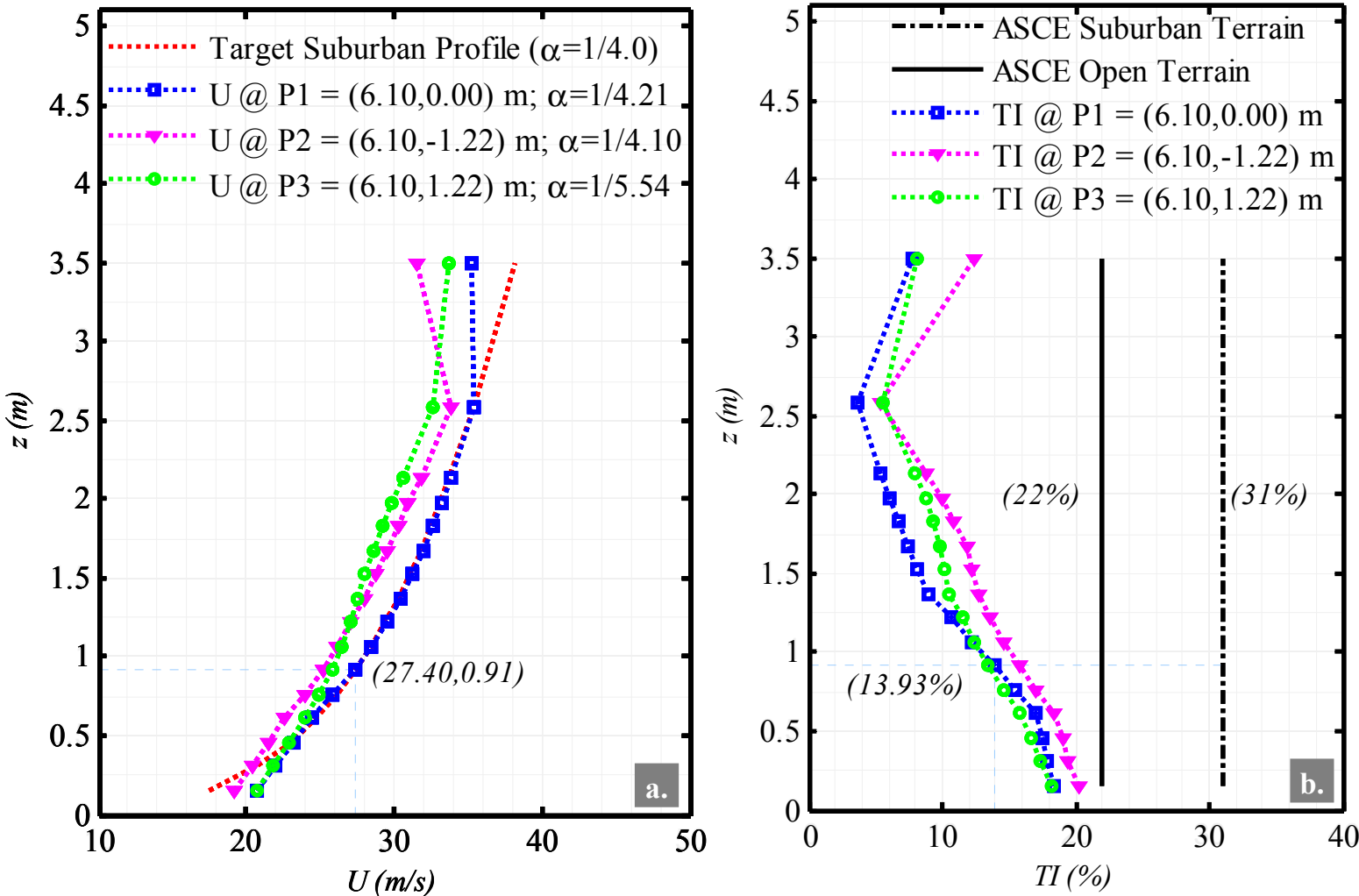

Figure 3.4 Simulation of atmospheric boundary layer: (a) Wind speed; (b) Turbulence intensity profile. 


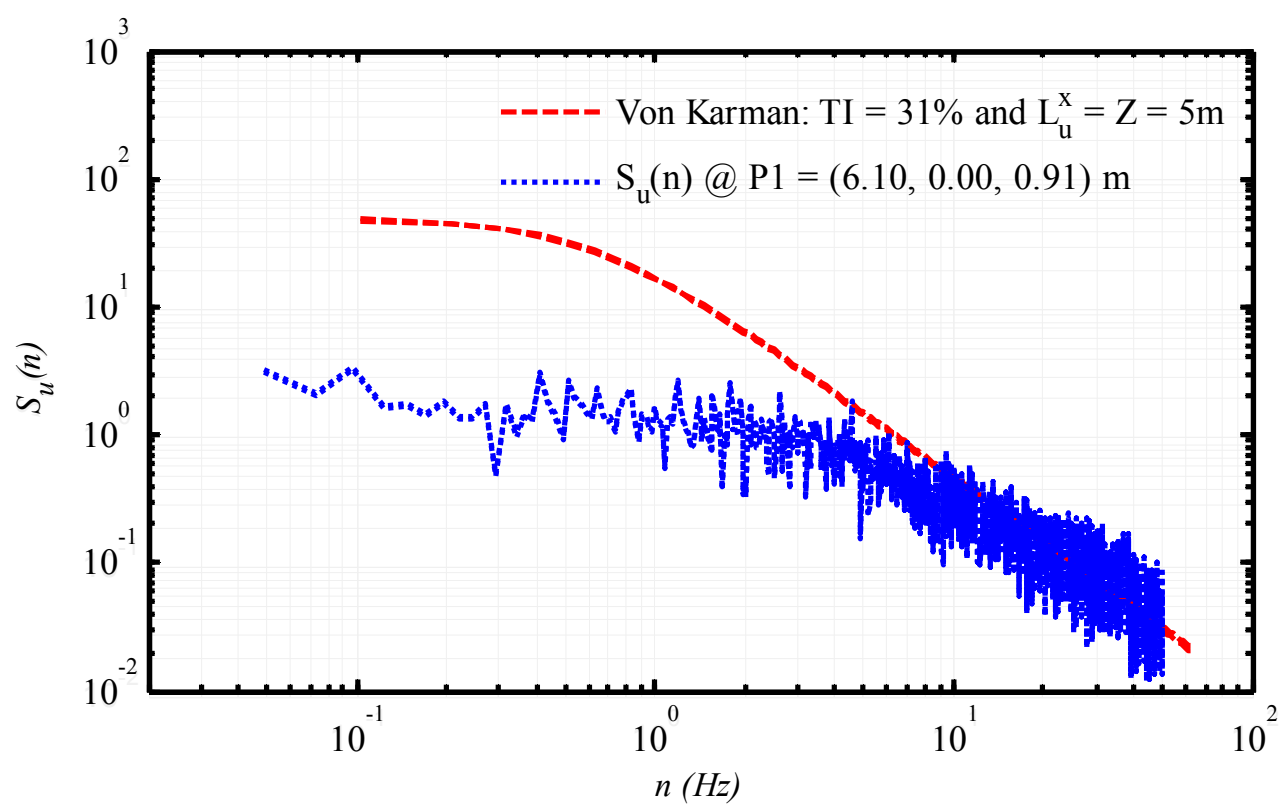

Figure 3.5 Power-spectral density of longitudinal wind speed, U.

\subsubsection{WDR simulation at WOW}

The tropical cyclone WDR generating device at the 12-fan WOW is made of a plumbing system consisting of four vertical lines of spray nozzles attached to the front of the frame supporting the spires (see Fig. 3.6). The pipelines are fed from a common horizontal pipe running over the top of the flow simulation box. The horizontal pipe is connected to a main water supply line of diameter $50.8 \mathrm{~mm}$ (2.0 in), supplying water at a constant rate of about $5 \mathrm{~m}^{3} / \mathrm{hr}$ and pressure of $345 \mathrm{KPa}$ (50 psi). Equally spaced TeeJet 8008 - E full cone spray nozzles installed along the length of the vertical lines spray raindrops at the desired rain rate. The target raindrop size distribution (RSD) for the simulation of TC WDR at WOW was derived from RSD data collected during Hurricane Alex, Charley, and Gaston (2004) through Tropical Rainfall Measuring Mission (TRMM) at Wallops station, Wallops Island, Virginia (Tokay et al. 2008). The field RSD data were modeled using three-parameter gamma distribution for which the parameters were obtained using the probability plot correlation coefficient (PPCC) method. Detailed 
procedures for estimation of target WDR rate based on target RSD and horizontal rain rate and selection of type and number of nozzles including investigation of the adequacy of the simulated WDR for aerodynamic testing of building models was reported by Baheru et al. (2012).

The simulation of WDR using spray nozzles adopted the same length and velocity-scales as used in the wind simulation. Figure 3.7 shows comparison between dimensionless form of simulated RSD measured at $(x, y, z)=(6.10,0.0,0.76),(6.10$, $1.22,0.76)$ and $(6.10,-1.22,0.76) \mathrm{m}$, and target RSDs based on field data and gamma model suggested by Willis and Tattelman (1989). The dimensionless form of the gamma model of raindrop size distribution $(N(D))$ is shown in Fig. 3.7, where $m$ is the shape parameter; $N_{w}$ is number concentration; $D_{\text {mass }}$ is the mass-weighted mean diameter. The simulation of RSD of TC WDR using the 12-fan WOW demonstrated close match to the target RSD for wide range of normalized raindrop size (for range of $0.6 \leq D / D_{\text {mass }} \leq 1.5$ ). However, the RSD plot of simulated WDR flow field had higher concentrations of large size raindrops with $D / D_{\text {mass }}>1.5$. Mean shape parameters of $3.65,4.0$, and 3.75 were obtained for the three coordinate locations across the flow field, all being within one standard deviation about the mean target shape parameter of $m=6.50$. The number concentration, $\log _{10} N_{w}$ and mass-weighted mean diameter, $D_{\text {mass }}$, at centerline of the flow filed (point P1) were obtained as 6.204 and 0.458 compared to the mean target value of $\log _{10} N_{w}=6.41$ and $D_{\text {mass }}=0.44$, respectively. Similar to the mean wind speed profile, minor deficits of WDR parameters $\left(N_{w}\right.$ and $\left.D_{\text {mass }}\right)$ were observed for measurements taken at $y= \pm 1.22 \mathrm{~m}(4.0 \mathrm{ft})$. Number concentration of $\log _{10} N_{w}=5.735$ and $\log _{10} N_{w}=5.669$ were obtained for coordinate points P2 $(y=1.22 \mathrm{~m}(4.0 \mathrm{ft}))$ and P3 $(y=-1.22 \mathrm{~m}(4.0 \mathrm{ft}))$ 
with corresponding to deficits of $7.56 \%$ and $8.14 \%$, respectively. The mass-weighted mean diameter values at those coordinate locations were $D_{\text {mass }}=0.424 \mathrm{~mm}$ and $D_{\text {mass }}=$ $0.438 \mathrm{~mm}$ with corresponding to deficits of $7.42 \%$ and $4.37 \%$, respectively.

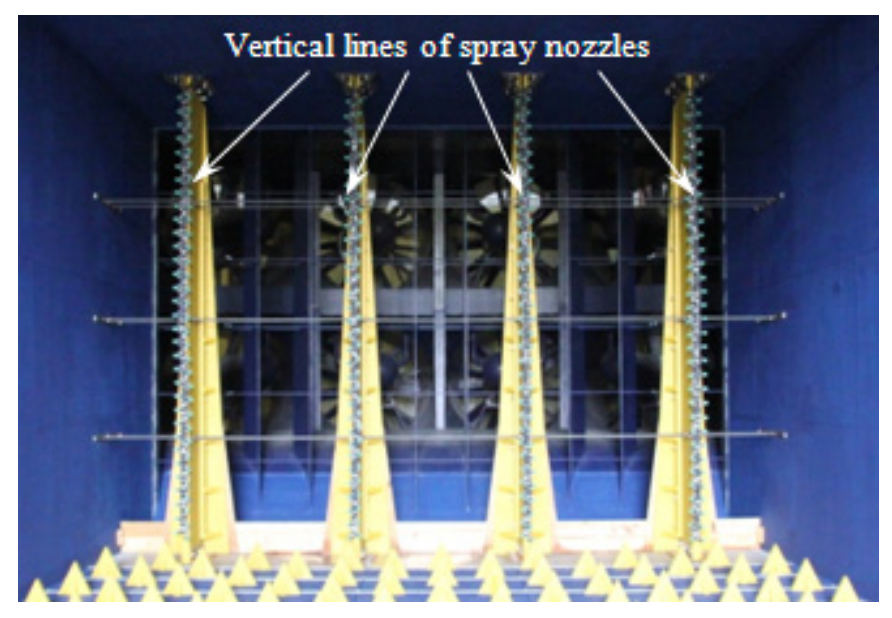

Figure 3.6 12-fan Wall of Wind (WOW) TC WDR generating spray nozzles layout.

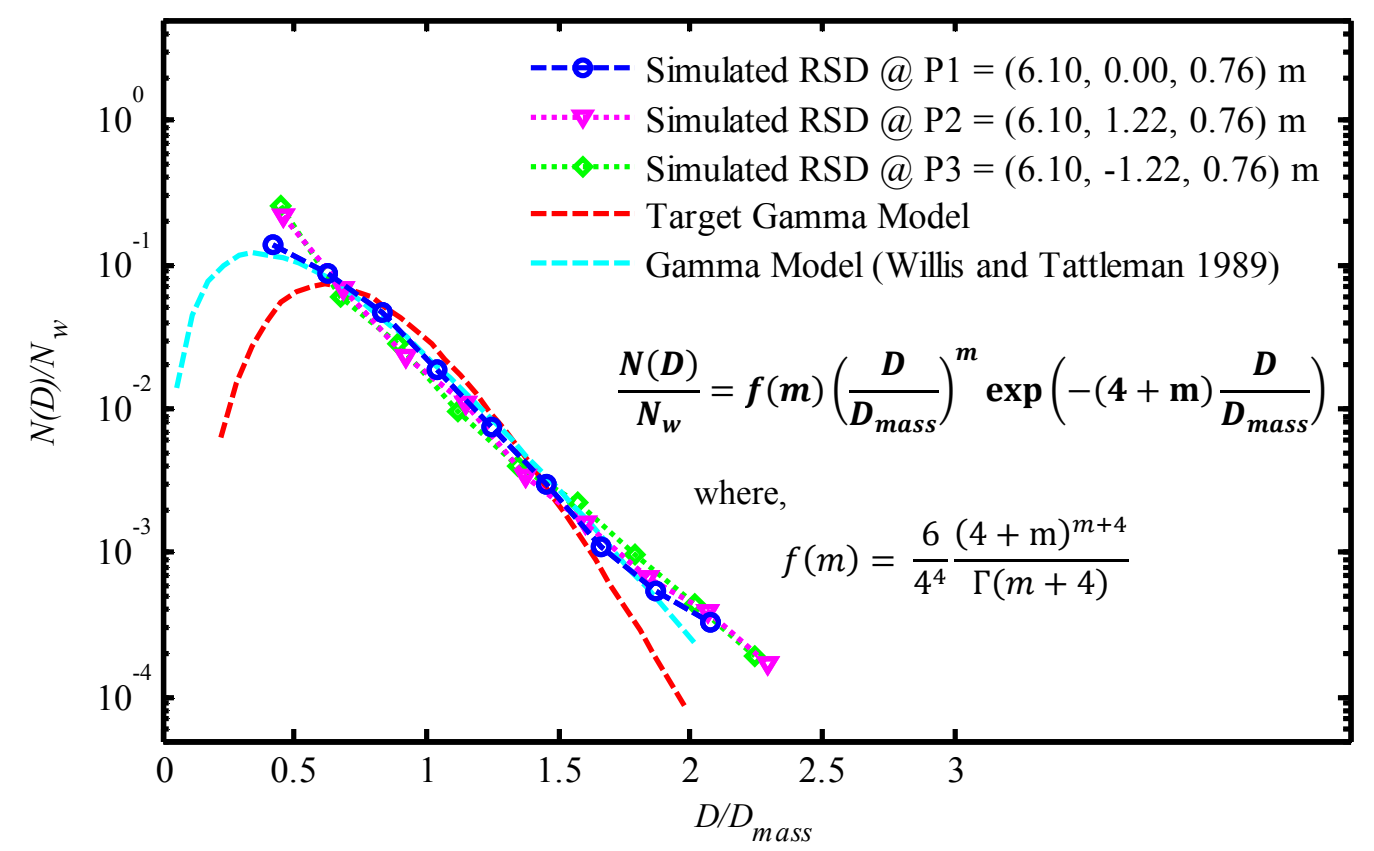

Figure 3.7 RSD of simulated WDR. 


\subsubsection{WDR measurement gauges}

Three types of custom-made rain measurement gauges were developed to quantify the free-field WDR rate, direct impinging raindrops on building façade, and rainwater deposition due to surface runoff. The free-field WDR rate within the flow field was measured using two custom-made rain collecting systems designed to capture raindrop flux passing through a vertical area. Figure $3.8 \mathrm{~b}$ shows the WDR rate measurement systems which consist of rain measurement gauge mounted on a vertical pole and connected to TB3 tipping bucket rain gauge using $25.4 \mathrm{~mm}$ (1.0 in) diameter tubing. The WDR collecting gauge had dimensions of $21.5 \mathrm{~cm}(8.5 \mathrm{in}) \times 26 \mathrm{~cm}(10.25$ in) $\mathrm{x} 12 \mathrm{~cm}$ (4.75 in) (width $\mathrm{x}$ height $\mathrm{x}$ depth). The vertical aperture on the front face of gauges was $217.5 \mathrm{~cm}^{2}\left(33.7 \mathrm{in}^{2}\right)$. The top openings of the tipping bucket rain gauges were covered and sealed with aluminum foil to inhibit raindrops, which fall onto the gauges, from entering into the tipping buckets. The TB3 rain gauge registered a pulse for every 0.254 $\mathrm{mm}(0.01 \mathrm{in})$ rainfall received through vertical openings of rain collecting buckets and recorded the time history data to ML1-FL data logger housed within the gauge's cover.

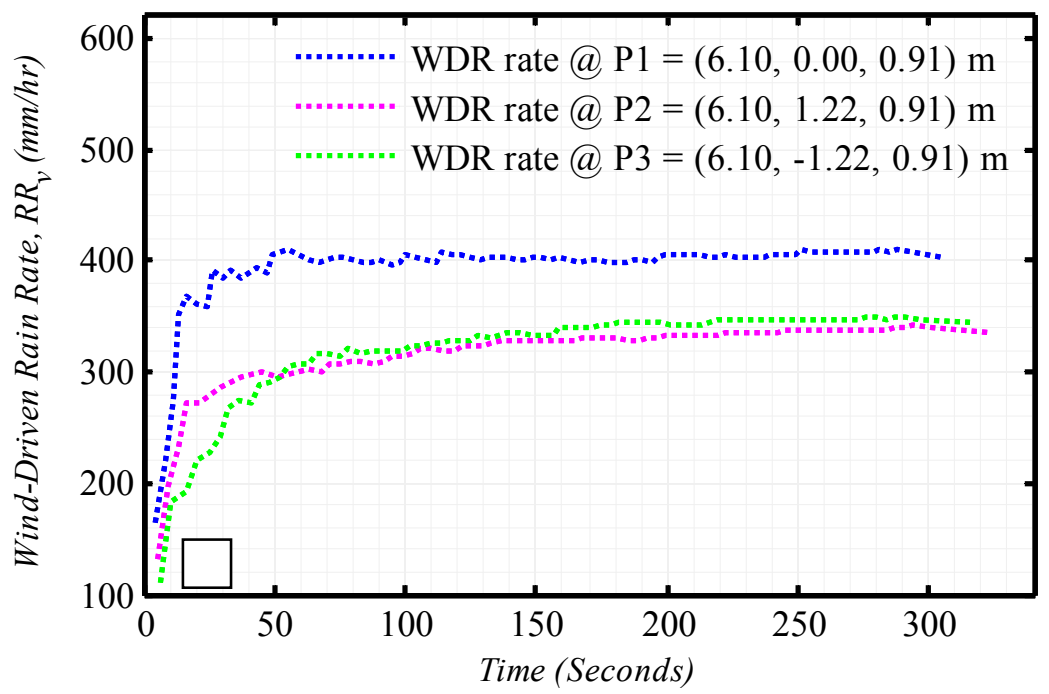




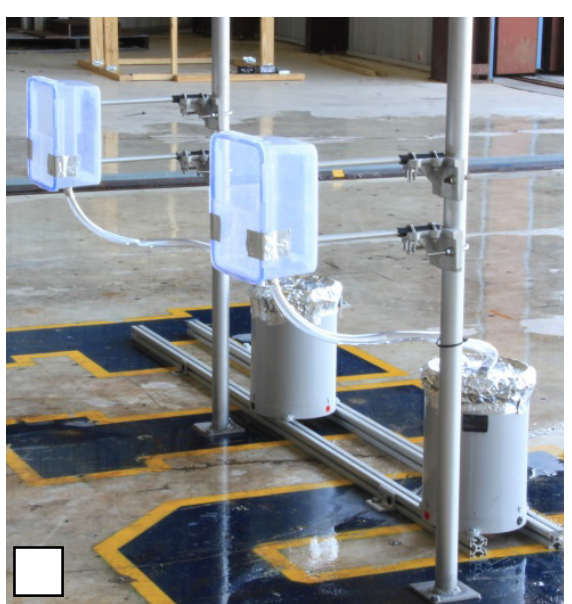

Figure 3.8 WDR rate measurement: (a) Time history of free-field WDR rate; (b) Measurement gauges.

The free field WDR rate measurements were taken for five minutes using the wind speed profile of Fig. 3.4a-b and simulated RSD of Fig. 3.7. Figure 3.8a shows the cumulative time history of free-field WDR rate as recorded by the TB3 tipping buckets for the three coordinate locations P1, P2, and P3 (shown in Fig. 3.8a) across the flow field. WDR rate of $406.4 \mathrm{~mm} / \mathrm{hr}(16.0 \mathrm{in} / \mathrm{hr})$ was measured at the centerline of the flow (coordinate point P1) while $340.4 \mathrm{~mm} / \mathrm{hr}(13.40 \mathrm{in} / \mathrm{hr})$ and $349.3 \mathrm{~mm} / \mathrm{hr}(13.75 \mathrm{in} / \mathrm{hr})$ were registered by rain gauges placed at coordinate locations P2 and P3. The measurements at the latter coordinate points depicted deficits of $16 \%$ and $14 \%$, respectively. The deficits in the WDR rates at coordinate locations off the center of the flow field could be related to the cumulative effect of non-homogeneity in simulated wind speed, turbulence intensity, and RSD.

Direct impinging and surface runoff WDR deposition on the building facades were measured using custom-made gauges developed for the current study. Each measurement gauge designed for quantifying RAF was provided with a rim around the periphery of the bucket's opening area in order to collect rainwater due to impinging raindrops only and blocking the surface runoff water from entering into the bucket. The 
gauge developed for quantifying the surface runoff, however, were made with flush edges of opening (i.e., edges without rim) so that it can collect rainwater due to surface runoff as well as direct impinging raindrops. The volume of rainwater due to the surface runoff only was then determined as the difference between the volumes measured using the two types of gauges (gauge without and with opening rim). Figure 3.9 shows details of rainwater measurement gauges used in this study. Both types of gauges had dimensions of $10.80 \mathrm{~cm}(4.25$ in) $x 16.50 \mathrm{~cm}(6.50$ in) $x 6.35 \mathrm{~cm}(2.50$ in) (width $\mathrm{x}$ height $\mathrm{x}$ depth). The WDR collecting opening at the front face of the gauges was $59.70 \mathrm{~cm}^{2}\left(9.253 \mathrm{in}^{2}\right)$. The gauges were mounted onto the opening area of the test building façades using a 2.54 $\mathrm{cm}$ (1.0 in) wide acrylic panel attached to the perimeter of the gauge. Each gauge was connected to a labeled beaker inside the test building using a $12.7 \mathrm{~mm}$ ( $0.5 \mathrm{in})$ diameter drainage plastic tube. The measurement was conducted by weighing the volume of rainwater in the beakers after each test.
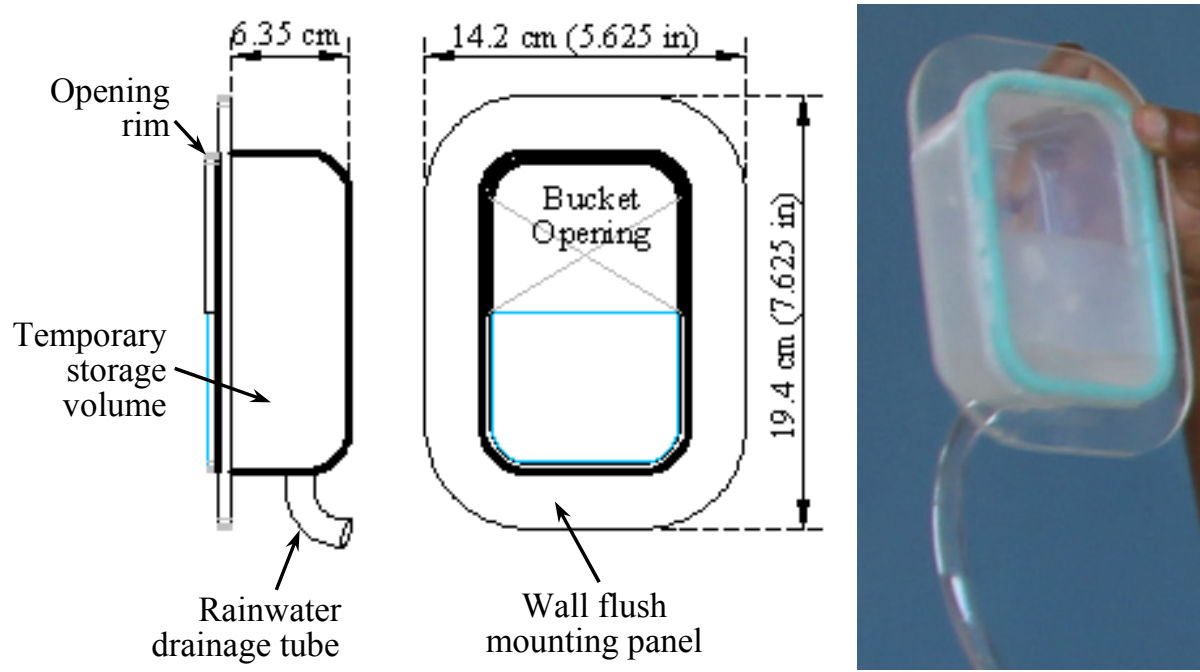

Figure 3.9 Custom-made rainwater measurement gauge 


\subsubsection{Test matrices}

The tests were conducted at mean wind speed of $26.50 \mathrm{~m} / \mathrm{s}(\approx 60.0 \mathrm{mph})$ (average from the three coordinate locations - see subsection 2.3) and WDR rate of $376.0 \mathrm{~mm} / \mathrm{hr}$ (14.80 in/hr) measured at the buildings' mean roof height. Three wind directions were considered: $0^{\circ}, 45^{\circ}$, and $90^{\circ}$, which produced data for all possible wind directions at $45^{\circ}$ considering the symmetry of the test buildings about $\mathrm{x}$ and $\mathrm{y}$-axes. Figure 3.10 shows the test wind directions in which the $0^{\circ}$ wind direction corresponds to wind perpendicular to the longer wall dimension of the building models. A total of 38 tests were conducted on the three building models, collecting either direct impinging raindrops only or surface runoff rainwater together with direct impinging raindrops. Table 3.1 summarizes the test protocol. The RAF test on the gable roof building was performed at two different wind speeds $(26.50 \mathrm{~m} / \mathrm{s}(60 \mathrm{mph})$ and $20.12 \mathrm{~m} / \mathrm{s}(45 \mathrm{mph}))$ keeping the same wind direction of $0^{\circ}$ to investigate the dependence of impinging raindrops distribution (or RAF) on the test wind speed. The WDR rate for the additional test wind speed $20.12 \mathrm{~m} / \mathrm{s}(45 \mathrm{mph})$ was $223.5 \mathrm{~mm} / \mathrm{hr}(8.8 \mathrm{in} / \mathrm{hr})$. The surface runoff was measured on the building façade by installing the gauges in a row at a given height at which the runoff is sought and all other openings were closed to avoid measurement interference of gauges at different heights. Accordingly, six rows (height on the building facade) of runoff bucket locations were considered, of which three row heights (bucket grid 1, 2, and 3 (see Table 3.1 and Fig 3.10)) were on the building walls while the remaining three rows (bucket grid 4,5 , and 6 ) were located on the roof surface. 


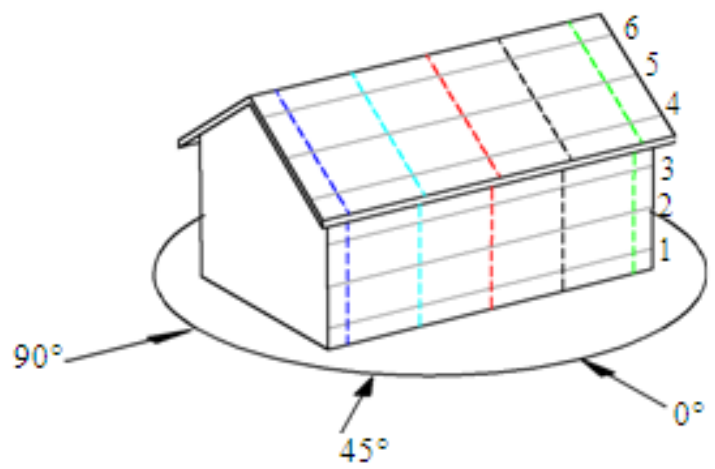

Figure 3.10 Test wind directions and gauge elevation grid for surface runoff measurement.

Table 3.1 Test protocol for rain admittance factor (RAF) and surface runoff coefficient (SRC) measurements

\begin{tabular}{|c|c|c|c|c|c|c|c|}
\hline \multirow{2}{*}{ Building Type } & \multirow{2}{*}{$\begin{array}{l}\text { Test } \\
\text { Type }\end{array}$} & \multirow{2}{*}{$\begin{array}{c}\text { Bucket } \\
\text { Loc. }\end{array}$} & \multicolumn{2}{|c|}{ Wind Speed $^{* *}$} & \multirow{2}{*}{$\begin{array}{c}\text { Rain Rate } \\
376.0 \mathrm{~mm} / \mathrm{hr}\end{array}$} & \multirow{2}{*}{ Wind Direction } & \multirow{2}{*}{$\begin{array}{l}\text { Number } \\
\text { of tests }\end{array}$} \\
\hline & & & $20.12 \mathrm{~m} / \mathrm{s}$ & $26.50 \mathrm{~m} / \mathrm{s}$ & & & \\
\hline Gable roof bldg & RAF & All & $\sqrt{ }$ & $\sqrt{ }$ & $\sqrt{ }{ }^{* *}$ & $0^{\circ}\left(360^{\circ}\right)$ & 2 \\
\hline Gable roof bldg & RAF & All & & $\sqrt{ }$ & $\sqrt{ }$ & $45^{\circ}, 90^{\circ}$ & 2 \\
\hline Hip roof bldg & RAF & All & & $\sqrt{ }$ & $\sqrt{ }$ & $0^{\circ}\left(360^{\circ}\right), 45^{\circ}, 90^{\circ}$ & 3 \\
\hline Flat roof bldg & RAF & All & & $\sqrt{ }$ & $\sqrt{ }$ & $0^{\circ}\left(360^{\circ}\right), 45^{\circ}, 90^{\circ}$ & 3 \\
\hline Gable roof bldg & SRC & grid $i(i=1$ to 6$)$ & & $\sqrt{ }$ & $\sqrt{ }$ & $0^{\circ}\left(360^{\circ}\right), 45^{\circ}, 90^{\circ}$ & 18 \\
\hline Flat roof bldg & SRC & grid $\mathrm{i}(\mathrm{i}=1$ to 3$)$ & & $\sqrt{ }$ & $\sqrt{ }$ & $0^{\circ}\left(360^{\circ}\right), 45^{\circ}, 90^{\circ}$ & 9 \\
\hline
\end{tabular}

The WDR rate for wind speed $20.12 \mathrm{~m} / \mathrm{s}(45 \mathrm{mph})$ was $223.5 \mathrm{~mm} / \mathrm{hr}(8.8 \mathrm{in} / \mathrm{hr})$.

\subsection{Test results and discussion}

The volumes of WDR deposition on the building models due to direct impinging raindrops and surface runoff rainwater were obtained from the tests for different wind directions. The RAFs were quantified as normalized rate of rainwater deposition where the free-field WDR rate measured at the mean-roof-height of the test building, $R R_{v}$, was used as a reference rain rate (see Eq. 1) (Straube, 2010):

$$
R A F=\frac{R R_{b, D I}}{R R_{v}}
$$

where $R R_{b, D I}$ is the rate of WDR deposition at a given location on the building façade due to direct impinging raindrops quantified as 


$$
R R_{b, D I}=\frac{V_{b, D I}}{A_{o} \cdot t}
$$

$V_{b, D I}$ is the volume of rainwater deposition as a result of direct impinging raindrops for the test duration of $t . A_{o}$ is the opening area of the measurement gauge.

Similarly, the SRCs were quantified as normalized surface runoff rainwater accumulation at a given location using Eq. 3 .

$$
S R C=\frac{R R_{b, S R}}{R R_{v}}
$$

where $R R_{b, S R}$ is the rate of WDR deposition at a given location on the building façade due to surface runoff rainwater and expressed as

$$
R R_{b, S R}=\frac{V_{b, S R}}{A_{S R} \cdot t}
$$

$V_{b, S R}$ is the volume of surface runoff rainwater accumulation for the test duration $t$ and $A_{S R}$ is called reference surface runoff area which is a function of the upstream height of the building façade and the perimeter of the opening of the measurement gauge. In order to characterize the variation of surface runoff rainwater using its coefficient (SRC), it was preferred to use the mean-roof-height of the building for walls instead of variable upstream height in calculating $A_{S R}$ for all wind directions. However, for the building roof, the plan dimension of the roof parallel to the wind directions was considered for $0^{\circ}$ and $90^{\circ}$ wind directions while diagonal plan dimension was used for $45^{\circ}$ wind direction. On the other hand, as a second dimension in the calculation of $A_{S R}$, the top edge of the opening was considered as wetted perimeter for $0^{\circ}$ and $90^{\circ}$ wind directions while the diagonal of the opening was used as a measure of the wetted perimeter for $45^{\circ}$ wind direction. 


\subsubsection{Rain admittance factor (RAF)}

\subsubsection{Distribution of RAFs}

The test-based RAF dataset were developed through testing of the three building models under simulated WDR condition for various wind directions. Figures 3.11a to 3.11c show the distribution of RAF on the façade of the gable roof building for $0^{\circ}, 45^{\circ}$, and $90^{\circ}$ wind directions. The windward faces of the building received higher concentration of impinging raindrops as expected while the leeward faces were shielded by the building itself and the orientation of the façade to the incoming WDR. For all wind directions (Fig. 3.11a, 3.11b, and 3.11c), the roof of the building received less amount of impinging raindrops as compared to the windward walls. This is due to the effect of high

wind speed condition, where raindrops have nearly horizontal flow-trajectory dominated by the inertial force induced by the wind. This fact coupled with flow separation produced less deposition of impinging raindrops on the building roof as compared to the walls. For example, this was strongly evident in case of flow separation at the ridge with no impinging raindrop deposition on the leeward part of the gable roof for WDR direction of $0^{\circ}$ (see Fig 3.11a).

For all the wind directions, the RAF values for the buildings' windward wall(s) increased with the wall height -- values ranging between $\mathrm{RAF}=0.0$ at the bottom of the walls to $\mathrm{RAF}=1.0$ at the top. On the contrary, the gable roof had RAF values with lower variation over the entire roof surface, $\mathrm{RAF}=0.2$ to 0.4 for windward gable roof when the WDR direction was $0^{\circ}$ and $\mathrm{RAF}=0.0$ to 0.3 for windward and leeward gable roof when the WDR directions were $45^{\circ}$ and $90^{\circ}$. A general symmetry in RAF values was observed on both wall and roof areas of the gable roof building for wind directions of $0^{\circ}$ and $90^{\circ}$ 
except minor local asymmetries on the roof that may have resulted from fluctuations in the flow separation and reattachment phenomena due to turbulence (see Fig. 3.11a). For wind direction of $45^{\circ}$, the leading edge/corner regions of the building received high concentration of impinging raindrops (RAF up to 0.80 ), and the RAF values decreased for locations farther from the leading edges/corners. Maximum values of RAF, as high as 1.0 or higher, were observed on the windward gable-end wall (especially near the top) for $45^{\circ}$ and $90^{\circ}$ wind directions (Fig $3.11 \mathrm{~b}$ and $3.11 \mathrm{c}$ ). This could be due to the local wind recirculation near the intersection of the gable end wall and the roof overhang which resulted in deposition of high concentration of impinging raindrops. Such high magnitude of RAF could cause large volume of WDR intrusion through gable-end wall breaches or gable-end vent during hurricanes (FEMA 2005; Pita et al. 2012).

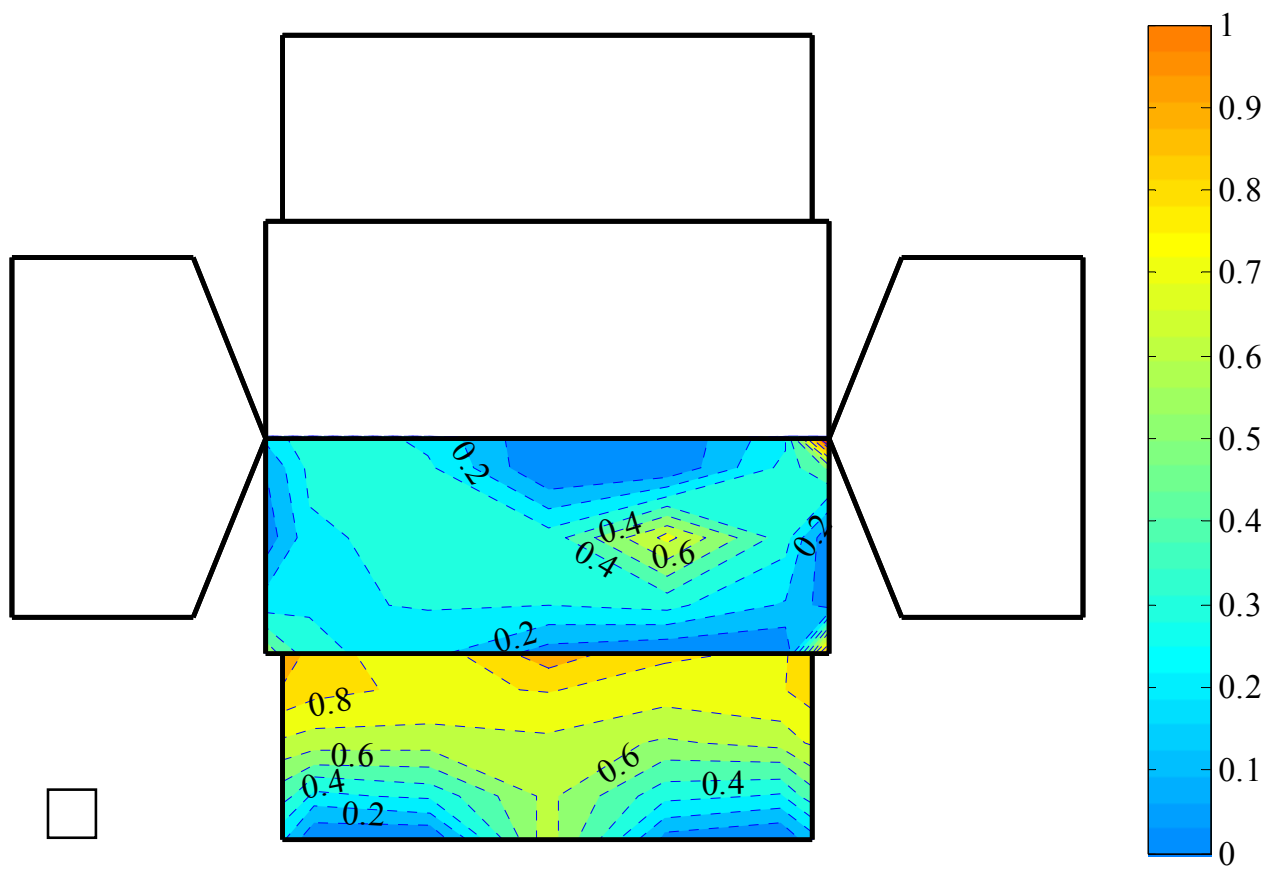



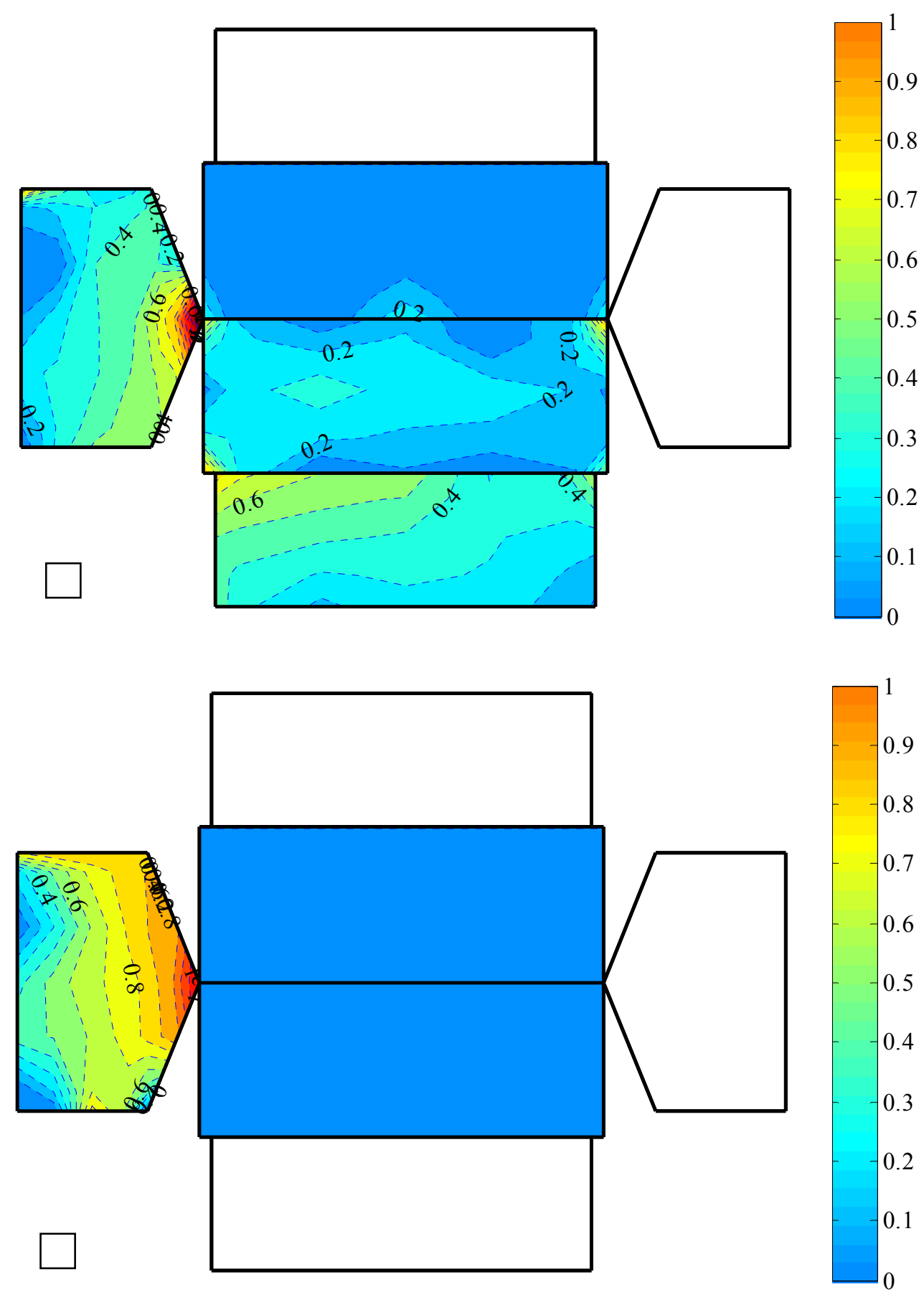

Figure 3.11 Distribution of RAF on gable building model for (a) $0^{\circ}$, (b) $45^{\circ}$, and (c) $90^{\circ}$ wind directions.

Figure 3.12 presents the RAF distribution on the flat roof building. For $0^{\circ}$ wind direction, the RAF values at the top of the windward wall were close to 0.8 for the gable and flat roof buildings showing that that there was no effect of gable roof overhang in 
reducing the impinging raindrops deposition in the upper portion of the windward wall (see Figs. 3.11a and 3.12). This is in contrary to previous results showing that the presence of overhang significantly reduced the RAF values on the upper region of the windward wall during rain events with lower wind speeds (Ge and Krpan 2007). The ineffectiveness of the overhang in reducing the RAF values near the upper portion of the windward wall, as evident from the current study, is attributed to the nearly horizontal flow-trajectory of the raindrops under high wind events such as in hurricanes. Also, the increased blockage effect for the gable roof shape and the overhang resulted in higher values of RAF around the lower central region of the windward wall (Fig 3.11a) as compared to those on the flat roof building (Fig 3.12a). In addition, the RAF values for the top portion of the gable end wall for $45^{\circ}$ and $90^{\circ}$ wind directions were higher than those for the top portions of the windward walls for the flat roof (see Fig. $3.11 \mathrm{~b}$ and c versus Fig. $3.12 \mathrm{~b}$ and c). This shows the vulnerability of gable end walls in terms of water intrusion through breaches or openings during hurricanes. 

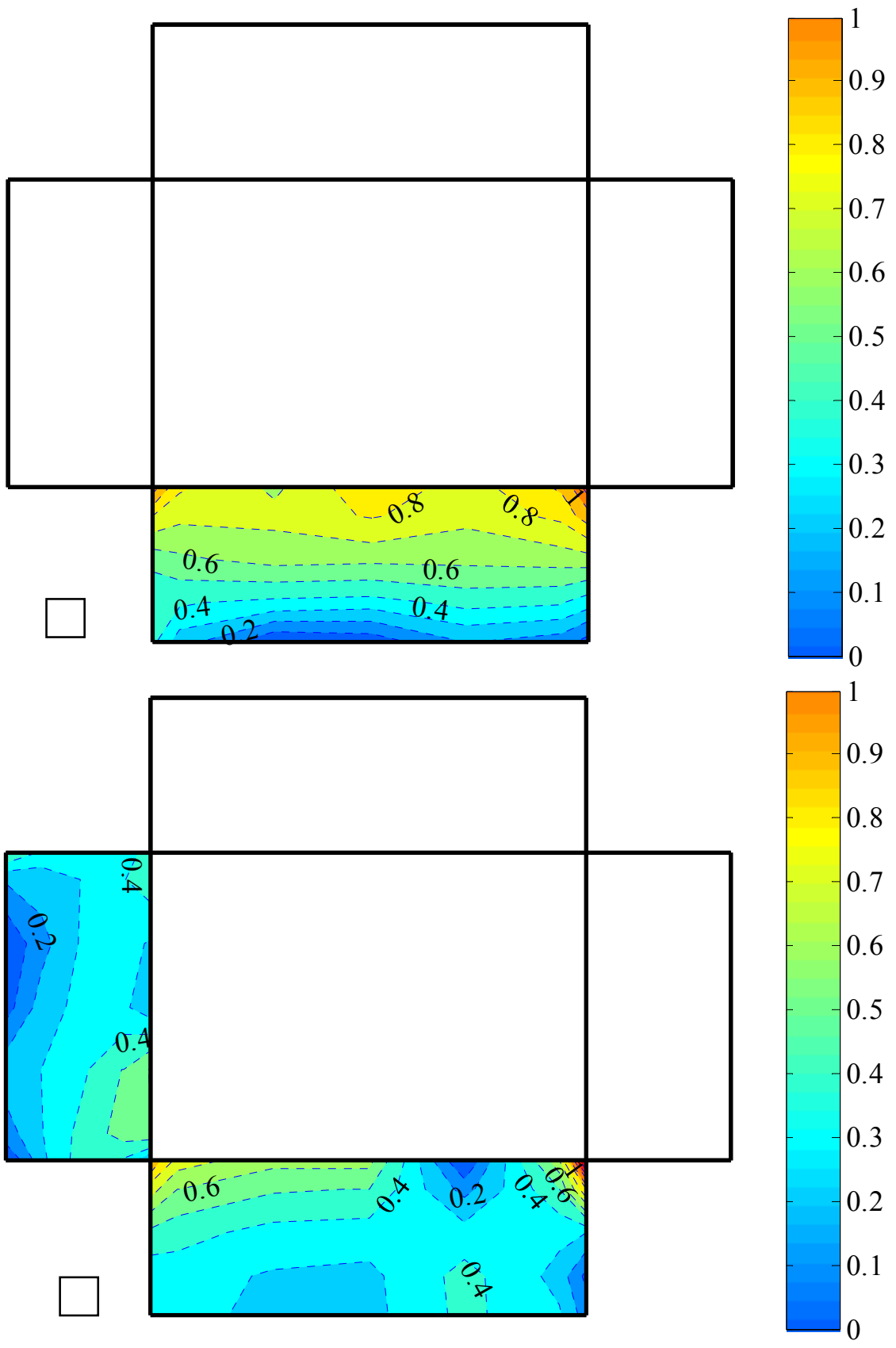


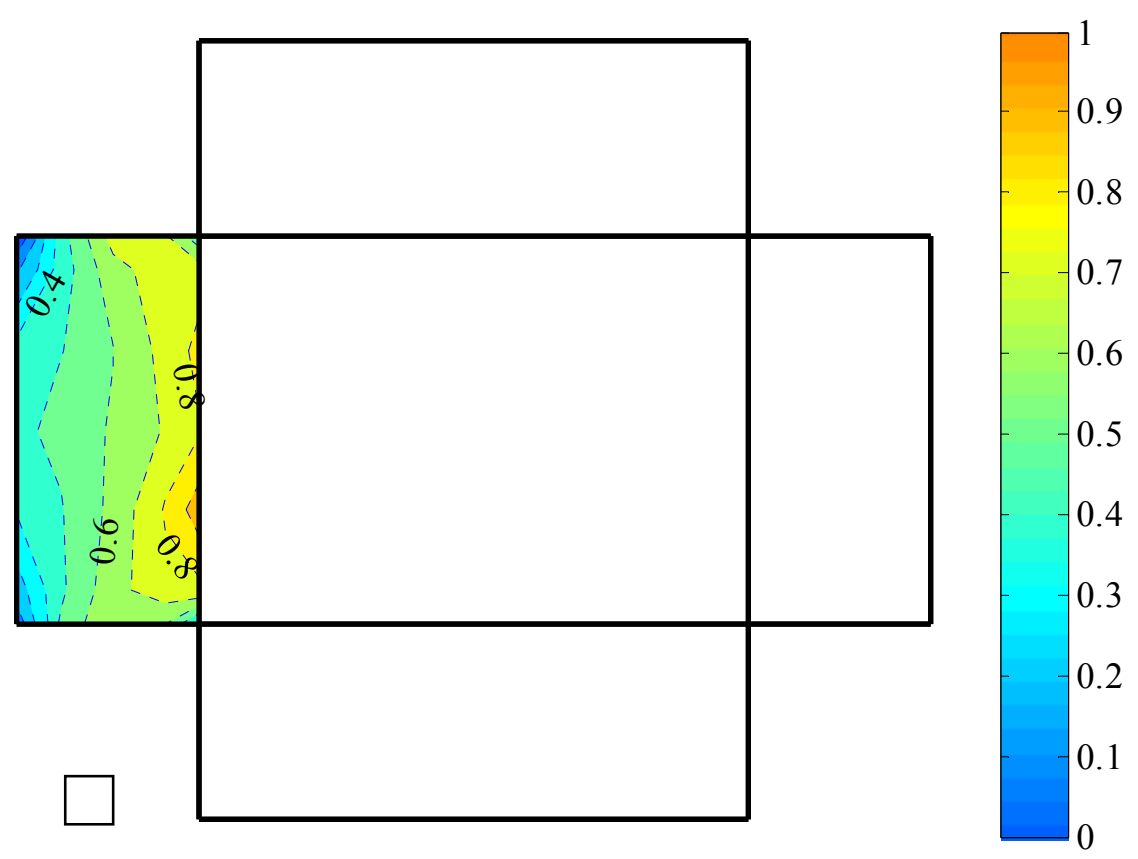

Figure 3.12 Distribution of RAF on flat building model for (a) $0^{\circ}$, (b) $45^{\circ}$, and (c) $90^{\circ}$ wind directions.

Figure 3.13 presents the RAF distribution on the hip roof building. For $0^{\circ}$ wind direction, a symmetrical high concentration of impinging raindrops deposition was observed (with RAF $=0.9$ ) about a quarter-length from the edge and at the mid-height of the hip roof building model (see Fig 3.13a). This may be explained as an effect of the two sloped ridges providing an escape path to the flow around those slopes. The raindrops that were unable to negotiate the flow trajectory were deposited near the two symmetric locations where high RAFs were observed. For $45^{\circ}$ wind direction, high RAF values close to 1.0 were observed near the windward roof corner. High RAF values near the sloped hip corners escalate the chances of significant water intrusion through these locations where external damage (failures of tiles and shingles) were frequently observed during hurricanes of the recent past (IBHS 2009). For the hip roof, the RAF values at the top portions of the windward walls were not as high as they were for the gable end walls for $45^{\circ}$ and $90^{\circ}$ wind directions. 


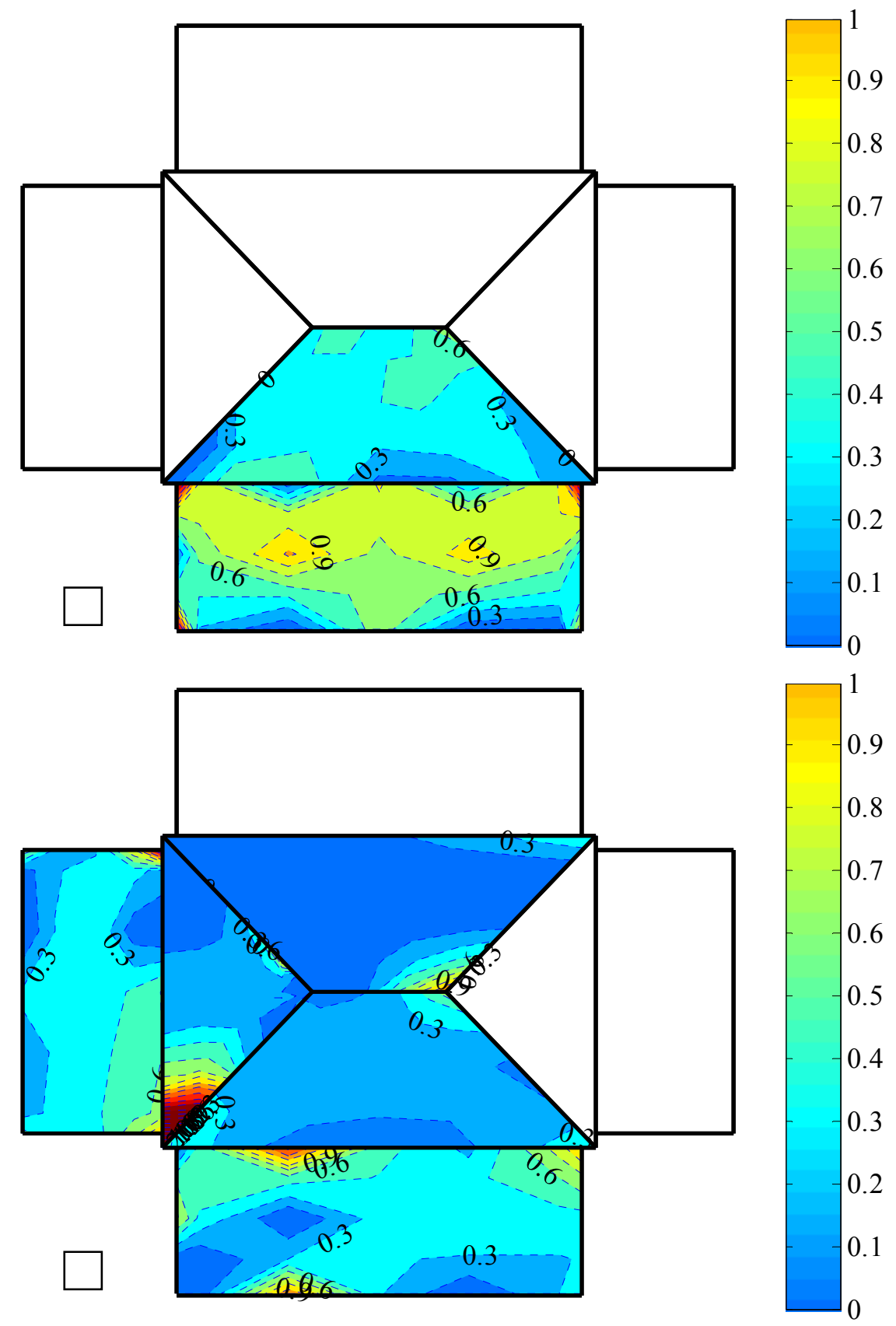




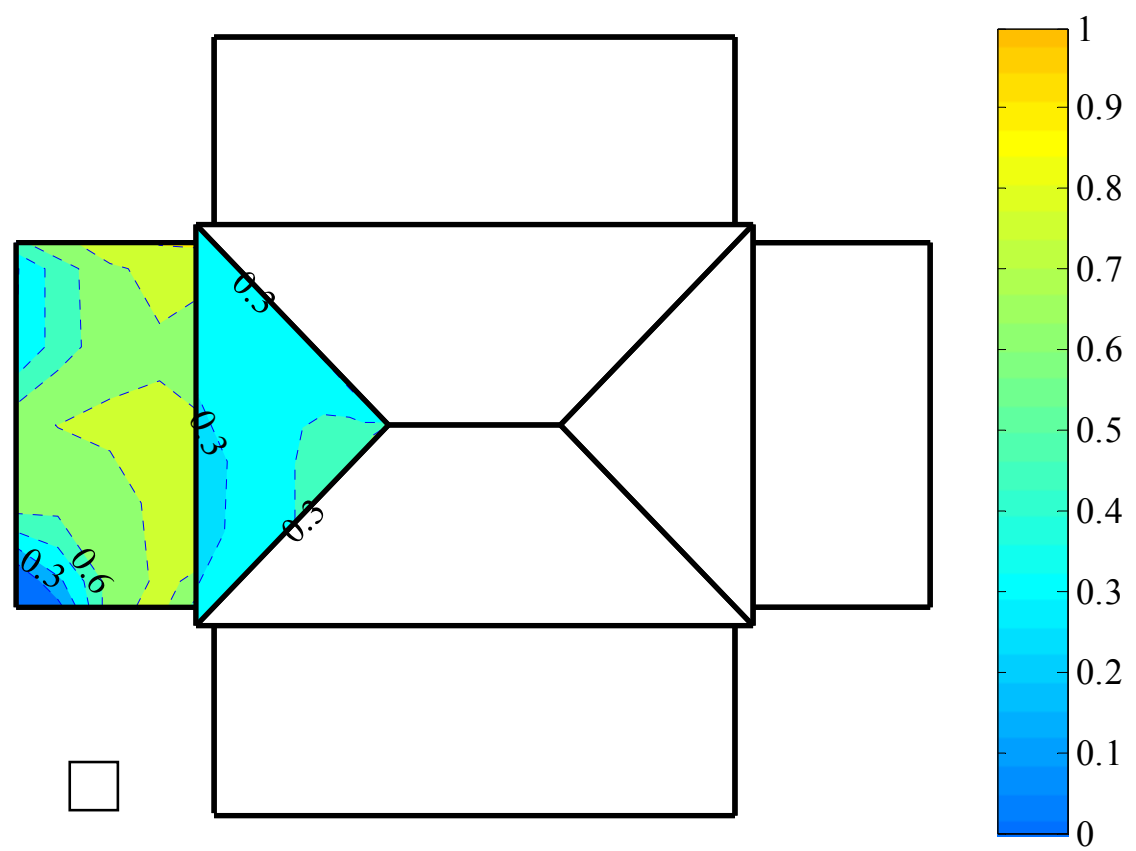

Figure 3.13 Distribution of RAF on hip building model for (a) $0^{\circ}$, (b) $45^{\circ}$, and (c) $90^{\circ}$ wind directions.

\subsubsection{RAF versus wind speed}

Although the main focus of the current study was to develop test-based data on RAF and SRC, the dependence of distribution of RAF on the wind speed was investigated by comparing the RAFs obtained at two wind speeds $(26.50 \mathrm{~m} / \mathrm{s}(60 \mathrm{mph})$ and $20.12 \mathrm{~m} / \mathrm{s}(45 \mathrm{mph}))$ for $0^{\circ}$ wind direction. The graph on Figure 3.14 shows the comparison of RAFs for measurement gauges located along the vertical lines on the façade for the two test wind speeds. Owing to the expected symmetry of RAF values about centerline $\mathrm{C}$, the graph only shows the comparison of RAF values on vertical lines A, B, and C. RAFs of about the same values were obtained from the two wind speed tests for elevation grids located on the vertical lines A and B. For centerline C, the RAF values at the two wind speeds were about the same magnitude for gauges located at elevation grid lines 2, 3, 4, and 5 while significant differences was observed for elevation grid 1 $(\mathrm{RAF}=0.63$ versus 0.90$)$, which was close to the bottom of the building wall. The 
measurement at grid location C-6 is not shown on the graph due to unreliable result for wind speed of $20.12 \mathrm{~m} / \mathrm{s}(45 \mathrm{mph})$. Note that the change in wind speed affects two important parameters that have direct relationship to the distribution of WDR deposition on the building facades: the wind induced inertial acceleration of raindrops and pitch angle of drops' trajectory. The increase in raindrops' inertial acceleration due to the increase in wind speed will force raindrops to change their path especially in the vicinity of the building while drops are trying to escape and undergo deflection due to the presence of the building. In addition, though the tests in the current study were focused on wind angles of attack in $x-y$ coordinate plane (azimuthal wind directions), the change in wind speed changes the pitch angles of raindrops' trajectories and affects the distribution of WDR deposition. However, it is apparent that the effect of such change in pitch angles due to change in wind speed is limited to certain range of wind speeds beyond which drops will essentially follow horizontal trajectory and have much higher horizontal speed compared to their terminal or falling velocity. The fact that the test results showed about the same RAF magnitudes for the two wind speeds for most of the grid locations on the building façade indicated that at such high wind speeds the rain admittance factors (RAFs) can be considered as independent of wind speed. However, RAFs in the flow separation regions could be affected by the change in wind speed. 


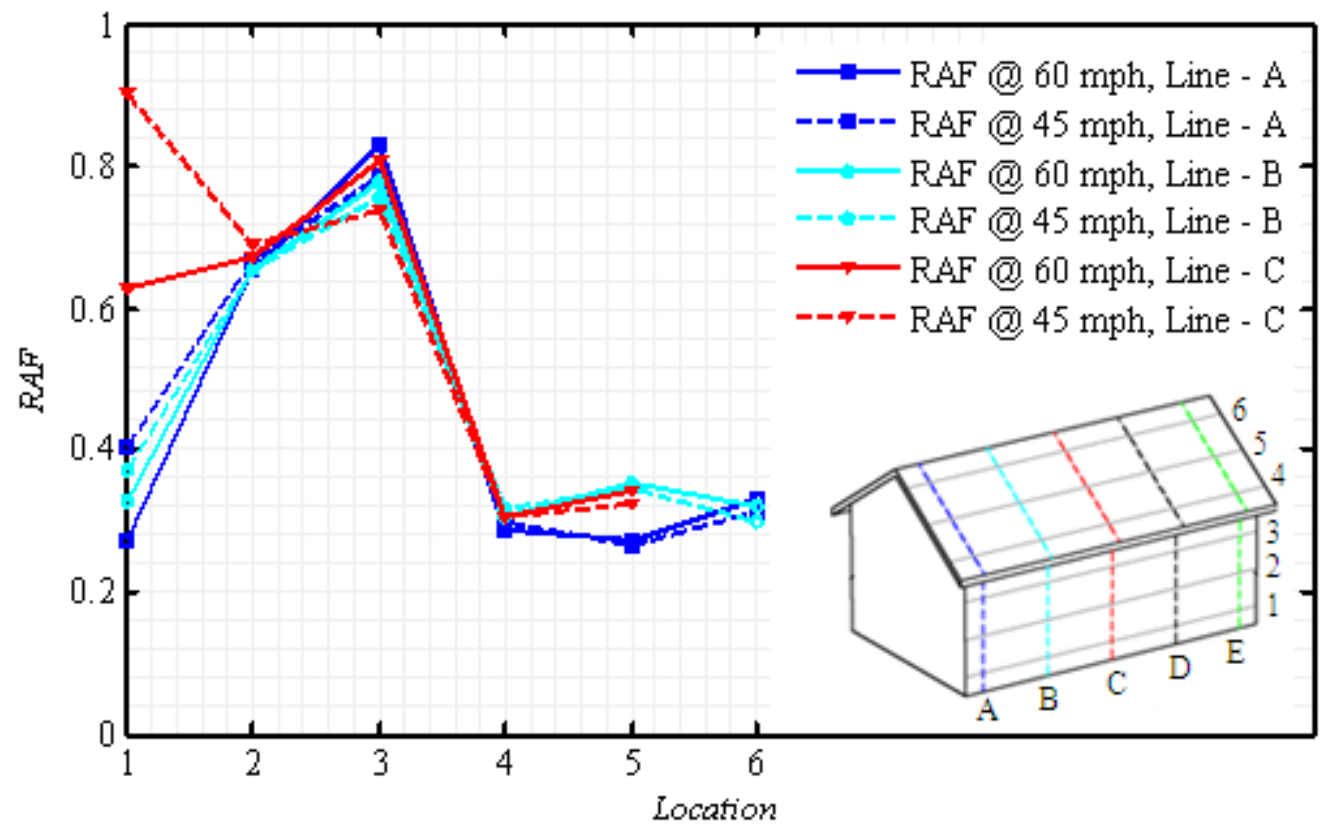

Figure 3.14 Rain admittance factor versus wind speed.

\subsubsection{Distribution of surface runoff coefficients (SRC)}

The surface runoff coefficients (SRCs) were determined from test measurements of runoff rainwater accumulation at different heights on the gable and flat roof building models. Figure 3.15 shows the distribution of SRCs on the gable roof building for the three wind directions. The leeward faces (specially the leeward gable roof) were exposed to a measureable amount of surface runoff rainwater accumulation as shown by the SRC values. This is in contrast to the direct impinging raindrops deposition that was negligible for leeward surfaces of the building models. This may be attributed to the wind action and pressure distribution which forced the surface rainwater to overflow to adjacent building surfaces even though the impinging raindrops depositions on those surfaces were low.

Contrary to the RAF distribution for $0^{\circ}$ wind direction, the SRC values on the windward wall of the gable building increased linearly with the decrease in height (values 
ranging $\mathrm{SRC}=0.16$ at the bottom of the wall to $\mathrm{SRC}=0.0$ at the top). For the top quarter of the wall height the gauges measured none or very low accumulation of surface runoff rainwater (see Fig. 3.15a). Though the overhang was ineffective in protecting the building façades from direct impinging raindrops during high wind speed, it shielded the leeward wall from possible surface runoff coming from the roof surface (Fig. 3.15a). There was no accumulation of surface runoff rainwater on the first half of the windward gable roof and the SRC values increased in the vicinity of the gable ridge for both $0^{\circ}$ and $45^{\circ}$. The leeward gable roof received low surface runoff water in case of $0^{\circ}$ wind direction. However, for $45^{\circ}$ wind direction, the leeward gable roof was exposed to significant runoff rainwater, in which the runoff rainwater was flowing to one side of the roof as directed by the wind flow (see Fig 3.15b). The high volume surface runoff flow on the leeward face for $45^{\circ}$ wind direction could be due to the interaction of building shape and wind flow which resulted in the formation of a curved pattern of WDR accumulation. The SRCs measurements for $90^{\circ}$ wind direction, shown on Figure 3.15c, depicted a similar increase of SRCs values with decrease in height on windward wall surface while the values were close to zero for the gable roof. 


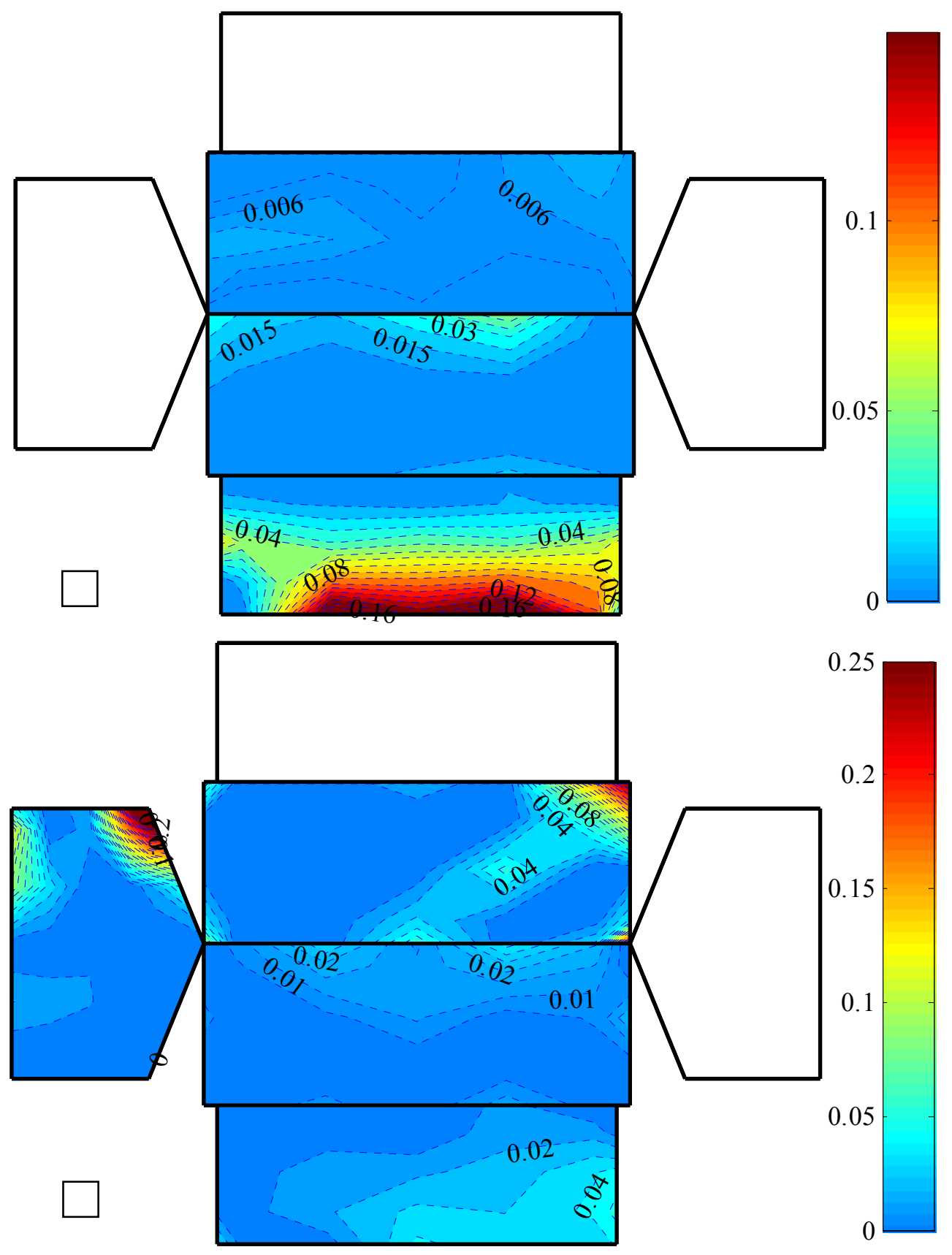




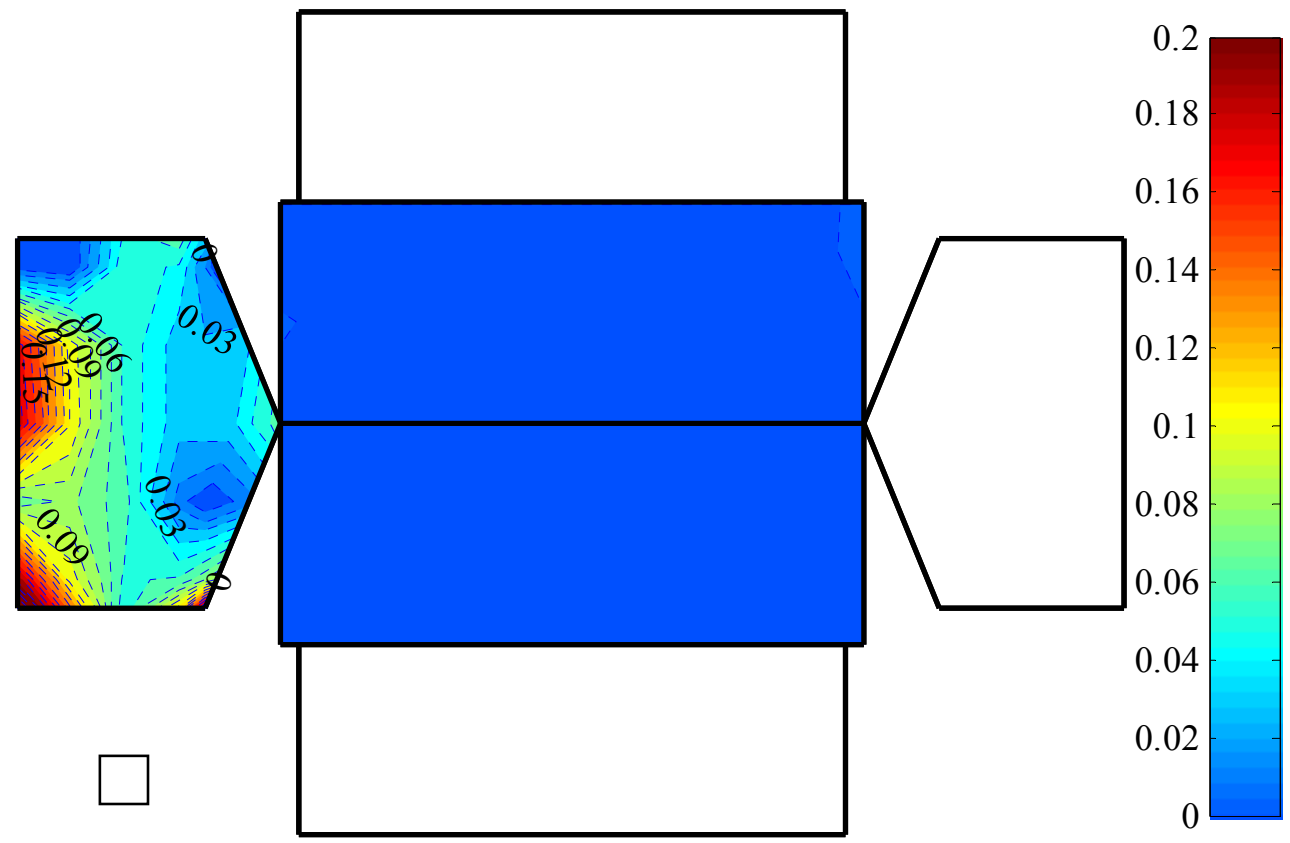

Figure 3.15 Distribution of SRC on gable building model for: (a) $0^{\circ}$, (b) $45^{\circ}$, and (c) $90^{\circ}$ wind directions.

Figure 3.16 shows the SRC distribution on the flat roof building. For the $0^{\circ}$ wind direction, the SRC values on the windward wall of the flat roof building increased linearly with the decrease in height, however the values were lower than those for the gable roof building (see Figs. 3.15a and 3.16a). For example, for the flat roof building the SRC values increased at a lower rate towards the bottom and reached about 0.06 and 0.12 at the mid-height and the bottom of the windward wall, respectively, while for the gable building the corresponding values were 0.07 and 0.16 . Similar effect was observed for the $90^{\circ}$ wind direction: SRC values at mid-height and the bottom of the windward wall were 0.05 and 0.14 versus 0.07 and 0.16 for the flat and gable roof buildings, respectively. The differences in distribution pattern could be due to the differences in the two roof shapes and the influence of the overhang for the gable roof which can create a downwash effect that can result is rapid increase of SRCs as the raindrops flow towards the bottom of the windward wall. Due to the absence of any roof overhang, the leeward wall of the flat roof 
building was exposed to noticeable surface runoff accumulations overflowing from the roof surface (SRC $=0.02$ to 0.03 ). For the $45^{\circ}$ wind direction, the SRCs for the walls were similar to those for the gable building case. However, there was minimal surface runoff accumulation for the flat roof as opposed to the leeward gable roof.
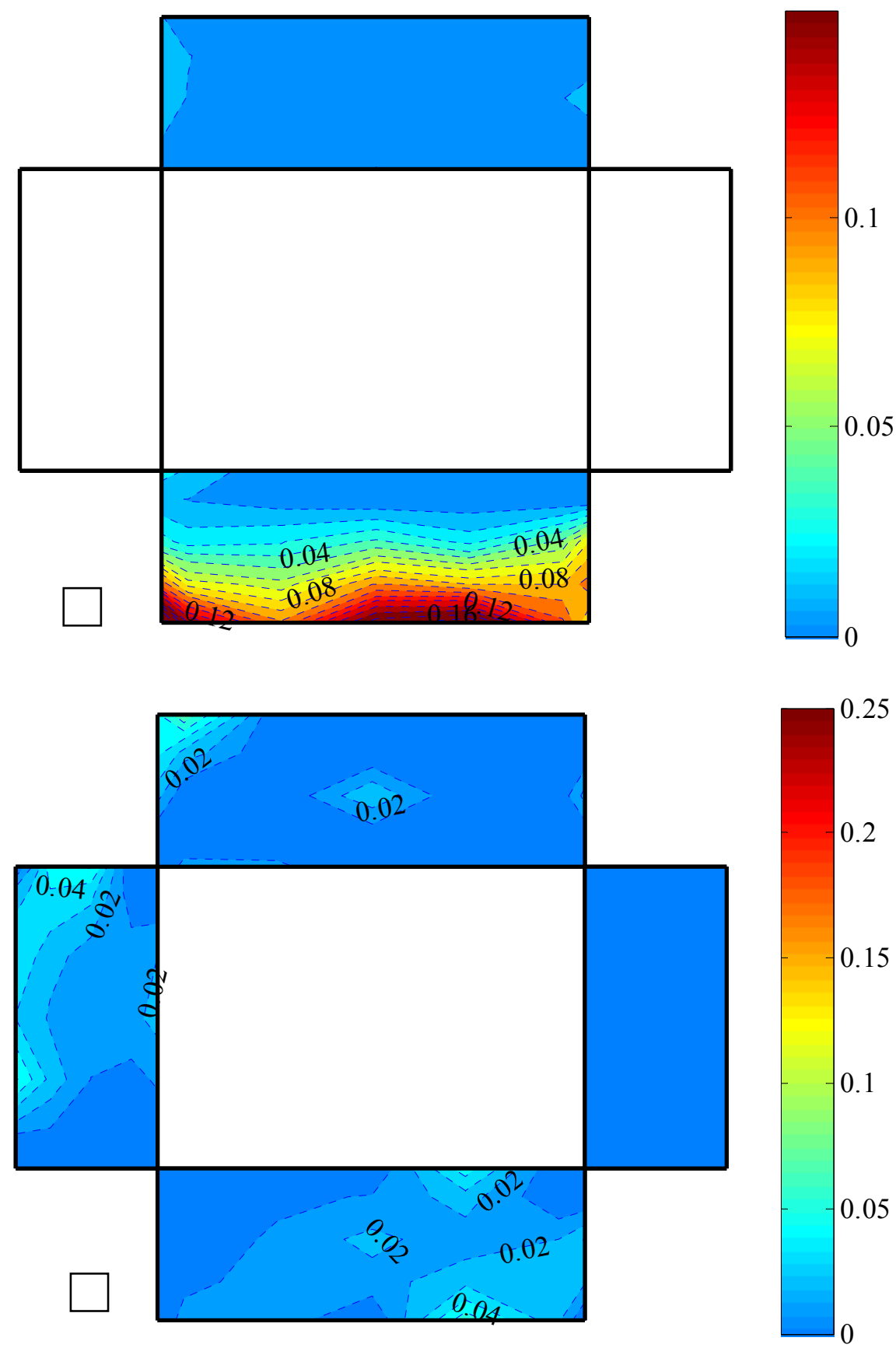


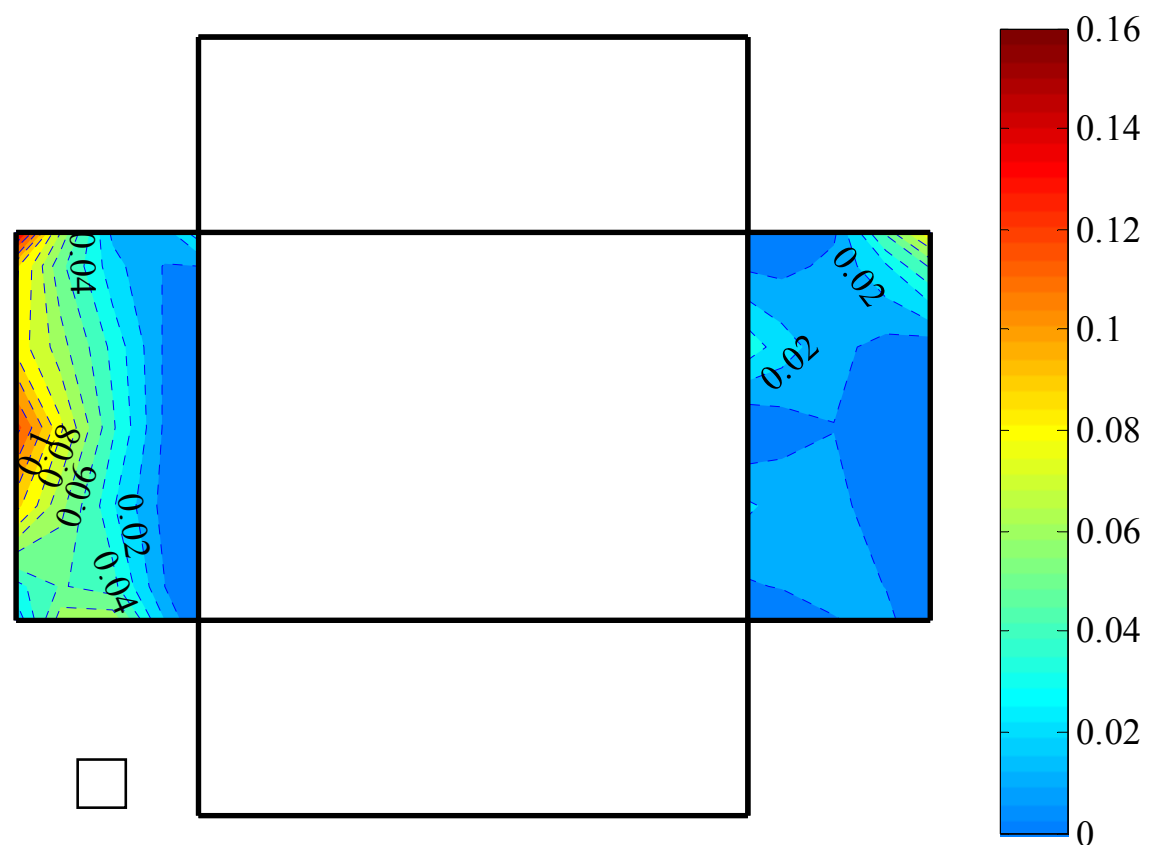

Figure 3.16 Distribution of SRC on flat building model for: (a) $0^{\circ}$, (b) $45^{\circ}$, and (c) $90^{\circ}$ wind directions.

It is important to note that the surface runoff volume at any specific location on a building façade is highly dependent on the transient water absorption capacity of building envelope material (Blocken and Carmeliet 2012; Blocken et al. 2013). The current study, however, utilized building models built of acrylic claddings, which has no water absorption capacity and characterized with low affinity to water, implying exclusion of water absorption during the test measurements. The application of such test results is mainly focused on quantification of surface runoff WDR on impermeable building claddings (e.g., sliding glass doors, vinyl cladding) and on building envelopes after exposure to saturation condition. The latter is a common phenomenon during tropical storms and hurricanes where torrential rain soaks building materials beyond their saturation point. In addition to water absorption of building envelope material, the SRCs distribution is also affected by building surface roughness as the friction between the water film and building surface is one of the forces controlling the rainwater flow over 
the building facade. However, in case of high wind speed (such as tropical storms and hurricanes), the wind action and pressure distribution are the dominant forces that determine the flow path and distribution of surface rainwater for commonly used building envelope materials. Therefore, the dataset developed under the current study can be used in development and validation of numerical models considering the above conditions.

\subsection{Conclusions}

The current study developed test-based data on the rain admittance factors (RAFs) and surface runoff coefficients (SRCs) for three types of building shapes using simulated wind-driven rain (WDR) conditions. The following points summarize the major findings deduced based on the test results:

- The windward walls of the buildings received high concentrations of direct impinging raindrops (high magnitudes of RAFs) as compared to the horizontal (or sloped) roof for all wind directions. No impinging raindrops deposition was observed on the leeward walls and roof façades.

- For $45^{\circ}$ wind direction, the leading edge/corner regions of the buildings received high volume impinging rain and the deposition of raindrops decreased toward the far-end edges/corners of the facades.

- For $0^{\circ}$ and $90^{\circ}$ wind directions, the gable-end wall was exposed to high rate of impinging raindrops deposition due to flow recirculation near the intersection of the gable-end wall and the roof overhang. For $90^{\circ}$ wind direction, the surface runoff accumulation increased rapidly towards the bottom of gable-end wall.

These phenomena could cause large volume of WDR intrusion through gable-end 
wall breaches or gable-end vent during tropical storms and hurricanes increasing the vulnerability of gable roof buildings.

- Comparison of impinging raindrops deposition on gable and flat roof buildings for $0^{\circ}$ wind direction revealed the ineffectiveness of overhang to protect or reduce WDR deposition on walls at high wind speeds such as in tropical storms and hurricanes. The overhang, in case of gable and hip roofs, caused downwash effect increasing both directing impinging and surface runoff on the wall surface. On the contrary, the presence of overhang protected the leeward walls from surface runoff rainwater over flowing from the roof.

- Higher values of RAF were observed near the windward sloped ridges of hip roof. This effect coupled with the high risk of roof elements failure in this region due to high suction can cause significant water intrusion into attic spaces.

- For $0^{\circ}$ and $90^{\circ}$ wind directions, the SRC values on the windward walls increased toward the bottom of the wall. A similar increase was also observed on the windward gable roof near the roof ridge for $0^{\circ}$ wind direction. This phenomenon escalates the chances of water intrusion during failure of ridge elements or through ridge vents.

- Unlike the direct impinging raindrops deposition, for $45^{\circ}$ wind direction, the leading edge/corner regions of the buildings received less volume surface runoff rainwater, and the rainwater accumulation increased toward the far-end edges/corners of the facades. High magnitude of SRC were obtain on the leeward gable roof depicting curved pattern of high surface runoff rainwater flow which could be formed due to interaction of roof shape and wind flow. 
The RAF and SRC dataset can be used for estimation of WDR deposition on building façades as well as water intrusion through building envelope defects, openings, and breaches during tropical storms and hurricane wind-driven rain conditions. Moreover, the dataset can also be used for validation of numerical and/or computational fluid dynamics (CFD) methods to predict WDR deposition on building façades.

\section{References}

Aly, A. M., Chowdhury, A. G., and Bitsuamlak, G. (2011). "Wind profile management and blockage assessment for a new 12-fan Wall of Wind facility at FIU." Wind and Structures, 14(4), 1-16.

Baheru, T., Chowdhury, A. G., Bitsuamlak, G., and Tokay, A. (2012). "A parametric representation of wind-driven rain in experimental setups." Applied Technology Council and Structural Engineering Institute Conference (ATC \& SEI 2012) Advances in Hurricane Eingineering: Learning from our pastMiami, FL, 270-282.

Bitsuamlak, G. T., Dagnew, A., and Chowdhury, A. G. (2010). "Computational assessment of blockage and wind simulator proximity effects for a new full-scale testing facility." Wind and Structures, 13(1), 21-36.

Bitsuamlak, G. T., Gan Chowdhury, A., and Sambare, D. (2009). "Application of a fullscale testing facility for assessing wind-driven-rain intrusion." Building and Environment, 44(12), 2430-2441.

Blocken, B., and Carmeliet, J. (2002). "Spatial and temporal distribution of driving rain on a low-rise building." Wind and Structures, 5(5), 441-462.

Blocken, B., and Carmeliet, J. (2004). "A review of wind-driven rain research in building science." J. Wind Eng. Ind. Aerodyn., 92, 1079-1130.

Blocken, B., and Carmeliet, J. (2005). "High-resolution wind-driven rain measurements on a low-rise building - experimental data for model development and model validation." J. Wind Eng. Ind. Aerodyn., 93, 905-928.

Blocken, B., and Carmeliet, J. (2007). "Validation of CFD simulations of wind-driven rain on a low-rise building facade." Building and Environment, 42, 2530-2548.

Blocken, B., and Carmeliet, J. (2012). "A simplified numerical model for rainwater runoff on building facades: Possibilities and limitations." Building and Environment, 53(0), 59-73. 
Blocken, B., Derome, D., and Carmeliet, J. (2013). "Rainwater runoff from building facades: A review." Building and Environment, 60(0), 339-361.

Blocken, B., Dezsö, G., Beeck, J. v., and Carmeliet, J. (2010). "Comparison of calculation models for wind-driven rain deposition on building facades." Atmospheric Environment, 44, 1714-1725.

Choi, E. C. C. (1993). "Simulation of wind-driven rain around a building." J. Wind Eng. Ind. Aerodyn., 46\&47, 721-729.

Choi, E. C. C. (1994). "Determination of wind-driven rain intensity on building faces." $J$. Wind Eng. Ind. Aerodyn., 51, 55-69.

Chowdhury, A. G., Bitsuamlak, G. T., Fu, T.-C., and Kawade, P. (2012). "A study on roof vents subjected to simulated hurricane effects." Natural Hazards Review, ASCE, $12(4), 158-165$.

Dao, T. N., and Lindt, J. W. v. d. (2010). "Methodology for wind-driven rainwater intrusion fragilities for light-frame wood roof systems." Journal of Structural Engineering, ASCE, 136(6), 700-706.

FEMA (2005). "Mitigation Assessment Team Report - Hurricane Ivan in Alabama and Florida; Observations, Recommendations, and Technical Guidance." FEMA, ed.

FEMA (2005). "Summary Report on Building Performance, 2004 Hurricane Season." FEMA, ed., Federal Emergency Management Agency.

Fu, T.-C., Aly, A. M., Chowdhury, A. G., Bitsuamlak, G., Yeo, D., and Simiu, E. (2012). "A proposed technique for determining aerodynamic pressures on residential homes." Wind and Structures, 15(1), 27-41.

Ge, H., and Krpan, R. (2007). "Field measurement of wind-driven rain on a low-rise building in the coastal climate of British Columbia." 11th Canadian Conference on Building Science and TechnologyBanff, Alberta.

Ge, H., and Krpan, R. (2009). "Wind-driven rain study in the coastal climate of British Columbia." British Columbia Institute of Technology, Burnaby, British Columbia, 151.

Hangan, H. (1999). "Wind-driven rain studies. A C-FD-E approach." J. Wind Eng. Ind. Aerodyn., 81, 323-331.

Karagiozis, A., Hadjisophocleous, G., and Cao, S. (1997). "Wind-driven rain distributions on two buildings." Journal of Wind Engineering and Industrial Aerodynamics, 67-68(0), 559-572. 
Kubilay, A., Derome, D., Blocken, B., and Carmeliet, J. (2013). "CFD simulation and validation of wind-driven rain on a building facade with an Eulerian multiphase model." Building and Environment, 61(0), 69-81.

Nore, K., Blocken, B., Jelle, B. P., Thue, J. V., and Carmeliet, J. (2007). "A dataset of wind-driven rain measurements on a low-rise test building in Norway." Building and Environment, 42, 2150-2165.

Pita, G. L., Pinelli, J.-P., Cocke, S., Gurley, K., Mitrani-Reiser, J., Weekes, J., and Hamid, S. (2012). "Assessment of hurricane-induced internal damage to low-rise buildings in the Florida Public Hurricane Loss Model." Wind Eng. Ind. Aerodyn., 104$106,76-87$.

Richards, P. J., Hoxey, R. P., Connell, B. D., and Lander, D. P. (2007). "Wind-tunnel modelling of the Silsoe Cube." J. Wind Eng. Ind. Aerodyn., 95, 1384-1399.

Straube, J. F. (1998). "Moisure Control and Enclosure Wall Systems." University of Waterloo.

Straube, J. F. "Simplified prediction of driving rain on buildings: ASHRAE 160P and WUFI 4.0." Proc., Building Science Press, 1-16.

Straube, J. F., and Burnett, E. F. P. "Simplified prediction of driving rain on buildings." Proc., International Building Physics Conference, 375-382.

Tokay, A., Bashor, P. G., Habib, E., and Kasparis, T. (2008). "Raindrop size distribution measurements in tropical cyclones." Monthly Weather Review, American Meteorological Society, 136(May 2008), 1669-1685.

Van-Mook, F. J. R. "Full-scale measurements and numeric simulations of driving rain on a building." Proc., the 10th International Conference on Wind Engineering, 21-24.

Van-Mook, F. J. R. (2002). "Driving rain on building envelopes." Ph.D. Thesis, Building Physics Group (FAGO), Eindhoven University of Technology, Eindhoven University Press, Eindhoven, the Netherlands.

Van den Brande, T., Blocken, B., and Roels, S. (2013). "Rain water runoff from porous building facades: Implementation and application of a first-order runoff model coupled to a HAM model." Building and Environment, 64(0), 177-186.

Willis, P. T., and Tattelman, P. (1989). "Drop-size distributions associated with intense rainfall." J. Appl. Meter., 28, 3-15.

Yeo, D., and Chowdhury, A. (2013). "Simplified Wind Flow Model for the Estimation of Aerodynamic Effects on Small Structures." Journal of Engineering Mechanics, 139(3), 367-375. 
Yu, B., and Chowdhury, A. G. (2009). "Gust Factors and Turbulence Intensities for the Tropical Cyclone Environment." Journal of Applied Meterology and Climatology, 48(March), 534-552.

Yu, B., Chowdhury, A. G., and Masters, F. (2008). "Hurricane Wind Power Spectra, CoSpectra, and Integral Length Scales." Boundary Layer Meteorology, 129(3), 411-430. 


\section{ESTIMATION OF WIND-DRIVEN RAIN INTRUSION THROUGH BUILDING ENVELOPE DEFECTS AND BREACHES DURING TROPICAL CYCLONES}

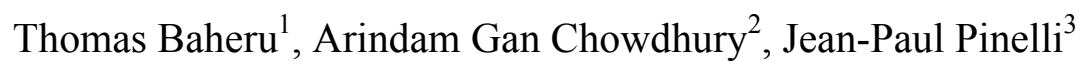

(A paper under review for the journal of Natural Hazards Review)

Abstract: Wind-driven rain (WDR) intrusion through building envelope defects and breaches is a major source of damage to building interior components and contents during hurricane landfall. The extent of total building interior damage (damage to building interior components, utility, and contents) is a function of the total volume of WDR intrusion which in turn is dependent on the size of openings, wind speed, and rain intensity. Currently, the volume of rainwater intrusion through a given opening on a building façade is estimated using a semi-empirical model with of parametric information based on engineering judgment. This paper presents a test-based WDR intrusion model which uses values of parameters developed through testing of building models under simulated WDR conditions. The model estimates the total volume of rainwater intrusion through an opening as a summation of WDR volume due to direct impinging raindrops and surface runoff rainwater from the undamaged envelope area. Test-based WDR intrusion data measured using a building model with envelope defects and breaches were used to validate the applicability of the new WDR intrusion model to full-scale buildings.

1 Doctoral Candidate, Dept. of Civil and Environmental Engineering and International Hurricane Research Center, Florida International University, 10555 West Flagler St., Miami, FL 33174. E-mail: tbahe001@fiu.edu

2 Associate Professor, Dept. of Civil and Environmental Engineering and International Hurricane Research Center, Florida International University, 10555 West Flagler St., Miami, FL 33174 (Corresponding Author). E-mail: chowdhur@,fiu.edu

3 Professor, Dept. of Civil Engineering, Florida Institute of Technology, 150 West University Blvd., Melbourne, FL 32901-6975. E-mail: pinelli@,fit.edu 
Comparison between model estimation results and WDR intrusion measurements through simulated window sill cracks and envelope breaches demonstrated reasonable agreement. The model presented herein can be used to predict the WDR intrusion and subsequent interior damage to low-rise buildings during tropical storms and hurricanes.

Keywords: Low-rise building; Raindrop size distribution; Surface runoff; Tropical cyclone; Wind-driven rain; Wall of Wind

\subsection{Introduction}

Wind-driven rain (WDR) intrusion through building envelope openings -including defects, breaches, and functional openings such as vents -- is a major source of damage to building interior components and contents during tropical storms and hurricanes (collectively termed as tropical cyclones). To date hurricane induced building damage models assess the total interior damage (damages to building interior components, utility, and contents) as a function of total volume of WDR intrusion through various openings (FEMA-HAZUS 2009; FPHLM-4.1 2011). Such damage models implement semiempirical WDR intrusion models to estimate the volume of rainwater ingress through openings on various components of a building envelope. However, these semi-empirical models rely on assumed values of WDR parameters (such as distribution of impinging rain: rain admittance factor (RAF), accumulation of surface runoff rainwater: surface runoff coefficients (SRC), etc.) to account for the various physical phenomena involved in WDR intrusion. The models usually use values for those parameters mainly derived based on engineering judgments. This is the cause of significant uncertainty in the estimation of the total volume of rainwater ingress and subsequent interior damage. Dao 
and Lindt (2010) proposed a mechanistic framework for WDR estimation that can be used to assess hurricane-induced building interior damage. Although this methodology has a merit of accounting for the two possible WDR intrusion mechanisms - impinging raindrops and surface runoff - in the model, documented data on the respective WDR parameters pertaining to tropical cyclone conditions are scarce, if any. Moreover, the model at its preliminary stage can only be applied to a certain configuration of the envelope openings such as major roof deck breaches. The current study developed a WDR estimation model that can be applied to most possible types of envelope openings using the previously suggested basic formulation by Dao and Lindt (2010) in conjunction with experimental investigation of rainwater intrusion under hurricane WDR conditions.

Development of WDR intrusion model relies on identifying the basic attributes that define the physical process of WDR intrusion. The three attributes that define hurricane induced WDR intrusion in buildings are presence of pathways, mechanism of rainwater intrusion, and driving force (Beall 2000; Straube 1998). The pathways for WDR intrusion could be: (1) building envelope defects such as poorly sealed edges of windows and doors, poorly fitted plumbing and electrical units, unsealed expansion joints, door thresholds, and time-dependent wall cracks (Mullens et al. 2006; Pita 2012); (2) existing openings such as roof and soffit vents (Chowdhury et al. 2012; Jesteadt et al. 2007); and (3) envelope breaches caused by high wind pressure and/or impact of windborne debris (Cope 2004; Masters et al. 2010). Having the path for rainwater intrusion, the mechanisms by which WDR enters in to the building interior determines the total volume of rainwater intrusion. Passage of impinging raindrops through the opening and accumulation of surface runoff rainwater are the two possible mechanisms of rainwater 
ingress in to the building interior (Dao and Lindt 2010). The rainwater ingress volumes from direct impinging rain and surface runoff rainwater at a given location on a building façade are characterized by the rain admittance factor (RAF) and surface runoff coefficient (SRC), respectively (Blocken and Carmeliet 2012; Straube and Burnett 2000). The wind induced inertial force is the main driving force along with gravitational and viscous forces dictating raindrops trajectories and intrusion of rainwater through an opening. The turbulent wind plays an important role in the formation of the flow patterns of deposited WDR on building façade, affecting the distribution of impinging raindrops deposition and accumulation of surface runoff rainwater (Baheru et al. 2013). Moreover, the wind induced pressure difference across the opening drives in the WDR together with air resulting in significant rainwater intrusion in to the building interior especially in case of smaller openings such as envelope defects and exposure of roof underlayment to hurricane WDR (Bitsuamlak et al. 2009; Dao and van de Lindt 2012).

WDR intrusion models use the WDR deposition models combined with area of openings to estimate the rate and volume of rainwater ingress. Numerous models have been developed and used in the past, to estimate WDR deposition at specific locations on a building façade. The three most common WDR models are the two semi-empirical models provided by International Organization for Standardization 15927-3 (ISO 2009) and Straube and Burnett (2000) and the computational fluid dynamics (CFD) based model first developed by Choi (1994) and later revised by Blocken and Carmeliet (2005). Detailed review and comparison of these models were presented by Blocken and Carmeliet (2010). Although the models have important differences in their formulation, they use the same basic framework to quantify the volume of impinging rain on the 
building façade based on wind speed, wind direction, rain intensity, and building shape. Pita et al. (2012) used the WDR model by Straube and Burnett (2000) to estimate the volume of WDR intrusion through various openings on the building envelope and predicted the expected total building interior damage during hurricanes. In the absence of field and experimental data, the WDR intrusion model by Pita (2012) implemented simplified assumptions and adjustment factors to account for the various factors affecting the WDR intrusion in buildings during storms. For this reason the model estimated the total volume of rainwater ingress through a given opening on a building façade using assumed rain admittance factors irrespective of the change in wind direction, and a single value of the surface runoff coefficient irrespective of opening location and wind direction. A more realistic WDR intrusion model was implemented by Dao and van de Lindt (2012) taking in to consideration the direct impinging rain falling onto the opening area, as well as surface runoff rainwater from the upstream undamaged envelope area. The model used direct impinging and surface runoff coefficients estimated using CFD schemes suggested by Choi (1993). However, it was indicated that the accuracy of the model was somehow debatable and that there is a need to investigate the model parameters experimentally (Dao and Lindt 2010).

Based on the basic formulation by Dao and Lindt (2010)), this paper presents the development of a test-based WDR intrusion model which can be used to estimate the WDR intrusion through envelope defects and breaches during tropical storms and hurricanes. The new model quantifies the WDR intrusion based on opening types and uses experimental data of model parameters based on 12-fan Wall of Wind wind-drivenrain testing (Baheru et al. 2013). This WDR intrusion model can be implemented in 
hurricane induced building damage models to predict the total building interior damage and subsequent economic loss. Section 2 presents the development of the WDR intrusion model for various types of openings that cause WDR intrusion in buildings. Section 3 describes the methodology used to develop test-based data of rain admittance factors (RAF) and surface runoff coefficients (SRC) distributions on a scaled building model as well as full-scale WDR intrusion measurements for model validation purposes. Section 4 presents the characterization of WDR intrusion model parameters (RAF and SRC) for a gable-roof building based on the scaled model testing and compares the WDR intrusion volume predicted by the model to the actual volume measured in full-scale experiments. The conclusions of the study along with summarized major findings are presented in Section 5 .

\subsection{Wind-driven rain intrusion model}

The total volume of WDR intrusion through a given opening on a building envelope is calculated as (Dao and Lindt 2010)

$$
V_{t o t}=V_{D I}+V_{S R}
$$

where, $V_{\text {tot }}$ is the total volume of rainwater intrusion through a given opening, and $V_{D I}$ and $V_{S R}$ are WDR intrusion due to direct impinging raindrops and surface runoff, respectively. Though the basic formulation of the WRD intrusion (Eq. 1) is similar for any opening type, the following subsections present separate WDR estimation models as applicable to defects and breaches in the building envelope. 


\subsubsection{WDR intrusion through envelope defects}

Envelope defects are characterized as small opening areas randomly distributed over the entire building surface. Many factors can contribute to the size of the total envelope defect area of a building including age of building, construction practice, type of building material used (based on local building code requirements), maintenance, and weather conditions. In the past, WDR intrusion through envelope defects caused significant damages to interior components of buildings during tropical cyclones especially in case of tropical storms and Category 1 hurricanes without any noticeable external envelope damage (FEMA 2005; Mullens et al. 2006). This suggests that there is a need to investigate the WDR intrusion through defects even for lower wind speeds. Although the opening areas of the defects are usually very small compared to major breaches and openings, the continuous supply of rainwater through surface runoff and the development of high pressure differences across the opening could drive in significant rainwater volume through defects. Therefore, in the current study, it is hypothesized that the major portion of rainwater intrusion through defects is due to the surface runoff rainwater in which a film of surface rainwater is pushed into the building interior by pressure difference across the opening. In addition, a smaller fraction of the total WDR intrusion through a defect is also contributed by raindrops directly impinging onto the defect area. Therefore, the total WDR intrusion through defects using Eq. 1 can be expressed as

$$
V_{\text {tot }}=f_{v} \cdot R A F \cdot I R \cdot A_{d e f}+S R C \cdot I R \cdot A_{S R}
$$


where $I R$ is the total amount of free-field WDR (free-field impinging rain) per unit vertical area measured during the duration of the event. $I R$ can be estimated by integrating the WDR rate measurement for the length of the storm duration. The WDR rate is a function of wind speed and for the current study the measurement was referenced to the wind speed at the mean-roof-height of the test building. $A_{d e f}$ is the defect area, and $A_{S R}$ is the reference surface runoff area as discussed in subsection 4.2. The factor, $f_{v}$, is called the velocity ratio, which is the ratio of the wind speed through the defect area to that of the free-stream wind speed, accounting for the increased speed of air as it passes through the tiny defect areas. The effect of increase in wind speed due to the presence of envelope opening mainly affects the trajectory of impinging raindrops and the factor is only applicable to the volume of rainwater intrusion from impinging rain. The velocity ratio is a function of the pressure loss across the defect opening and is estimated based on a simplified empirical equation of flow passing through a porous plate (Freid and Idelchik 1989):

$$
f_{v}=\frac{V_{d e f}}{V}=(K+1)^{1 / 2}
$$

where $K$ is the pressure loss factor as the wind passes through the defect area and is calculated as a function of the envelope porosity, $P=A_{d e f} / A ; A$ is surface area of building component on which the defect is located.

$$
K=\frac{1}{P^{2}}\left(\left(\frac{1-P}{2}\right)^{1 / 2}+(1-P)\right)^{2}
$$




\subsubsection{WDR intrusion through envelope breaches}

For envelope breaches and functional openings, the formulation of the WDR intrusion equation was developed based on the assumption that there will be pressure equalization due to the large area of opening as compared to defect area. Therefore, the velocity ratio is assumed to be unity and the two components of WDR intrusion in Eq. 1 for the case of breaches and functional openings are estimated as

$$
V_{t o t}=R A F \cdot I R \cdot A_{b}+S R C \cdot I R \cdot A_{S R}
$$

where $A_{b}$ is the area of breach or opening.

\subsection{Development of test-based WDR intrusion data}

The test-based WDR data required to facilitate the use and validation of WDR estimation models were developed in two stages. In the first stage, model parameters (RAF and SRC) data were obtained by testing a large-scale building model under simulated hurricane WDR condition. Validation data of rainwater intrusion through different types of envelope openings were collected in the second stage using full-scale measurements. The subsequent subsections discuss the building models and details of test setups.

\subsubsection{Building model for RAF and SRC measurements}

The test-based RAF and SRC data were obtained using a 1:4 gable-roof building model built of double acrylic walls and roof elements attached to an internal wooden framing system (see Fig. 4.1). The model had base plan dimensions of $1.52 \times 2.30 \mathrm{~m}^{2}$ $\left(5.0 \times 7.5 \mathrm{ft}^{2}\right)$ and eave height of $0.76 \mathrm{~m}(2.5 \mathrm{ft})$. The slope of the gable roof was 5:12 
with overhang length of $7.62 \mathrm{~cm}$ ( 3.0 in) on all sides. The length scale was selected based on blockage limitations for an open jet facility. The maximum blockage of $10 \%$, considering diagonal wind angle for the current testing, was lower than the tolerable limit of $16 \%$ as estimated for the 12 -fan Wall of Wind open-jet facility by Bitsuamlak et al. (2010) and Aly et al. (2011). The double acrylic wall and roof claddings were designed with grid-format of openings used to mount WDR collecting gauges developed specifically for the current study. Two types of custom-made WDR collecting gauges were used to capture the direct impinging raindrops and surface runoff rainwater separately. A total of 92 gauges were installed over the entire building surface with even distribution as shown in Figure 4.1. Fifteen gauges, 3 rows by 5 columns of gauges, were located on each building façade with an additional gauge used on each gable-end wall. The gauges were connected to labeled water collecting containers/beakers inside the building using a $12.7 \mathrm{~mm}(0.5 \mathrm{in})$ diameter drainage plastic tube. The measurement was conducted by weighing the volume of rainwater in the beakers after each test. The testbased RAF and SRC data developed using the scaled building model are presented in Section 4 .

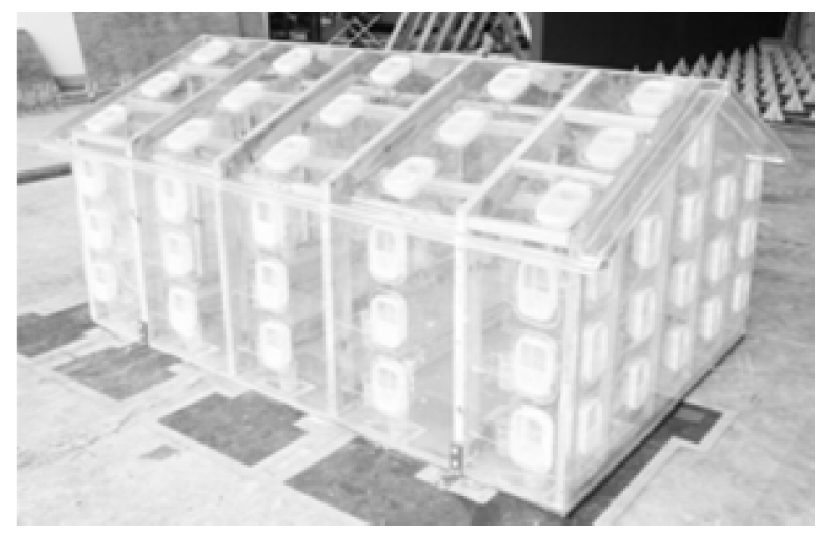

Figure 4.1 Large-scale building model with WDR collecting buckets 


\subsubsection{Building model for WDR intrusion volume measurements}

Data on rainwater intrusion volume through various types of openings were collected on a building model (Fig. 4.2a) built with common type of building materials. The building model was built of wooden framing draped with $1.6 \mathrm{~cm}(0.625$ in) thick plywood sheathing and covered with fiberglass insulation and gypsum board from inside and vapor barrier paper and vinyl siding from outside. The model had plan dimensions $2.4 \times 2.75 \mathrm{~m}^{2}\left(8.0 \times 9.0 \mathrm{ft}^{2}\right)$ and eave height $2.3 \mathrm{~m}(7.50 \mathrm{ft})$. The 5:12 sloped roof was covered with shingles and provided with a $30 \mathrm{~cm}(1 \mathrm{ft})$ long overhang on all sides. The selection of the building model dimensions was dictated by the need to keep a building shape similar to the scaled building model used for RAF and SRC study, but was constrained by the limitation of the flow field size of the Wall of Wind (WOW). The rainwater intrusion volumes, for validation of the WDR estimation model presented in this paper, were measured by simulating window sill cracks (envelope defect) and wall and roof deck breaches. The wall breaches were simulated by removing the lower panels of the two windows, which had areas of $45.7 \times 17.8 \mathrm{~cm}^{2}\left(18.0 \times 7.0 \mathrm{in}^{2}\right)$ and $40.6 \times 12.7$ $\mathrm{cm}^{2}\left(16.0 \times 5.0 \mathrm{in}^{2}\right)$ on walls parallel and perpendicular to the ridge line, respectively (see Fig 4.2a). The roof deck breach was simulated on the windward gable roof as shown in Fig. $4.2 \mathrm{c}$ and had opening size of $40.6 \times 68.6 \mathrm{~cm}^{2}\left(16.0 \times 27.0 \mathrm{in}^{2}\right)$. In addition to wall and roof deck breaches, separate window panels were designed with various widths of window sill cracks to simulate envelope defect on a separate test setup (see Fig 4.3a). 

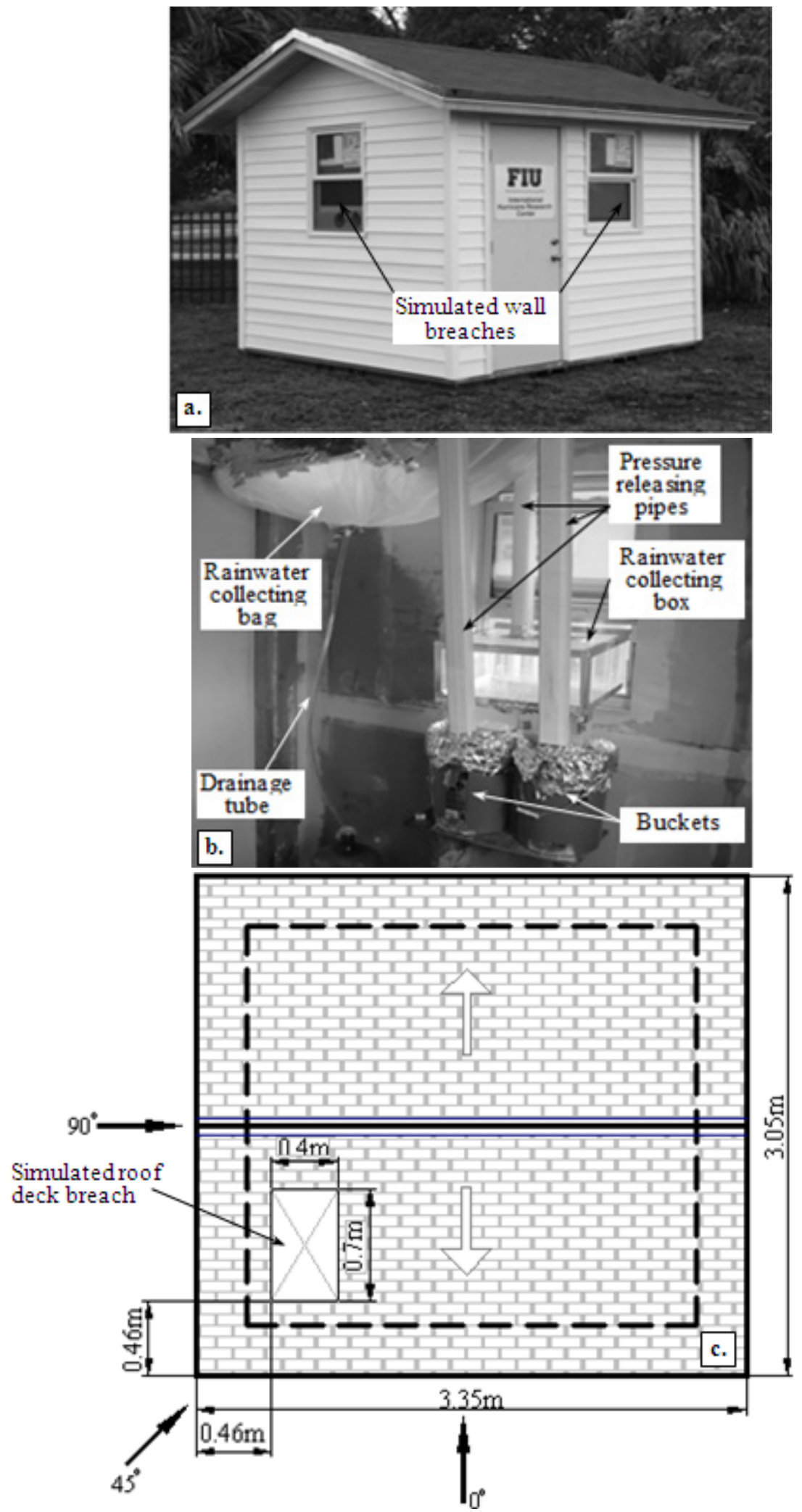

Figure 4.2 (a) Full-scale building model; (b) Rainwater collecting system inside the building model; (c) Roof layout and dimensions of simulated roof deck breach. 
The tests for WDR intrusion through simulated envelope openings were performed for direct impinging rain and surface runoff rainwater intrusion separately. A $10 \mathrm{~mm}(0.4 \mathrm{in})$ thick acrylic strip installed above the openings was used to divert the surface runoff rainwater during direct impinging rain intrusion measurements. The volume of rainwater due to the surface runoff only was then determined as the difference between the volumes from the two measurements (measurement without and with acrylic strip). Custom designed rainwater collecting box connected to two buckets using plastic drainage tubes were installed inside the building to collect WDR intrusion through simulated wall and roof deck breaches. The boxes and the buckets were connected to pipes that released the pressure development within them to the interior of the test building (see Fig 4.2b). Allowing the flow of wind to building interior using those pipes made it possible to create realistic pressure differences across the simulated wall and roof deck breaches. Such provision of allowing realistic pressure difference formation across openings during WDR intrusion measurements was noted by Chowdhury et al. (2012) and Bitsuamlak et al. (2009) as important to the accuracy of the total volume of rainwater intrusion measurements. This was accomplished by introducing five holes on the water collecting box in case of simulated window sill cracks (see Fig 4.3b). The total area of the holes was made to be approximately equal to the crack area in order to ensure the realistic wind inflow and pressure differences across the cracks. The weights of the rainwater collected in the buckets were recorded after each test. 

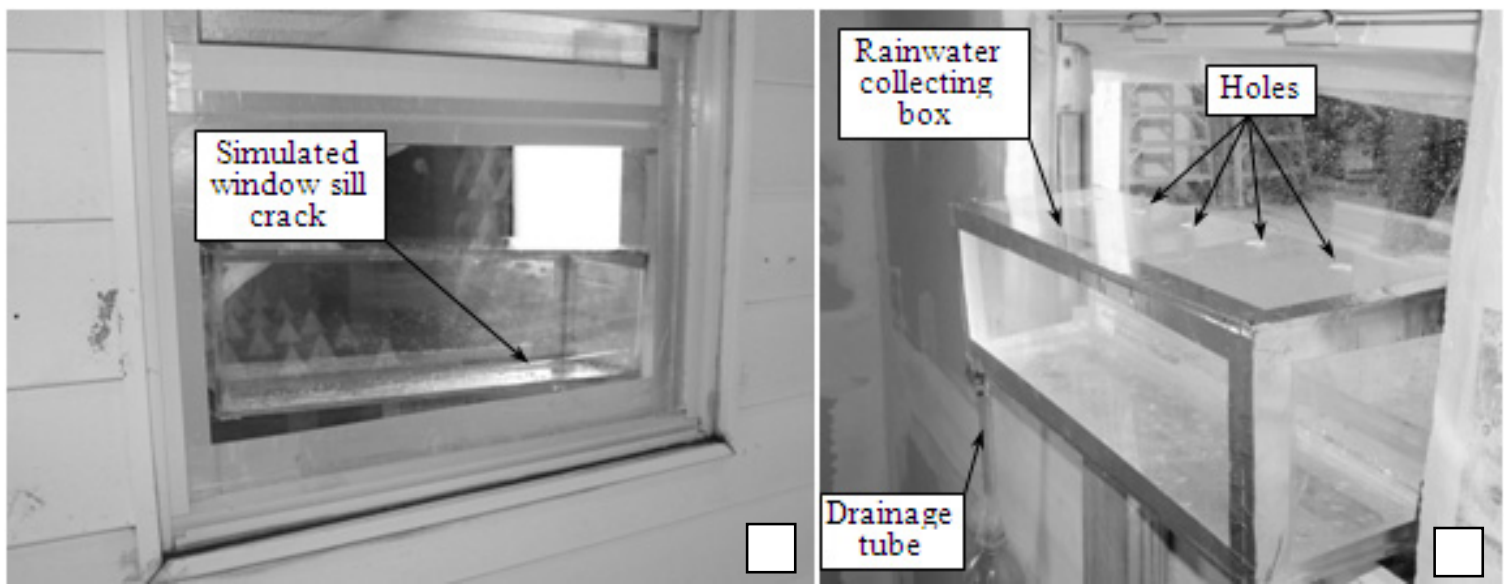

Figure 4.3 (a) Simulated window sill crack; (b) WDR measurement system.

\subsubsection{2-fan Wall of Wind Flow and WDR characteristics}

The tests on large- and full-scale building models to acquire WDR intrusion data were conducted using the 12-fan Wall of Wind (WOW) facility at FIU. The 12-fan WOW is capable of simulating hurricane wind speed and associated tropical cyclone WDR. Twelve fans each driven by $522 \mathrm{KW}$ (700 horse-power) electric motor and arranged in two-rows of convex arc produce air flow field $(6.10 \mathrm{~m}(20 \mathrm{ft})$ wide and 4.28 m (14 ft) high) large enough to test low-rise building models at large scale. The wind flow produced from each fan merges into a contraction zone designed to generate a laterally uniform flow field with desired high wind speed. Vertical flow straighteners installed at the exit of the contraction zone direct the flow in the longitudinal direction. A $9.75 \mathrm{~m}$ (32ft) long flow simulation box downstream of the contraction zone confines the air flow and provides the required fetch length to develop the desired atmospheric boundary layer (ABL) flow characteristics. Triangular spires and floor roughness elements, designed through rigorous trial-and-error experimentation, generate the flow 
turbulence and power-law mean wind speed profile representing $\mathrm{ABL}$ wind flow $(\mathrm{Fu}$ 2013). Figure 4.4 shows the schematic view of 12 -fan WOW.

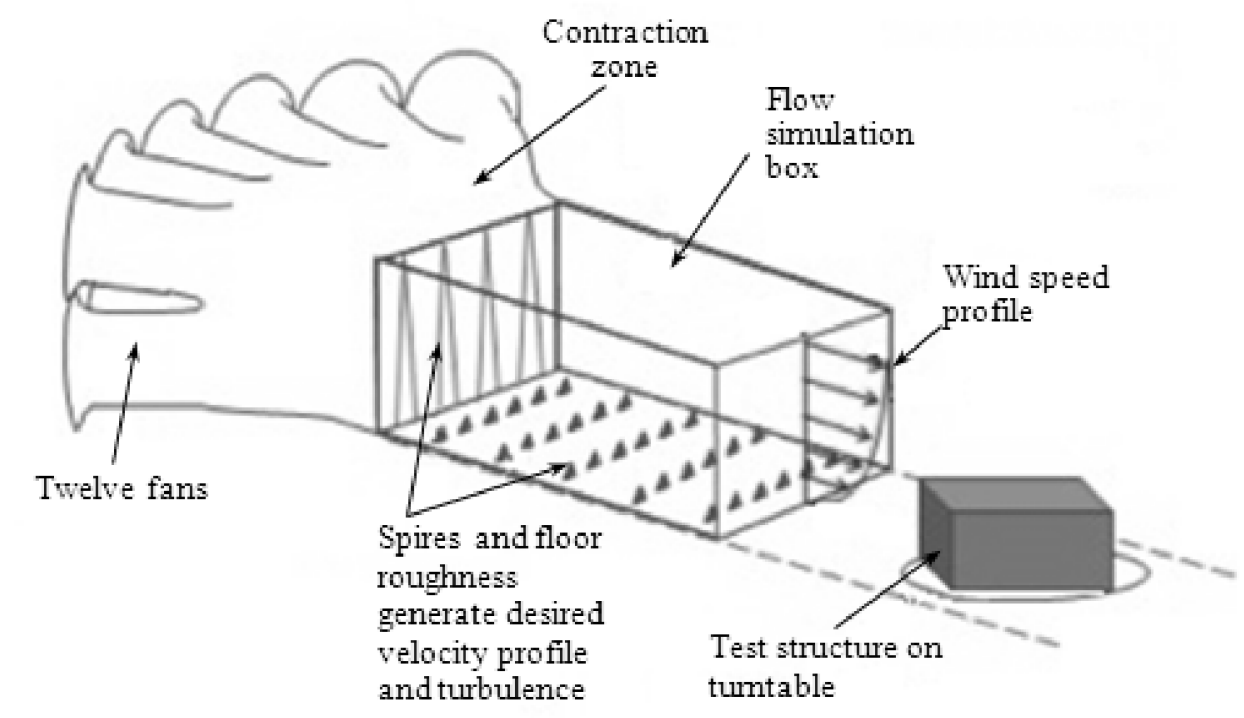

Figure 4.4 Schematic-diagram of 12-fan Wall of Wind (WOW).

Suburban terrain wind profile with target power-law coefficient of $\alpha=1 / 4.0$ was simulated in the experimental setup for acquiring WDR intrusion data using the largeand full-scale building models. The wind speed and turbulence intensity measurements were conducted using a vertical rake system built specifically for wind measurement purposes. The rake system consisted of pressure tubes mounted at various elevations on a vertical mast in the wind field and connected to a 16-channel Scanivalve DSA pressure scanner to record differential pressure time histories that were converted to instantaneous wind speeds. In addition to the pressure sensors, eight Cobra Probes were mounted on the measurement mast to capture the turbulence characteristics of the flow in the three major directions. Figure 4.5 shows the wind profile measurement setup with measurement rake placed at the testing section (at $6.10 \mathrm{~m}$ (20ft) from the exit of the flow simulation box). 
Wind speed measurements at the WOW indicated a close match between target and simulated wind speed profiles. Figure 4.6 presents the simulated wind speed and turbulence intensity profiles at the centerline of the flow field as compared to the target suburban profiles. The centerline mean wind speed (for 50\% throttle of the fans' motor power used in the current study) was $27.40 \mathrm{~m} / \mathrm{s}(61.30 \mathrm{mph})$ at the mean-roof-height of the large-scale test building $(\mathrm{z}=0.91 \mathrm{~m}(3.0 \mathrm{ft}))$. The power-law coefficients at the center of the flow field was found to be $\alpha=1 / 4.21$. Longitudinal turbulence intensity of $13.93 \%$ was obtained at the mean-roof-height, $\mathrm{z}=0.91 \mathrm{~m}(3.0 \mathrm{ft})$. The WOW turbulence intensity was lower than the target value due to the missing low frequency fluctuations in the flow field. The use of such partial turbulence simulation method, focusing mainly on correctly simulated high frequency turbulence fluctuations, has been proven to be adequate for aerodynamic testing of large-scale low-rise building models such as that of the Texas Tech building and Silsoe cubic building (Freid and Idelchik 1989; Fu et al. 2012; Richards et al. 2007; Yeo and Chowdhury 2013)

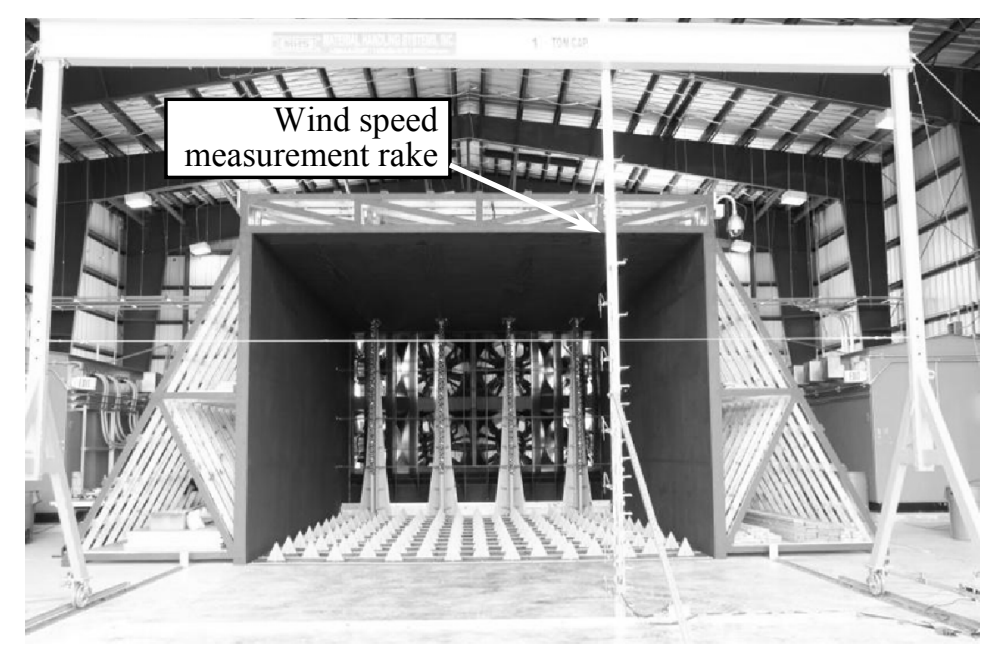

Figure 4.5 12-fan Wall of Wind (WOW) wind speed measurement rake in place. 


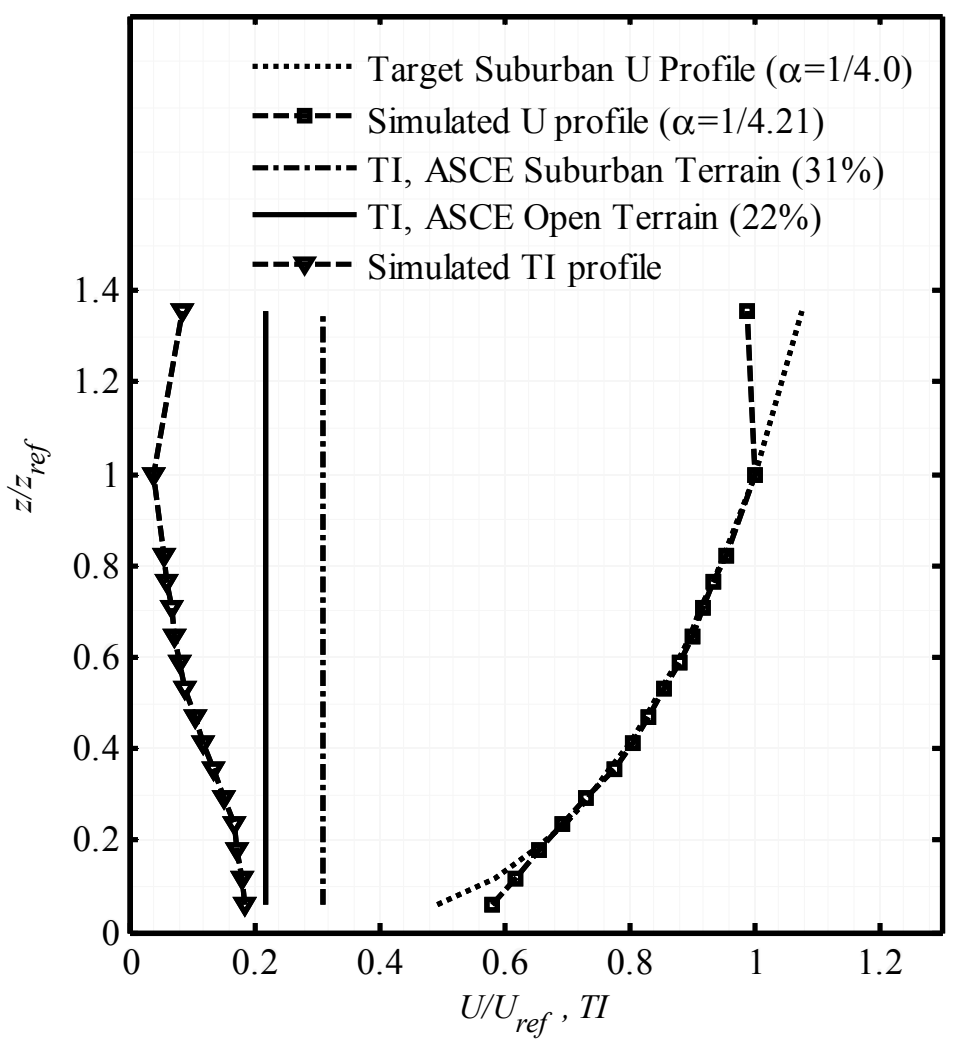

Figure 4.6 Simulation of atmospheric boundary layer: Wind speed and turbulence intensity profile.

The tropical cyclone WDR generating device at the 12-fan WOW is made of a plumbing system consisting of four vertical lines of spray nozzles attached to the front of the frame supporting the spires (see Fig. 4.7). The pipelines are fed from a common horizontal pipe running over the top of the flow simulation box. The horizontal pipe is connected to a main water supply line of diameter $50.8 \mathrm{~mm}$ (2.0 in), supplying water at a constant rate of about $5 \mathrm{~m}^{3} / \mathrm{hr}$ and pressure of $345 \mathrm{KPa}$ (50 psi). Equally spaced TeeJet 8008 - E full cone spray nozzles installed along the length of the vertical lines spray raindrops at the desired rain rate.

The target raindrop size distribution (RSD) for the simulation of tropical cyclone (TC) WDR at WOW was derived from RSD data collected during Hurricane Alex, 
Charley, and Gaston (2004) through Tropical Rainfall Measuring Mission (TRMM) at Wallops station, Wallops Island, Virginia (Tokay et al. 2008). The field RSD data were modeled using three-parameter gamma distribution for which the parameters were obtained using the probability plot correlation coefficient (PPCC) method. Detailed procedures for (1) estimation of target WDR rate based on target RSD and horizontal rain rate, and (2) selection of type and number of nozzles including investigation of the adequacy of the simulated WDR for aerodynamic testing of building models was reported by Baheru et al. (2012). Figure 4.8 shows comparison between dimensionless form of simulated RSD measured at centerline of the flow field and target RSD based on field data and gamma model suggested by Willis and Tattelman (1989). The dimensionless form of the gamma model of raindrop size distribution $(N(D))$ equation is shown in Figure 4.8, where $m$ is the shape parameter; $N_{w}$ is number concentration; $D_{\text {mass }}$ is the mass-weighted mean diameter. The simulation of RSD of TC WDR using the 12-fan WOW demonstrated close match to the target RSD for wide range of normalized raindrop size (for range of $0.5 \leq D / D_{\text {mass }} \leq 1.5$ ) ensuring the representation major portion of concentration of raindrops. Mean shape parameters of 4.0 was obtained at the centerline of the flow field as compared to the mean target shape parameter of $m=6.50$ (within one-half of standard deviation about the mean value). The number concentration, $\log _{10} N_{w}$ and mass-weighted mean diameter, $D_{\text {mass }}$, at centerline of the flow filed (point P1) were obtained as 6.204 and 0.458 compared to the mean target value of $\log _{10} N_{w}=$ 6.41 and $D_{\text {mass }}=0.44$, respectively. 


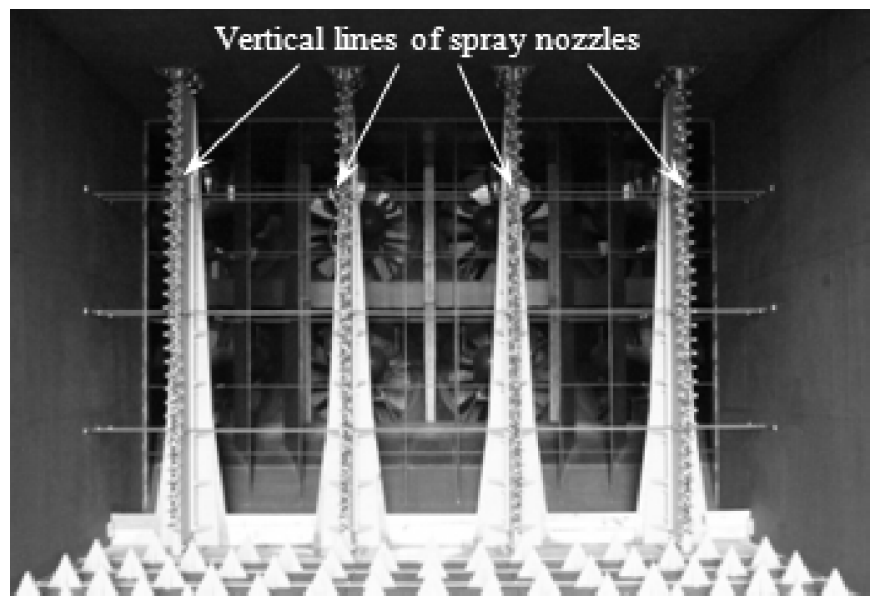

Figure 4.7 12-fan Wall of Wind (WOW) TC WDR generating spray nozzles layout.

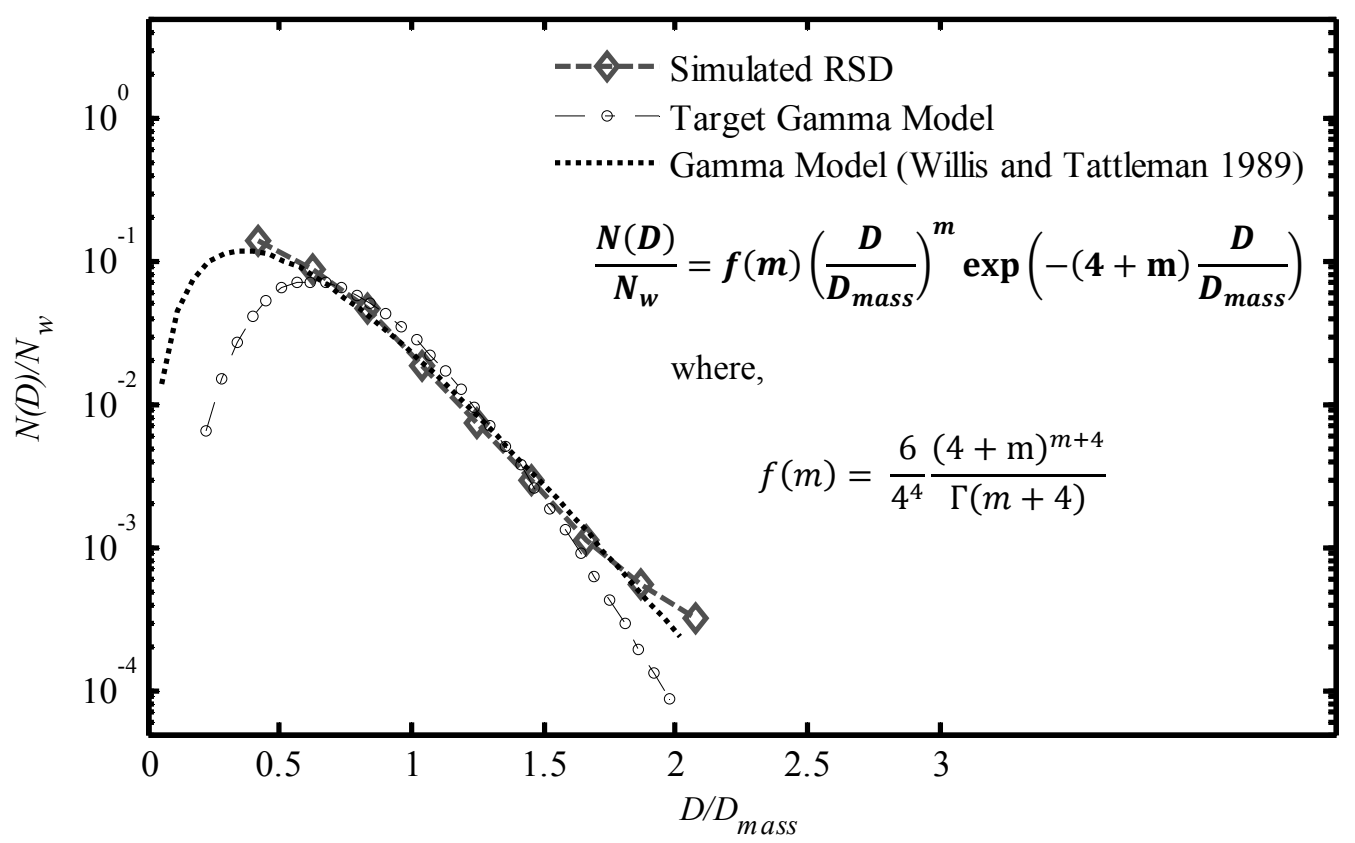

Figure 4.8 RSD of simulated WDR.

\subsubsection{Test protocol}

A total of 21 tests were performed in the first stage using the scaled building model to acquire RAF and SRC data for three major wind direction. Table 4.1 summarizes the detail test parameters used during the tests. The tests were conducted at mean wind speed of $26.50 \mathrm{~m} / \mathrm{s}(60.0 \mathrm{mph})$ and WDR rate of $376.0 \mathrm{~mm} / \mathrm{hr}(14.80 \mathrm{in} / \mathrm{hr})$ 
measured at the buildings' mean roof height. Owing to the plan symmetry of the test building, three wind directions were considered: $0^{\circ}, 45^{\circ}$, and $90^{\circ}$. The volume of direct impinging rain for a given wind direction on the building was quantified at once by installing the measurement gauges over the building surface. However, the surface runoff rainwater for each wind direction was measured by installing the gauges in a row at a given height at which the runoff is sought and keeping all other openings closed to avoid measurement interference of gauge measurements at different heights. Accordingly, six rows of gridlines (heights on the building facade) of runoff bucket locations were considered for each wind direction, of which the three row-heights were on the building walls while the remaining three rows were located on the roof surface.

Table 4.1 Rain admittance factor and surface runoff coefficient test parameters

\begin{tabular}{lccccc}
\hline Test Type & Gauge Location & $\begin{array}{c}\text { Wind Speed } \\
(\mathbf{m} / \mathbf{s})\end{array}$ & $\begin{array}{c}\text { WDR Rate } \\
(\mathbf{m m} / \mathbf{h r})\end{array}$ & Wind Direction & $\begin{array}{c}\text { Number } \\
\text { of tests }\end{array}$ \\
\hline RAF & All & 26.50 & 376.0 & $0^{\circ}\left(360^{\circ}\right), 45^{\circ}, 90^{\circ}$ & 3 \\
SRC & grid i (i=1 to 6) & 26.50 & 376.0 & $0^{\circ}\left(360^{\circ}\right), 45^{\circ}, 90^{\circ}$ & 18 \\
\hline
\end{tabular}

In the second stage of the test, the WDR intrusions through envelope defects and breaches were measured at full-scale using the test matrices shown in Table 4.2. Higher wind speeds of $35.5 \mathrm{~m} / \mathrm{s}(80 \mathrm{mph})$ and $44.6 \mathrm{~m} / \mathrm{s}(100 \mathrm{mph})$ were used for tests of rainwater intrusion through window sill cracks and envelope breaches to represent realistic WDR intrusions during tropical storm and hurricane conditions. The envelope damages in the current study represented $5.4 \%$ and $2.3 \%$ for roof deck and wall breaches, respectively. The WDR intrusion through window sill crack (length: $45.8 \mathrm{~cm}$ (18.0 in)) was measured for three crack widths of $0.5,1.0$, and $2.0 \mathrm{~mm}$. Only $0^{\circ}$ wind direction was 
considered for WDR intrusion through cracks and the rainwater intrusion through wall and roof deck breaches were measured $0^{\circ}$ and $45^{\circ}$ wind directions. All the tests were conducted for 5 minutes test duration.

Table 4.2 Test matrices for WDR intrusion envelope defects and breaches

\begin{tabular}{lccccc}
\hline $\begin{array}{l}\text { Envelope } \\
\text { Opening }\end{array}$ & Opening Size $\left(\mathbf{c m}^{2}\right)$ & $\begin{array}{c}\text { Wind Speed } \\
(\mathbf{m} / \mathbf{s})\end{array}$ & $\begin{array}{c}\text { WDR Rate } \\
(\mathbf{m m} / \mathbf{h r})\end{array}$ & Wind Direction & $\begin{array}{c}\text { Number } \\
\text { of tests }\end{array}$ \\
\hline Roof deck breach & 2785.0 & 44.60 & 223.5 & $0^{\circ}\left(360^{\circ}\right), 45^{\circ}$ & 4 \\
Wall breach & 814.0 and 516.0 & 44.60 & 223.5 & $0^{\circ}\left(360^{\circ}\right), 45^{\circ}$ & 4 \\
Window sill crack & Width $=0.5,1.0,2.0 \mathrm{~mm}$ & 35.50 & 223.5 & $0^{\circ}\left(360^{\circ}\right)$ & 6 \\
\hline
\end{tabular}

\subsection{Results and discussion}

\subsubsection{Rain admittance factors (RAFs)}

The rain admittance factors (RAFs) on the surfaces of the gable-roof building were obtained from the measurements of WDR deposition as a result of direct impinging rain. The RAFs were quantified as normalized rate of rainwater deposition where the free-field WDR rate measured at the mean-roof-height of the test building, $R R_{v}$, was used as a reference rain rate (see Eq. 6).

$$
R A F=\frac{R R_{b, D I}}{R R_{v}}
$$

where $R R_{b, D I}$ is the rate of WDR deposition at a given location on the building façade due to direct impinging raindrops quantified as

$$
R R_{b, D I}=\frac{V_{b, D I}}{A_{o} \cdot t}
$$


where $V_{b, D I}$ is the volume of rainwater deposition as a result of direct impinging raindrops for the test duration of $t$. $A_{o}$ is the opening area of the measurement gauge. Figures 4.9a-c show the contour and RAF zonation plots for the three wind directions. The zonations plot provided the mean and standard deviation (StDev) of RAF value for each zone based on the spatial distribution of RAF values within the zone area. The blank façades in the plots indicate that no measurable rainwater volume was collected on those façades during the tests. The RAF zonations following the pattern of direct impinging raindrops deposition were developed on the basis of keeping the StDev minimum within each zone (the maximum StDev was 0.20). The mean and StDev of RAF values were used in the current study to facilitate the prediction of WDR intrusion using the new WDR estimation model.

The RAF measurements indicated that, for all wind directions, the windward building façades were exposed to high concentration of impinging rain while the leeward faces received little raindrops. Due to high spatial variability of the RAF values on the windward wall, for $0^{\circ}$ wind direction, three zones were introduced with RAF (mean, StDev $)=(0.3,0.18),(0.6,0.12)$, and $(0.8,0.08)$ located at the bottom, mid-height, and top of the wall, respectively (see Fig. 4.9a). A relatively higher dispersion of 0.18 was noted for the bottom zone due to the increase in impinging rain deposition at the middle section of the bottom zone. On the contrary, the RAF values on the windward gable roof depicted lower spatial variation and two zones were assigned with RAF of (mean, StDev) $=(0.2,0.10)$ and $(0.3,0.15)$ for eave and ridge regions, respectively (see Fig 4.9a). For the $45^{\circ}$ wind direction, the leading edge/corner zones had relatively higher mean RAF values of $($ mean, $\mathrm{StDev})=(0.5,0.15)$ and the values decreased to $($ mean, $\mathrm{StDev})=(0.3$, 
$0.15)$ and $(0.4,0.12)$ for the remaining far-end zones (see Fig 4.9b). Maximum mean RAF values of $($ mean, StDev $)=(1.0,0.10)$ and $(0.9,0.1)$ were obtained on the gable-end wall for wind directions of $45^{\circ}$ and $90^{\circ}$. This provided a reason for the high vulnerability of building interior components due to rainwater intrusion through failure of gable-end walls during past hurricanes (FEMA 2005). Similar to the $0^{\circ}$ wind direction, the windward wall in case of $90^{\circ}$ wind direction was assigned with three zones in which the mean RAF value decreased from top to bottom (see Fig 4.9c). The entire gable roof was exposed to a minimum mean RAF value of 0.05 to 0.20 with lower spatial dispersion of 0.1 to 0.2 for $45^{\circ}$ and $90^{\circ}$ wind directions, respectively. 


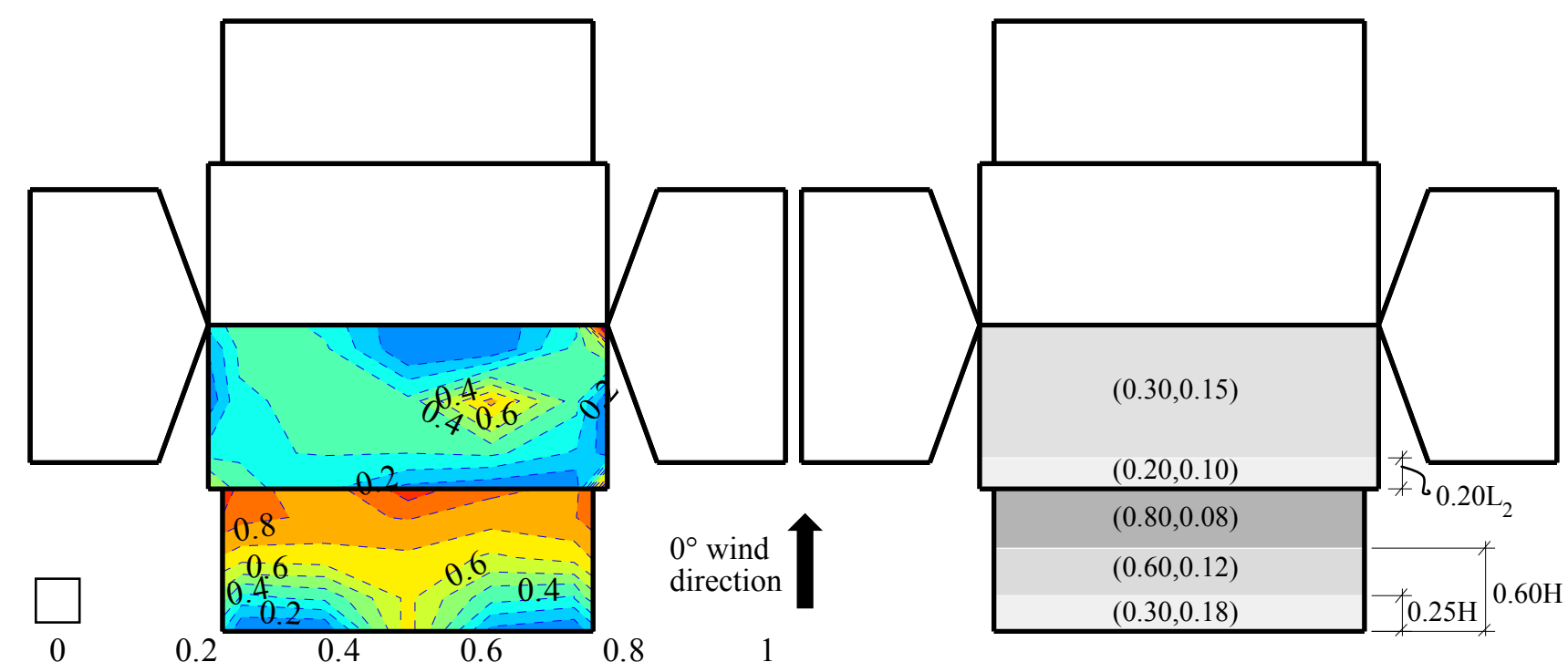




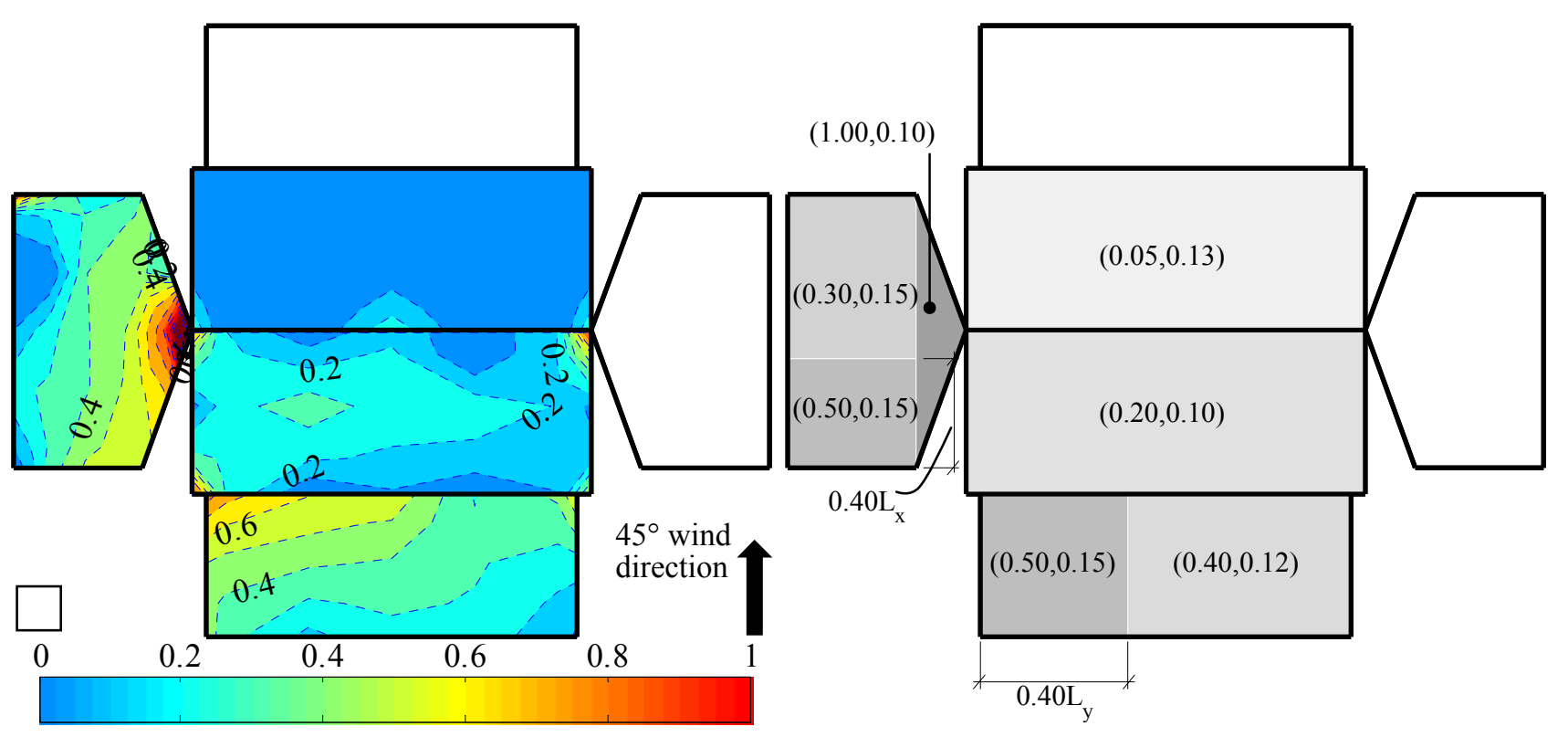




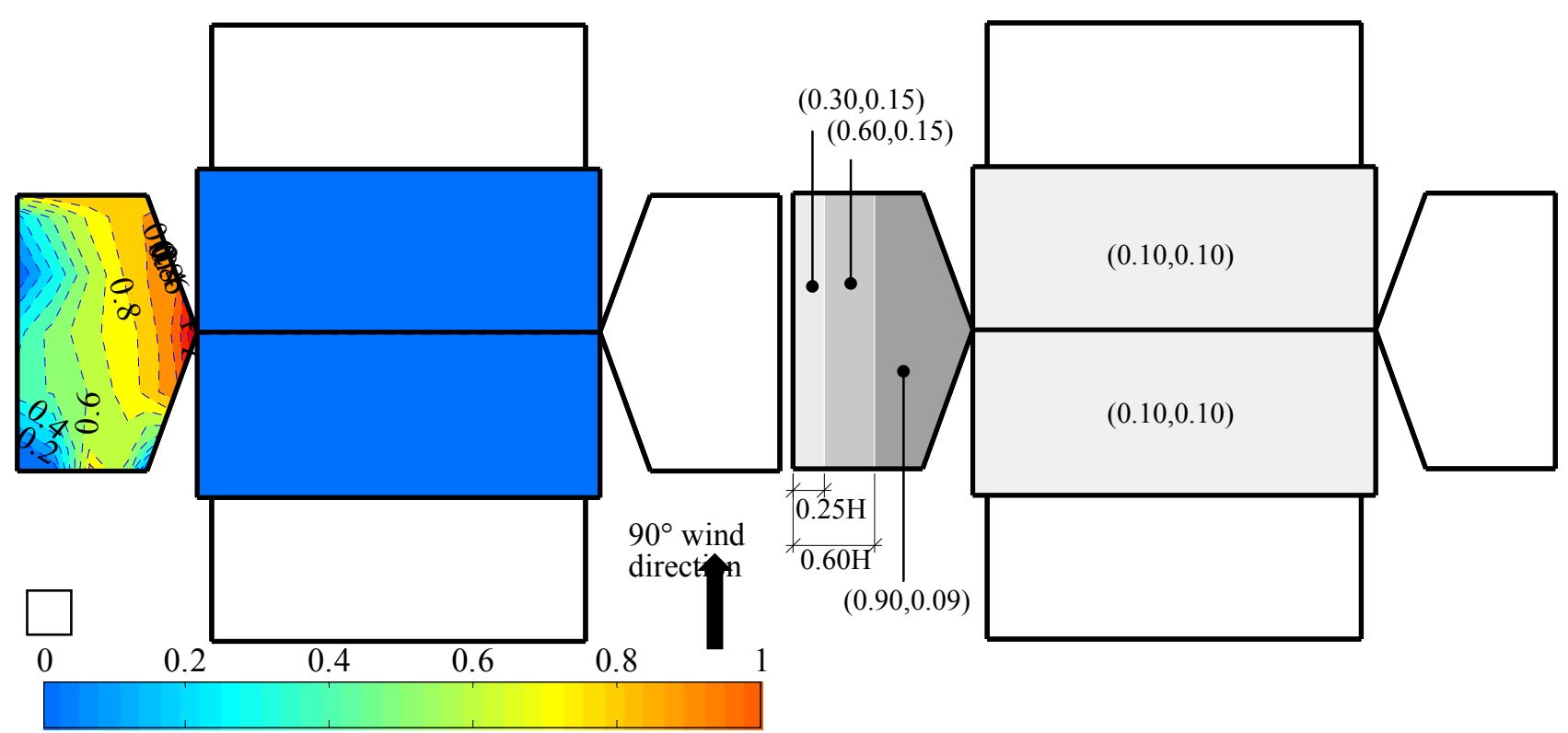

Figure 4.9 Distribution of RAF on gable roof building for (a) $0^{\circ}$, (b) $45^{\circ}$, and (c) $90^{\circ}$ wind directions. 


\subsubsection{Surface runoff coefficients (SRCs)}

The surface runoff coefficients (SRCs) were determined from test measurements of runoff rainwater accumulation at different heights on the building façades. Similar to RAFs, the SRCs were quantified as normalized surface runoff rainwater deposition at a given location using Eq. 8 .

$$
S R C=\frac{R R_{b, S R}}{R R_{v}}
$$

where $R R_{b, S R}$ is the rate of WDR deposition at a given location on the building façade due to surface runoff rainwater and expressed as

$$
R R_{b, S R}=\frac{V_{b, S R}}{A_{S R} \cdot t}
$$

where $V_{b, S R}$ is the volume of surface runoff rainwater accumulation for the test duration $t$ and $A_{S R}$ is called reference surface runoff area. The application of the scaled model based $S R C$ values in estimating surface runoff rainwater volume for real buildings requires proper scaling of the area upstream of the opening. This upstream area is responsible for the surface runoff accumulation and eventual intrusion through the critical perimeter for the opening, the latter being the edge(s) of the opening mostly responsible for water intrusion. For this study, based on experimental observations, the critical perimeters for various openings were considered as: 1 . Upstream edge of a wall or roof opening for $0^{\circ}$ and $90^{\circ}$ wind directions; 2. Diagonal of a wall or roof opening for $45^{\circ}$ wind direction (as two sides of the opening will be critical and the diagonal provides a measure of the critical perimeter). The other dimension needed to obtain the non-dimensional SRC 
values was chosen as: 1. Mean roof height for wall SRCs for all wind directions; 2. For roof SRCs (a) the plan dimension of the roof parallel to the wind for $0^{\circ}$ and $90^{\circ}$ wind directions, and (b) the diagonal roof dimension for $45^{\circ}$ direction. Such nondimensionalization allows for not only estimating surface runoff rainwater volume for a real building which is the exact scaled up version of the model tested, but also for real buildings that deviate (within reasonable limits) in configuration from the model in terms of geometric scale. The scaling allows, to a certain extent, for consideration of a slightly larger/smaller upstream area for such buildings which are not exact replica of the model tested. This assumption was shown to the satisfactory based on the comparison of model based surface rainwater intrusion estimates (using the SRCs on the scaled model) to the surface rainwater intrusion measurements obtained at full scale using a building that was not the exact scaled up replica (see Sec. 4.3). This assumption will not be applicable for estimating surface rainwater intrusion for buildings that have significant scale distortion with respect to the model tested, as the SRCs will no longer be applicable.

Figures 4.10a-c show the contour and SRC zonation plots for the three wind directions. The SRC zonations were also developed on the basis of minimizing the standard deviation (StDev) within each zone and the maximum StDev was 0.066. In general, the windward walls and the entire gable roof surfaces of the building were exposed to accumulation of surface runoff rainwater while the leeward walls were protected by the roof overhang. The SRCs increased down the walls and toward the leeward edges/corners on the gable roof. Due to high variability of SRC values on the windward wall in case of $0^{\circ}$ wind direction, three SRC zones were introduced with $($ mean, StDev $)=(0.108,0.044),(0.056,0.020)$, and $(0.010,0.007)$ for bottom, mid- 
height, and top zones, respectively. Higher dispersion of SRCs $(\mathrm{StDev}=0.044)$ was obtained for the bottom zone as the surface runoff accumulation increased rapidly toward the bottom. The windward gable roof was divided in to two SRC zones of (mean, StDev) $=(0.003,0.003)$ for eave zone and $($ mean, StDev $)=(0.017,0.010)$ for ridge zone while the leeward roof was assigned with a single SRC zone of (mean, StDev $)=(0.004,0.003)$. For $45^{\circ}$ wind direction, the leading edge/corner zones had lower mean SRC values of $(0.010,0.011)$ and $(0.001,0.005)$ and the values increased to $($ mean, StDev $)=(0.025$, $0.010)$ and $(0.039,0.066)$ for the remaining far-end zones (see Fig $4.10 \mathrm{~b})$. This is in contrast to mean RAF values which were higher for leading edges/corner zones. As the pattern of the surface runoff accumulation on the windward gable roof for $45^{\circ}$ wind direction was the same as for $0^{\circ}$ wind direction, two SRC zones with (mean, StDev) $=$ $(0.003,0.003)$ and $($ mean, StDev $)=(0.012,0.008)$ for eave and ridge zones were used. However, for $45^{\circ}$ wind direction, the leeward gable roof had high SRC values with the highest values of (mean, StDev) $=(0.036,0.009)$ on the most leeward edge zone (see Fig 4.10b). Similar to $0^{\circ}$ wind direction, the windward wall for $90^{\circ}$ wind direction had three SRC zone assignments with (mean, StDev $)=(0.109,0.061),(0.028,0.032)$, and $(0.010$, 0.010) for bottom, mid-height, and top zones, respectively. SRC value of (mean, StDev) $=(0.001,0.001)$ was assigned to the entire roof for $90^{\circ}$ wind direction. 


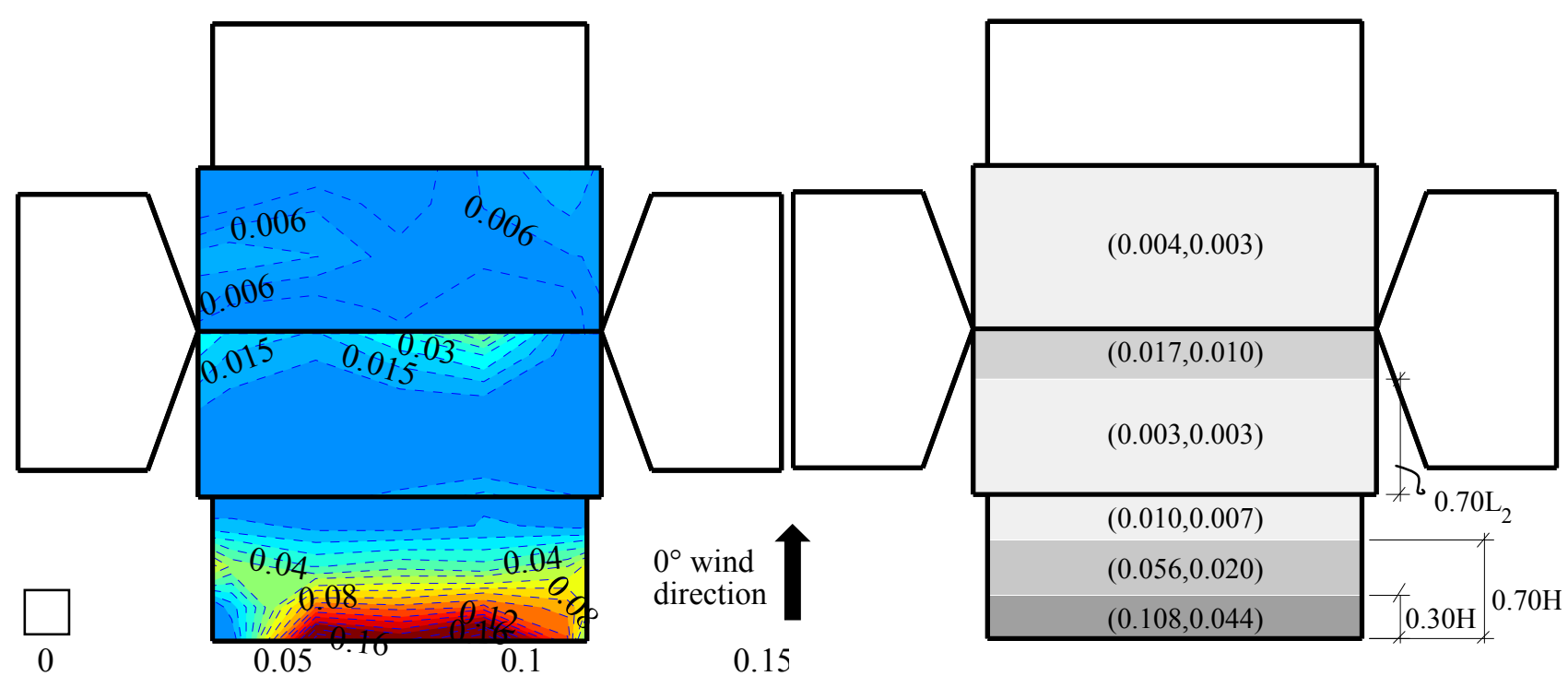




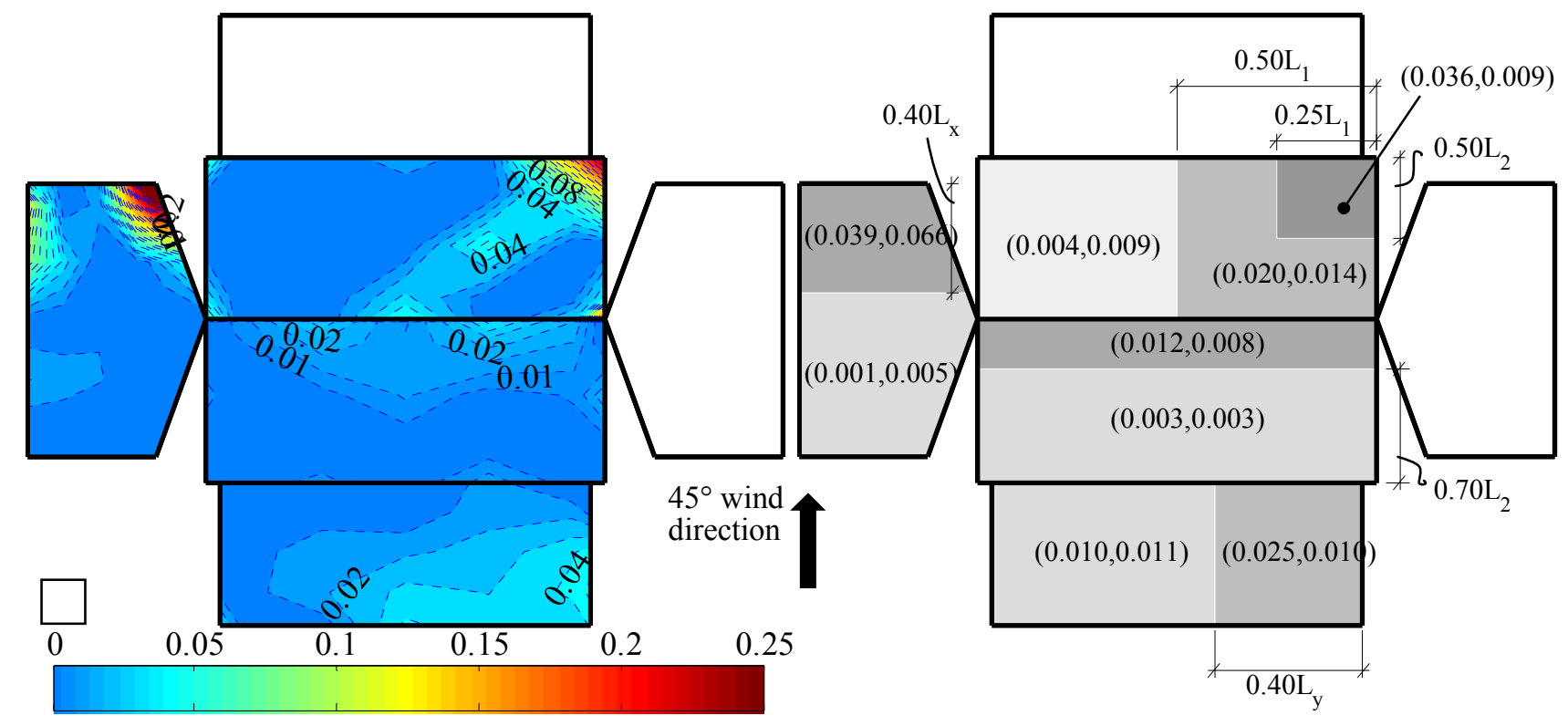




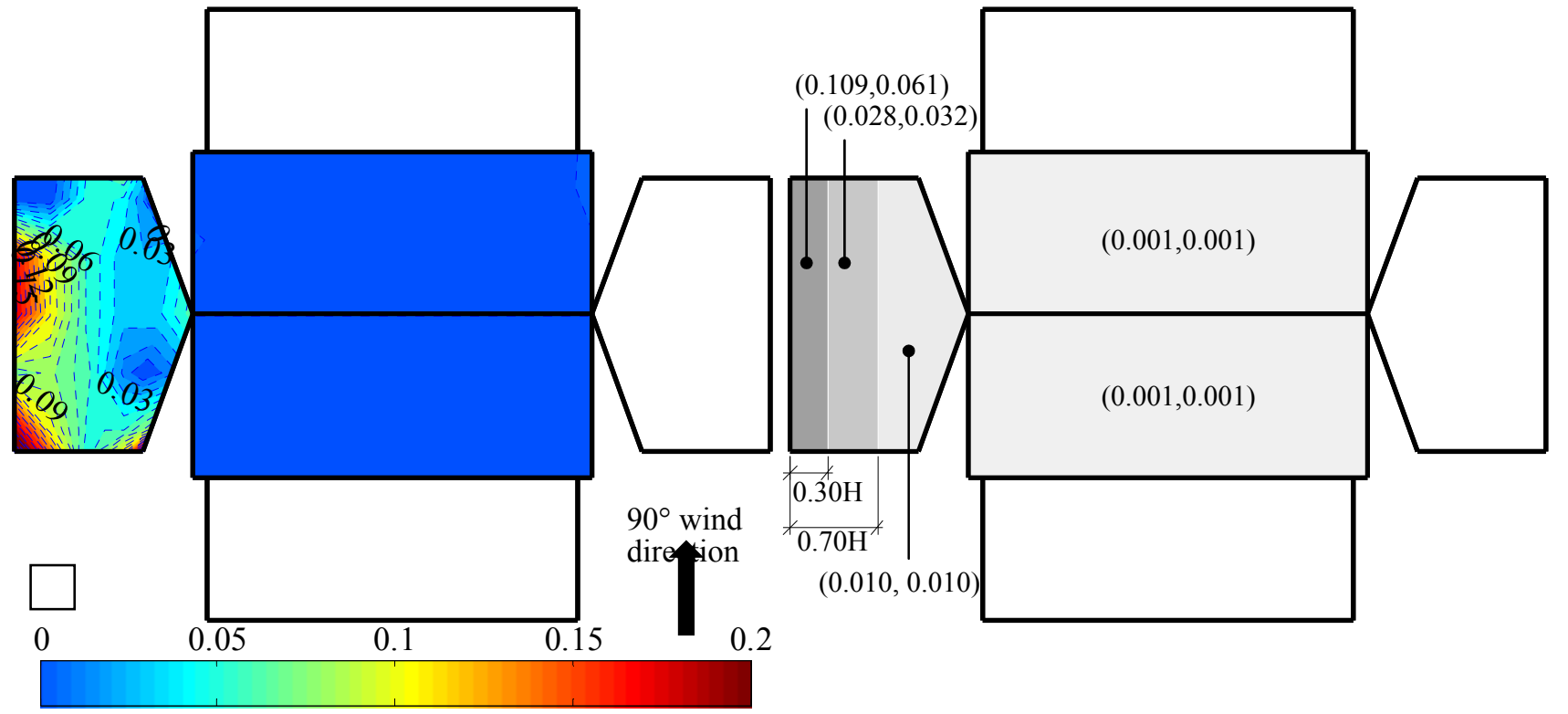

Figure 4.10 Distribution of SRC on gable roof building for (a) $0^{\circ}$, (b) $45^{\circ}$, and (c) $90^{\circ}$ wind directions. 


\subsubsection{Comparison of WDR intrusion volume predicted by the model to the actual volume measured at full scale}

The WDR intrusion through simulated wall and roof breaches were estimated using Eq. 5 of the WDR estimation model presented in Section 2. The RAF and SRC values were obtained based on the location of the breaches in reference to RAF and SRC zonations presented in the previous section. The RAF value for given envelope breach was determined based on where the area falls in the RAF zonation plot of the particular wind direction. Area average technique was implemented whenever the breach was between RAF zones. On the other hand, the SRC value of a breach was decided based on the location of its top periphery as the surface runoff water intrusion, in general, is determined by the location and size of the breach perimeter. The estimated volumes of direct impinging rain, surface runoff, and total rainwater intrusions were compared separately with measurement counterparts to validate the application of the newly developed WDR estimation model. The model estimation included minimum and maximum estimates based on one standard deviation of RAF and SRC values about their respective mean.

Figure 4.11 shows comparison between model estimation and measurements of WDR intrusion through the windward wall and roof breaches for the $0^{\circ}$ wind direction. The windward wall breach was located between the heights $0.6 \mathrm{H}$ and $0.68 \mathrm{H}$, with RAF and SRC values: $($ mean, StDev $)=(0.80,0.08)$ and $(0.030,0.007)$, respectively. Although the wall breach was located in the mid-height zone for SRC zonation plot shown in Figure 4.9a, the top zone was used as the upper edge of the breach at which the surface runoff rainwater entered into the opening was very close to the top zone $(0.68 \mathrm{H}$ versus 
$0.70 \mathrm{H})$. The RAF and SRC values for the roof deck breach were (mean, StDev) $=(0.20$, $0.15)$ and $(0.003,0.003)$, respectively (see Fig $4.9 \mathrm{a}$ and $10 \mathrm{a})$. Due to the high variability of the RAF values within the breach areas (or façade area), a significant difference was observed between the model mean estimation and measured direct impinging WDR intrusion. However, the surface runoff rainwater intrusion was mainly dependent on the top edge (or some portion of the opening perimeter) SRC values, which led to better accuracy of estimated intrusion through wall breach (see Fig 4.11). As a result, the total measured WDR intrusion through the windward wall (2426 ml) was within one standard deviation about the mean estimated volume of the total WDR intrusion $(1850 \mathrm{ml})$. Higher values of the measured WDR intrusion on the windward wall could be related to the change in the flow trajectory of raindrops due to the presence of large opening. The flow of wind into the opening could force raindrops to follow the same trajectory. The reverse effect was observed on direct impinging rain intrusion through roof deck breach in which less impinging rain ingress was measured as compared to estimated volume based on mean RAF values $(63.4 \mathrm{ml}$ versus $1038.3 \mathrm{ml})$. As the roof was generally exposed to suction, the escaping volume of air through the roof deck breach diverted the impinging raindrops and in effect, resulted in less volume of direct impinging WDR intrusion. Similar to the wall breach, the surface runoff rainwater intrusion through the roof deck breach matched well with that of estimated volume. The total measured WDR intrusion through roof deck breach was found to be about one and half standard deviations $(1.5 \sigma)$ lower than the mean estimated volume $(216.7 \mathrm{ml}$ versus $271.7 \mathrm{ml})$. 


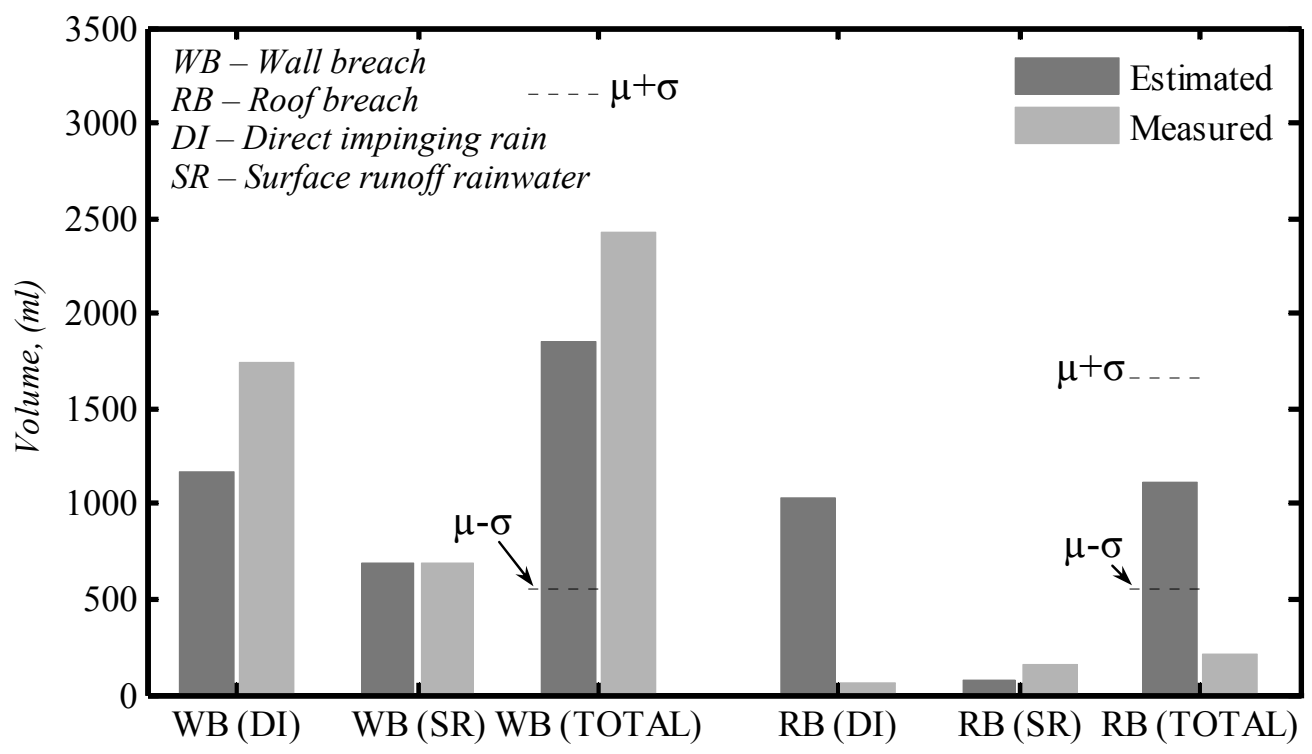

Figure 4.11 WDR intrusion through simulated wall and roof deck breaches for $0^{\circ}$ wind direction.

Figure 4.12 shows comparisons of impinging rain, surface runoff rainwater, and total volume of WDR intrusion through wall and roof breaches for $45^{\circ}$ wind direction. Higher impinging rain intrusion through windward wall breach was obtained while lower intrusion was measured through the roof deck breach comparing to mean volumes of model estimation. This was in agreement with the comparison results for $0^{\circ}$ wind direction. The differences between measurement and model estimation of impinging rain intrusion were $210.0 \mathrm{ml}$ (higher) and $1032 \mathrm{ml}$ (lower) for the wall and roof breaches, respectively. The measurement of surface runoff rainwater intrusion through the wall and roof deck breaches indicated that the model prediction match better in case of surface runoff $(0.0 \mathrm{ml}$ versus $21.3 \mathrm{ml}$ for the wall breach and $221.0 \mathrm{ml}$ versus $202.0 \mathrm{ml}$ for the roof breach). The total measured WDR intrusion through the wall breach was about one standard deviation higher than the estimated mean total volume of WDR intrusion, while in case of roof breach the total measured volume was about one and half standard deviations $(1.5 \sigma)$ lower than the mean estimated volume. 


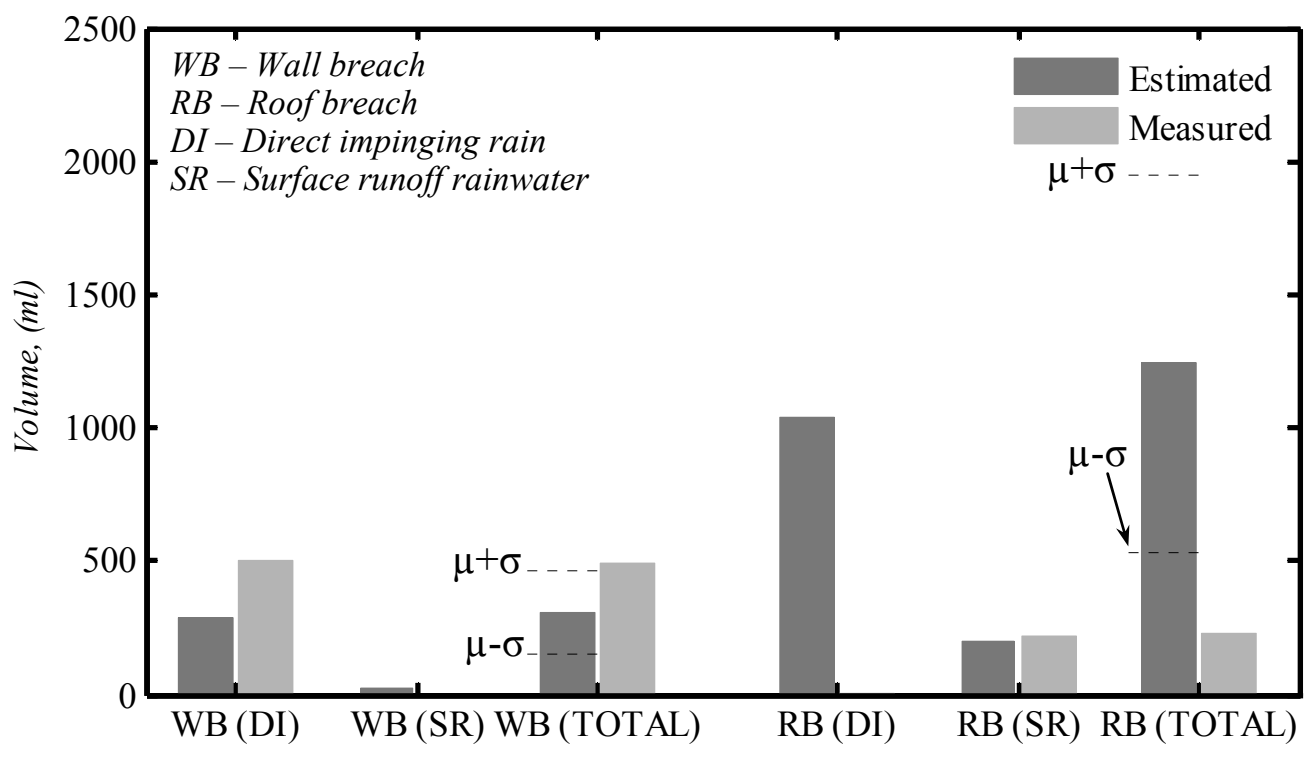

Figure 4.12 WDR intrusion through simulated wall and roof deck breaches for $45^{\circ}$ wind direction.

In addition to the simulated envelope breaches, model estimation and measurement of WDR intrusion through various widths of simulated window sill cracks were compared. Figure 4.13 shows the comparison between WDR intrusion through cracks due to impinging rain, surface runoff rainwater, and total volume for $0^{\circ}$ wind direction. The model estimation volumes of rainwater ingress through cracks were calculated using eq. 2 of Section 2. The cracks were simulated on the windward window of the full-scale test building for which the RAF and SRC values were (mean, StDev) = $(0.60,0.12)$ and $(0.030,0.020)$, respectively. Measurement and estimation of WDR intrusion through cracks showed that the total volume of rainwater intrusion through such tiny window sill cracks during tropical cyclone WDR conditions could exceed the WDR intrusion through major envelope breaches that are not perpendicular to the WDR direction. In the current study, the total volume through cracks was exceeded only by the volume of WDR intrusion through windward wall breach when the wind direction was perpendicular to the building wall. This is of practical importance during tropical storms 
and hurricanes where buildings experience significant interior damage due to rainwater intrusion through defects without any noticeable external envelope damage (FEMA 2005; Mullens et al. 2006). The measurement results also proved the hypothesis that the WDR intrusion through cracks (or in general envelope defects) was predominantly due to the surface runoff rainwater (see Fig 4.13). The defect opening on the building envelope acted as a sink point where the rainwater brought by the surface flow was pushed in to the building interior by high wind pressure differences across the opening. The wind induced pressure difference resulted in velocity increase ratio, $f_{v}$, of 50.7, 24.7, and 11.0 for the simulated crack width of $0.5,1.0$, and $2.0 \mathrm{~mm}$, respectively. As a result, the surface runoff rainwater contributed between 80 to $90 \%$ to the total volume of WDR intrusion through cracks of various widths (see Fig 4.13). Moreover, the measurement of surface runoff rainwater intrusion through cracks indicated the volume increased linearly with the increase in crack width. The prediction of WDR intrusions through cracks closely matches with the model estimates except for water intrusion due to surface runoff as the crack width decreases. The volume differences for surface runoff rainwater intrusions were 192.9, 76.4, and $6.9 \mathrm{ml}$ for $0.5,1.0$, and $2.0 \mathrm{~mm}$, respectively. This could be due to the overflow of surface water as the crack width decreases. The measured total volumes of WDR through the three simulated cracks were within one standard deviation about the mean estimated volumes. 


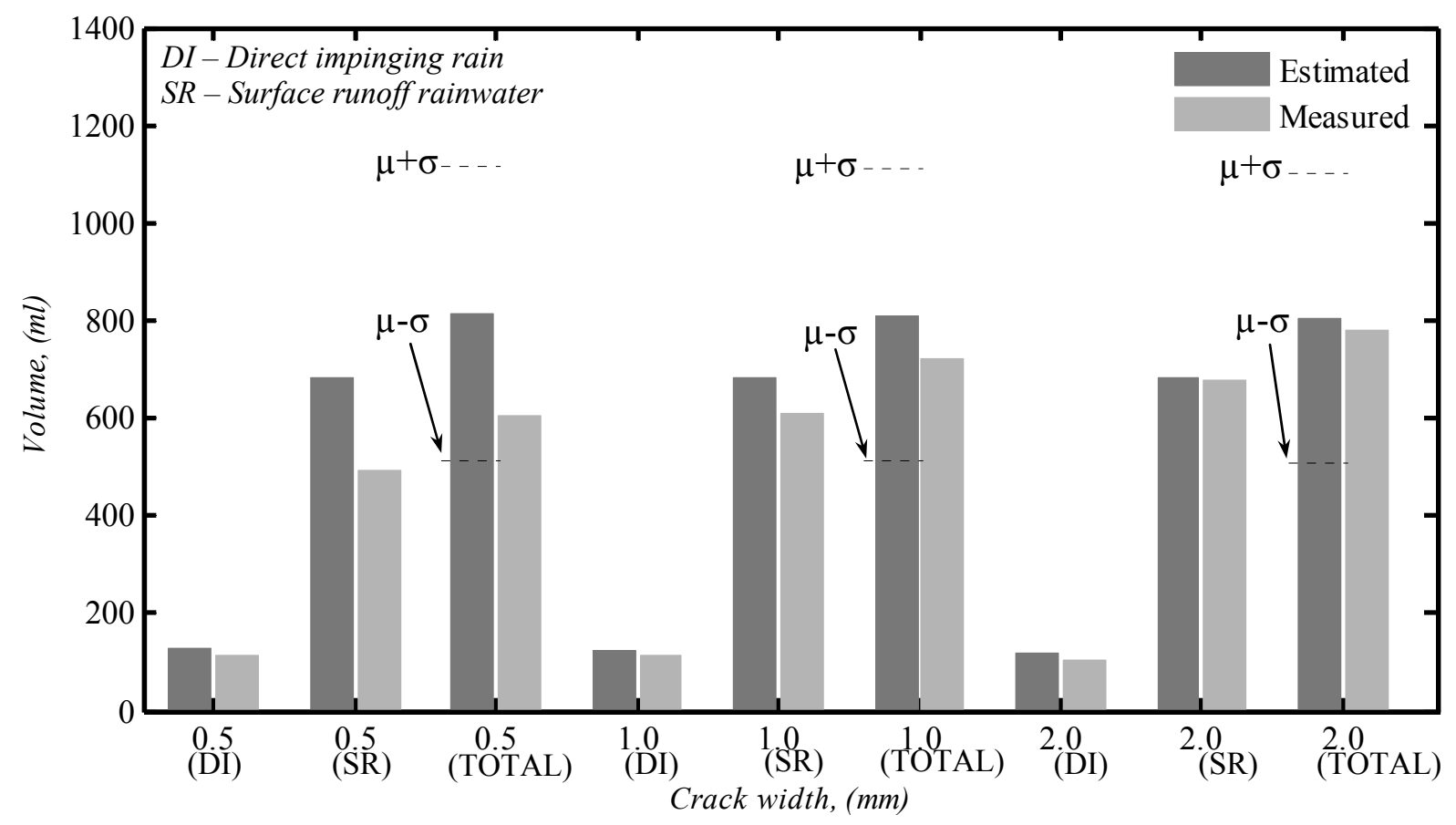

Figure 4.13 WDR intrusion through simulated window sill crack.

\subsection{Conclusions}

This paper presents a WDR intrusion model for the estimation of the rainwater intrusion through building envelope defects and breaches during tropical cyclones. The model uses test-based data of impinging rain and surface runoff parameters (rain admittance factors and surface runoff coefficients) to quantify the total volume of WDR intrusion through an opening. The study further validated the application of the new model by comparing model prediction to their experimental counterparts measured through simulated low-rise building envelope defects and breaches. The following points summarize the newly proposed WDR estimation model and major findings pertaining to the comparative study (model prediction using RAFs and SRCs versus measurements of rainwater intrusion): 
- Test-based data of RAF and SRC showed that the windward façades of the building were exposed to high concentration of impinging rain and accumulation of surface runoff rainwater while the leeward faces received little rain.

- The RAFs decreased down the walls and the roof had lower RAF compared to the walls. On the other hand, the SRCs increased down the walls and toward the leeward edges/corners on the gable roof.

- The estimation of impinging rain intrusion through envelope breaches located on a windward wall surface is susceptible to high variation due to the variability of rain admittance factor (RAF) within the breach area. However, estimation of surface runoff rainwater intrusion resulted in better accuracy as the SRCs for the breaches were determined based on their top periphery for which SRC variability is minimum.

- For breaches located on facades exposed to positive wind pressure (windward facade), the model estimated less mean volume of WDR intrusion due to impinging raindrops as compared to measured volume while the opposite was true for breaches located on façades exposed to negative (suction) wind pressure. The higher measured volume on the windward façade could be related to the flow of wind in to the opening which forced raindrops to follow the same trajectory. On the contrary, in cases of openings located on facades exposed to suction, the escaping air through the opening diverted the impinging raindrops and resulted in less volume of direct impinging WDR intrusion.

- Measurement and estimation of WDR intrusion through cracks showed that the total volume of rainwater intrusion through envelope defects during tropical 
cyclone WDR conditions could exceed the WDR intrusion through major envelope breaches that are not perpendicular to the WDR direction. This is of practical importance during tropical storms and hurricanes where buildings experience significant interior damage due to rainwater intrusion through defects without any noticeable external envelope damage.

- Measurements of WDR intrusion through cracks indicated that the total volume of WDR intrusion through defects was predominantly due to the surface runoff rainwater ( 80 to $90 \%$ of the total volume) in which the surface runoff rainwater was pushed in to the building interior by high wind pressure differences across the opening.

The model presented in this study can be used for the estimation of WDR deposition on building façades as well as water intrusion through building envelope defects, openings, and breaches during tropical storms and hurricane wind-driven rain conditions. Moreover, the test-based RAFs and SRCs dataset can also be used for validation of other numerical and/or computational fluid dynamics (CFD) methods to predict WDR deposition on building façades.

\section{References}

Aly, A. M., Chowdhury, A. G., and Bitsuamlak, G. (2011). "Wind profile management and blockage assessment for a new 12-fan Wall of Wind facility at FIU." Wind and Structures, 14(4), 1-16.

Baheru, T., Chowdhury, A. G., Bitsuamlak, G., and Tokay, A. (2012). "A parametric representation of wind-driven rain in experimental setups." Applied Technology Council and Structural Engineering Institute Conference (ATC \& SEI 2012) Advances in Hurricane Eingineering: Learning from our pastMiami, FL, 270-282. 
Baheru, T., Chowdhury, A. G., and Pinelli, J.-P. (2013). "Wind-driven rain deposition on building façade: Development of test-based data." 12th Americas Conference on Wind Engineering (12ACWE): Wind Effects on Structures, Communities, and Energy Generation Seattle, WA.

Beall, C. (2000). "Water penetration in building envelopes." Interface (October 2000), 29-36.

Bitsuamlak, G. T., Chowdhury, A. G., and Sambare, D. (2009). "Application of a fullscale testing facility for assessing wind-driven-rain intrusion." Building and Environment 44, 2430-2441.

Bitsuamlak, G. T., Dagnew, A., and Chowdhury, A. G. (2010). "Computational assessment of blockage and wind simulator proximity effects for a new full-scale testing facility." Wind and Structures, 13(1), 21-36.

Bitsuamlak, G. T., Gan Chowdhury, A., and Sambare, D. (2009). "Application of a fullscale testing facility for assessing wind-driven-rain intrusion." Building and Environment, 44(12), 2430-2441.

Blocken, B., and Carmeliet, J. (2005). "High-resolution wind-driven rain measurements on a low-rise building-experimental data for model development and model validation." J. Wind Eng. Ind. Aerodyn., 93, 905-928.

Blocken, B., and Carmeliet, J. (2010). "Overview of three state-of-the-art wind-driven rain assessment models and comparison based on model theory." Building and Environment, 45, 691-703.

Blocken, B., and Carmeliet, J. (2012). "A simplified numerical model for rainwater runoff on building facades: Possibilities and limitations." Building and Environment, 53(0), 59-73.

Choi, E. C. C. (1993). "Simulation of wind-driven rain around a building." J. Wind Eng. Ind. Aerodyn., 46\&47, 721-729.

Choi, E. C. C. (1994). "Determination of wind-driven rain intensity on building faces." J. Wind Eng. Ind. Aerodyn., 51, 55-69.

Chowdhury, A. G., Bitsuamlak, G. T., Fu, T.-C., and Kawade, P. (2012). "A study on roof vents subjected to simulated hurricane effects." Natural Hazards Review, ASCE, $12(4), 158-165$.

Cope, A. D. (2004). "Predicting the vulnerability of typical residential buildings to hurricane damage." PhD dissertation University of Florida. 
Dao, T., and van de Lindt, J. (2012). "Loss Analysis for Wood Frame Buildings during Hurricanes. I: Structure and Hazard Modeling." Journal of Performance of Constructed Facilities, 26(6), 729-738.

Dao, T. N., and Lindt, J. W. v. d. (2010). "Methodology for wind-driven rainwater intrusion fragilities for light-frame wood roof systems." Journal of Structural Engineering, ASCE, 136(6), 700-706.

FEMA-HAZUS (2009). "HAZUS MH MR3." Multi-hazard Loss Estimation Methodology: Hurricane ModelFederal Emergency Management Agency (FEMA), Washington, D.C.

FEMA (2005). "Mitigation Assessment Team Report - Hurricane Charley in Florida; Observations, Recommendations, and Technical Guidance." FEMA 488.

FEMA (2005). "Summary Report on Building Performance, 2004 Hurricane Season." FEMA, ed., Federal Emergency Management Agency.

FPHLM-4.1 (2011). "Florida Public Hurricane Loss Model 4.1." Florida Public Hurricane Loss Projection Model (FPHLPM), Laboratory for insurance, financial, and economic research, International Hurricane Research Center(IHRC), Miami, FL.

Freid, E., and Idelchik, I. E. (1989). Flow Resistance: A Design Guide for Engineers, Taylor \& Francis Ltd, Hemisphere, New York.

Fu, T.-C. (2013). "Development of effective approaches to the large-scale aerodynamic testing of low-rise buildings." PhD dissertation Florida International University.

Fu, T.-C., Aly, A. M., Chowdhury, A. G., Bitsuamlak, G., Yeo, D., and Simiu, E. (2012). "A proposed technique for determining aerodynamic pressures on residential homes." Wind and Structures, 15(1), 27-41.

ISO (2009). "Hygrothermal performance of buildings - calculation and presentation of climatic data - Part 3: calculation of a driving rain index for vertical surfaces from hourly wind and rain data." International Organization for Standardization, ISO 2009;15927-3.

Jesteadt, J. P., Reynolds, R. J., and Masters, F. J. (2007). "A preliminary investigation into wind-driven rain intrusion through soffits." Proc., 12th International Conference on Wind Engineering, International Association for Wind Engineering, Cairns, Australia.

Masters, F. J., Gurley, K. R., Shah, N., and Fernandez, G. (2010). "The vulnerability of residential window glass to lightweight windborne debris." Engineering Structures, 32(4), 911-921. 
Mullens, M., Hoekstra, B., Nahmens, I., and Martinez, F. (2006). "Water Intrusion in Central Florida Homes During Hurricane Jeanne in September 2004." Technical report, University of Central Florida Housing Constructability LabOrlando, FL.

Pita, G. L. (2012). "Hurricane vulnerability of commercial-residential buildings." PhD dissertation Florida Institute of Technology.

Pita, G. L., Pinelli, J.-P., Cocke, S., Gurley, K., Mitrani-Reiser, J., Weekes, J., and Hamid, S. (2012). "Assessment of hurricane-induced internal damage to low-rise buildings in the Florida Public Hurricane Loss Model." Wind Eng. Ind. Aerodyn., 104-106, 76-87.

Richards, P. J., Hoxey, R. P., Connell, B. D., and Lander, D. P. (2007). "Wind-tunnel modelling of the Silsoe Cube." J. Wind Eng. Ind. Aerodyn., 95, 1384-1399.

Straube, J. F. (1998). "Moisure Control and Enclosure Wall Systems." University of Waterloo.

Straube, J. F., and Burnett, E. F. P. "Simplified prediction of driving rain on buildings." Proc., International Building Physics Conference, 375-382.

Tokay, A., Bashor, P. G., Habib, E., and Kasparis, T. (2008). "Raindrop size distribution measurements in tropical cyclones." Monthly Weather Review, American Meteorological Society, 136(May 2008), 1669-1685.

Willis, P. T., and Tattelman, P. (1989). "Drop-size distributions associated with intense rainfall." J. Appl. Meter., 28, 3-15.

Yeo, D., and Chowdhury, A. (2013). "Simplified Wind Flow Model for the Estimation of Aerodynamic Effects on Small Structures." Journal of Engineering Mechanics, 139(3), 367-375. 


\section{CONCLUSIONS AND RECOMMENDATIONS}

\subsection{Summary of conclusions}

This dissertation is focused on the development of large-scale experimental methodologies for simulation of tropical cyclone wind-driven rain (WDR) and measurements of rainwater intrusion to acquire test-based data for development of hurricane-induced building interior and contents damage models. The study was performed using a three-stage approach to achieve the main objective of understanding the process of rainwater intrusion during tropical storms and hurricanes. The collected data and unveiled interdependence of WDR parameters were used to reformulating the WDR estimation equations in the interior damage model. The research stages are: i) Laboratory simulation of tropical cyclone WDR for experimental investigation of rainwater intrusion in buildings during tropical storms and hurricanes, ii) Investigation of the mechanisms of WDR deposition on building façades and intrusion through various envelope openings and development of test-based data on impinging rain and surface runoff parameters, and iii) Formulation of WDR estimation model and validation using rainwater intrusion data developed on full-scale building. The newly developed WDR estimation model can be used in hurricane-induced building interior damage model to facilitate prediction of expected damage as function storm intensity. The findings and/or contributions of each research stage are listed as follows:

i. Summary and conclusions on simulation of tropical cyclone WDR using the 12-fan Wall of Wind:

- Characterization of tropical cyclone (TC) WDR based on field measurements of raindrop size distribution (RSD) during Hurricane Alex, Charley, and Gaston 
(2004) indicated that the RSD falls in the family of three-parameter gamma distribution with defined physical ranges of parameters (shape, scale, and intercept), which depicted lognormal distributions. The mean and standard deviation of the gamma model of RSD were used as target to simulate WDR in the experimental setup.

- Experiment scale simulation of WDR requires similitude of water to air density ratio, Reynolds number (Re), and Froude number ( $\mathrm{Fr}$ ) similarity requirements between model- and full-scales. Although the Froude number (Fr) similarity requirement between model and prototype scale was employed in simulation of WDR using the 12-fan Wall of Wind, the increase in wind-induced drag force on individual raindrop in low Reynolds number (Re) region suggested that experimental simulation of WDR shall be performed at large scales.

- A procedural method of estimating target WDR rate as a function of test wind speed based on target RSD and rain rate was presented for simulation of WDR in experimental setups. The target median volume diameter dictated the selection of the type of nozzle to reproduce RSD of TC WDR. An iterative procedure was used to estimate the number of nozzles required to produce the target WDR rate in the test setup.

- The adequacy of the simulated WDR was investigated by comparing RSD parameters with their target values. The measured RSD parameters were found to be within the statistical limits showing reasonable simulation. The test results showed reasonable spatial homogeneity of the RSD parameters measured across the lateral and vertical sections of the flow field. This suggested the adequacy of 
the WDR simulation for the investigation of water intrusion effects on low rise building structures using large-scale building models.

ii. Summary and conclusions on investigation of the mechanisms of WDR deposition on building façades and intrusion through various types of envelope openings and development of test-based data on impinging rain and surface runoff parameters:

- The windward walls of the buildings received high concentrations of direct impinging raindrops (high magnitudes of RAFs) as compared to the horizontal (or sloped) roof for all wind directions. No impinging raindrops deposition was observed on the leeward walls and roof façades.

- For $45^{\circ}$ wind direction, the leading edge/corner regions of the buildings received high volume impinging rain and the deposition of raindrops decreased toward the far-end edges/corners of the facades.

- For $45^{\circ}$ and $90^{\circ}$ wind directions, the gable-end wall was exposed to high rate of impinging raindrops deposition due to flow recirculation near the intersection of the gable-end wall and the roof overhang. For $90^{\circ}$ wind direction, the surface runoff accumulation increased rapidly towards the bottom of gable-end wall. These phenomena could cause large volume of WDR intrusion through gable-end wall breaches or gable-end vent during tropical storms and hurricanes increasing the vulnerability of gable roof buildings.

- Comparison of impinging raindrops deposition on gable and flat roof buildings for $0^{\circ}$ wind direction revealed the ineffectiveness of overhang to protect or reduce WDR deposition on walls at high wind speeds. The overhang, in case of gable and hip roofs, caused downwash effect increasing both directing impinging and surface 
runoff on the wall surface. On the contrary, the presence of overhang protected the leeward walls from surface runoff rainwater over flowing from the roof.

- Higher values of RAF were observed near the windward sloped ridges of hip roof. This effect coupled with the high risk of roof elements failure in this region due to high suction can cause significant water intrusion into attic spaces.

- For $0^{\circ}$ and $90^{\circ}$ wind directions, the SRC values on the windward walls increased toward the bottom of the wall. A similar increase was also observed on the windward gable roof near the roof ridge for $0^{\circ}$ wind direction. This phenomenon escalates the chances of water intrusion during failure of ridge elements or through ridge vents.

- Unlike the direct impinging raindrops deposition, for $45^{\circ}$ wind direction, the leading edge/corner regions of the buildings received less volume surface runoff rainwater, and the rainwater accumulation increased toward the far-end edges/corners of the facades. High magnitude of SRC were obtain on the leeward gable roof depicting curved pattern of high surface runoff rainwater flow which could be formed due to interaction of roof shape and wind flow.

iii. Summary and conclusions based newly developed WDR estimation model and validation using full-scale experimental data:

- Test-based data of RAF and SRC showed that the windward façades of the building were exposed to high concentration of impinging rain and accumulation of surface runoff rainwater while the leeward faces received little rainwater. 
- The RAFs decreased down the walls and the roof had lower RAF compared to the walls. On the other hand, the SRCs increased down the walls and toward the leeward edges/corners on the gable roof.

- The estimation of impinging rain intrusion through envelope breaches located on a windward wall surface is susceptible to high variation due to the variability of rain admittance factor (RAF) within the breach area. However, estimation of surface runoff rainwater intrusion resulted in better accuracy as the SRCs for the breaches were determined based on their top periphery for which SRC variability is minimum.

- For breaches located on facades exposed to positive wind pressure (windward facade), the model estimated less mean volume of WDR intrusion due to impinging raindrops as compared to measured volume while the opposite was true for breaches located on façades exposed to negative (suction) wind pressure. The higher measured volume on the windward façade could be related to the flow of wind in to the opening which forced raindrops to follow the same trajectory. On the contrary, in cases of openings located on facades exposed to suction, the escaping air through the opening diverted the impinging raindrops and resulted in less volume of direct impinging WDR intrusion.

- Measurement and estimation of WDR intrusion through cracks showed that the total volume of rainwater intrusion through envelope defects during tropical cyclone WDR conditions could exceed the WDR intrusion through major envelope breaches. This is of practical importance during tropical storms and hurricanes 
where buildings experience significant interior damage due to rainwater intrusion through defects without any noticeable external envelope damage.

- Measurements of WDR intrusion through cracks indicated that the total volume of WDR intrusion through defects was predominantly due to the surface runoff rainwater ( 80 to $90 \%$ of the total volume) in which the surface runoff rainwater was pushed in to the building interior by high wind pressure differences across the opening.

The model presented in this study can be used for estimation of WDR deposition on building façades as well as water intrusion through building envelope defects, openings, and breaches during tropical storms and hurricane wind-driven rain conditions. Moreover, the test-based RAFs and SRCs dataset can also be used for validation of other numerical and/or computational fluid dynamics (CFD) methods to predict WDR deposition on building façades.

\subsection{Recommendations for future research}

The research developed wind-driven rain (WDR) data on common shapes of building models for purpose of estimation of rainwater intrusion through a given envelope opening as a function of storm intensity. Additional studies need to be conducted in order to further understand the parametric relationship of WDR intrusion and interior component and contents damage during hurricanes. The following research topics are recommended as future work:

- The RAF and SRC dataset developed in the current research considered distribution of rainwater over building surface which were nominally enclosed. 
However, the presence of openings at different locations on a building façade can affect the total volume of WDR intrusion through a specific opening. This is due to the change in the pressure difference across openings as compared the assumption of pressure equalization considered in development of WDR intrusion model for major openings. Studies on the effect of the presence of openings to the total volume of rainwater intrusion are needed as such scenarios represent the most probable conditions in envelope breaches during hurricanes. It is hypothesized that the agreement between the estimated and measured RAF values (as shown in Fig. 4.11 and Fig. 4.12) would improve if the roof and wall breaches were simulated separately instead of simultaneously. For such simulation, the driving force due to the pressure differentials in the full-scale measurements would be similar to those simulated during the large-scale measurements of RAF and SRC.

- The current study considered only WDR intrusion through openings located on walls and roof surface. However, future studies of WDR intrusion through damaged soffit panels will be of practical importance to address the repeated rainwater intrusion through soffits during hurricanes. Although some preliminary studies were conducted in the past, impinging rain and surface runoff WDR intrusion data through soffits are still scarce for development prediction models. Studies on the mechanisms of WDR intrusion through such inverted horizontal soffit surfaces will facilitate proper modeling of rainwater intrusion in damage prediction models. 
- The data produced under the current study are limited for specific roof slope and aspect ratio of building. More studies are needed to characterize the variation of the distribution of WDR deposition in relation to various roof slopes and aspect ratio of buildings.

- The tests for the current study were conducted on building models with smooth facades. However, the presence of architectural features on building surface and building façade material properties such as water absorption and surface roughness can significantly affect the total volume of rainwater deposition/accumulation at given location. Studies to investigate the effect of architectural features and building material properties are needed for accurate prediction of WDR intrusion.

- Mitigation techniques to reduce the rainwater intrusion through building envelope defects and breaches can be developed using experiment under simulated tropical storm and hurricane WDR conditions. 
VITA

\section{THOMAS SEYOUM BAHERU}

1979

2003

2003-2006

2006

2006-2009

2009-2014
Born, Addis Ababa, Ethiopia

B. Sc. in Civil Engineering, Addis Ababa University, Addis Ababa, Ethiopia

Civil/Structural Engineer, National Consultants, Addis Ababa, Ethiopia

M. Sc. in Structural Engineering, Addis Ababa University, Addis Ababa, Ethiopia

Structural Engineer, Berhan Tegegn Architectural and Engineering Service, Addis Ababa, ETH

Doctoral Candidate, Civil Engineering, Florida International University, Miami, FL, USA

Research Assistant, International Hurricane Research Center, Florida International University, Miami, FL

\section{JOURNAL PAPERS}

1. Chowdhury, A. G., Canino, I., Mirmiran, A., Suksawang, N., and Baheru, T. (2013). "Wind-Loading Effects on Roof-to-Wall Connections of Timber Residential Buildings." Journal of Engineering Mechanics, 139(3), 386-395.

2. Baheru, T., Chowdhury, A. G., Bitsuamlak, G., Masters, F. J., and Tokay, A. (2014). "Simulation of wind-driven rain associated with tropical storms and hurricanes using the 12-fan Wall of Wind." Building and Environment, 76(0), 18-29.

3. Fu, T.-C., Chowdhury, A. G., Bitsuamlak, G., and Baheru, T. (2014). "Partial turbulence simulation and aerodynamic pressures validation for an open-jet testing facility." Wind and Structures, (under Review).

4. Baheru, T., Chowdhury, A. G., Pinelli, J.-P., and Bitsuamlak, G. (2014). "Distribution of wind-driven rain deposition on low-rise buildings: Direct impinging raindrops versus surface runoff." J. Wind Eng. Ind. Aerodyn., (under Review).

5. Baheru, T., Chowdhury, A. G., and Pinelli, J.-P. (2014). "Estimation of Wind-Driven Rain Intrusion through Building Envelope Defects and Breaches during Tropical Cyclones." Natural Hazards Review, ASCE, (under Review). 


\section{CONFERENCE PAPERS AND ORAL PRESENTATIONS}

1. Baheru, T., Chowdhury, A. G., and Bitsuamlak, G. (2011). "Wind-driven rain generation at the Wall of Wind testing facility." Symposium Workshop on State of the Art Experimental Approaches for Wind Engineering and Wind Energy, Engineering Mechanics Institute Conference (EMI 2011), ASCE, Boston, MA, [Abstract and presentation, CD-ROM].

2. Baheru, T., Chowdhury, A. G., Bitsuamlak, G., and Tokay, A. (2012). "A parametric representation of wind-driven rain in experimental setups." in Proceedings: Applied Technology Council and Structural Engineering Institute Conference (ATC \& SEI 2012) - Advances in Hurricane Eingineering: Learning from our past, Miami, FL, 270-282, doi: 10.1061/97807844126226.024.

3. Baheru, T., Pita, G., Chowdhury, A. G., and Pinelli, J.-P. (2012). "Hurricane-induced interior damage to low-rise buildings: A status report of ongoing research at Florida International University." 3rd American Association for Wind Engineering Workshop (3AAWE), Hyannis (Cape Cod), MA, [Full paper and presentation, CD-ROM].

4. Baheru, T., Kargarmoakhar, R., Chowdhury, A. G., and Lin, C. X. (2012). "Largescale measurements of wind induced external convective heat transfer coefficient for building envelope." 3rd American Association for Wind Engineering Workshop (3AAWE), Hyannis (Cape Cod), MA, [Full paper and presentation, CD-ROM].

5. Baheru, T., Chowdhury, A. G., and Pinelli, J.-P. (2013). "Wind-driven rain deposition on building façade: Development of test-based data." 12th Americas Conference on Wind Engineering (12ACWE): Wind Effects on Structures, Communities, and Energy Generation Seattle, WA, [Full paper nominated for publication in J. Wind Eng. Ind. Aerodyn, CD-ROM.].

6. Baheru, T., Habte, F., and Chowdhury, A. G. (2014). "Full-scale testing to evaluate wind effects on residential tiled roofs." International Conference on Building Envelope Systems and Technologies (ICBEST), Aachen, Germany [Full paper]. 